\title{
WestVirginiaUniversity
}

THE RESEARCH REPOSITORY @ WVU

Graduate Theses, Dissertations, and Problem Reports

2011

\section{Pedagogical Practices: Nurturing and Maintaining Democratic Habits}

Lucretia Marie Hubler-Larimore

West Virginia University

Follow this and additional works at: https://researchrepository.wvu.edu/etd

\section{Recommended Citation}

Hubler-Larimore, Lucretia Marie, "Pedagogical Practices: Nurturing and Maintaining Democratic Habits" (2011). Graduate Theses, Dissertations, and Problem Reports. 3555.

https://researchrepository.wvu.edu/etd/3555

This Dissertation is protected by copyright and/or related rights. It has been brought to you by the The Research Repository @ WVU with permission from the rights-holder(s). You are free to use this Dissertation in any way that is permitted by the copyright and related rights legislation that applies to your use. For other uses you must obtain permission from the rights-holder(s) directly, unless additional rights are indicated by a Creative Commons license in the record and/ or on the work itself. This Dissertation has been accepted for inclusion in WVU Graduate Theses, Dissertations, and Problem Reports collection by an authorized administrator of The Research Repository @ WVU.

For more information, please contact researchrepository@mail.wvu.edu. 
Pedagogical Practices: Nurturing and Maintaining Democratic Habits

Lucretia Marie Hubler-Larimore

\author{
Dissertation submitted to the \\ College of Human Resources and Education \\ at West Virginia University \\ in partial fulfillment of the requirements \\ for the degree of
}

\author{
Doctor of Education \\ in \\ Curriculum and Instruction
}
Joy Faini Saab, Ed.D., Chairperson
David Callejo, Ed.D.
Paul Chapman, Ph.D.
Elizabeth Dooley, Ed.D.
Aimee Morewood, Ph.D.
Sam Stack, Ph.D.

Department of Curriculum and Instruction/Literacy Studies

\title{
Morgantown, WV \\ Copyright 2011
}

Keywords: democratic habits, school contexts, pedagogy, NCLB 


\section{ABSTRACT \\ Pedagogical Practices: Nurturing and Maintaining Democratic Habits}

\section{Lucretia Marie Hubler-Larimore}

This case study examined the pedagogical practices of four teachers of one public elementary school whose mission seeks to nurture and maintain democratic habits for participation in a democratic society. Historically, public schools have been charged with the duty of preparing young minds to live within in a democratic society and as such this argument has been cited as one of the fundamental reasons for providing public financial support of schools. The exploration of how pedagogical choices and curriculum development were used to create opportunities for experiencing democracy was considered within the specific social contexts of the school. Contexts considered included student composition, school organization, school size, school resources, and the effects of federal educational policy were measured vital to this case study. Findings included that democratic habits was an effective instructional tool but was limited due to the external contexts of federal educational policy. 


\section{Dedication}

I would like to dedicate this to my husband Tyson; and my parents, Gerald and Geraldine Hubler; and my sisters Jeannine Bagnall and Elizabeth Hubler-Rike, for their never-ending support and guidance. 


\section{Acknowledgments}

To my parents, Gerald and Geraldine Hubler, this would never have been possible or even imagined without your love, guidance, support, and encouragement. I would like to thank you for instilling in me a love of education and the belief in a true democracy.

To Tyson Larimore, my husband, thank-you for the endless hours of listening to my dissertation ramblings, supporting me, and always believing I would one day finish my dissertation. Your faith guided me through this and for that I will always be thankful.

To my sister, Jeannine Bagnall, for always being there to listen and for a shoulder to cry on when needed.

To my sister, Elizabeth Hubler-Rike, for always being there to listen and making me laugh when I greatly needed to.

Thank you to my doctoral dissertation committee that provided me guidance and mentoring throughout the entire doctorate process from excellent courses to the final stages of my dissertation. I would like to thank Dr. Joy Faini Saab for agreeing to be my advisor to serving as the chair of my committee. Thank you to Dr. David Callejo for providing me with feedback, direction, and ideas throughout this process. To Dr. Elizabeth Dooley for not only serving on my committee but also giving my first opportunities to work with pre-service teachers. To Dr. Sam Stack for sharing his ideas, thoughts, his expansive knowledge of John Dewey, and encouraging my work. To Dr. Aimee Morewood and Dr. Paul Chapman for not only agreeing to serve on my committee but also providing me with support, guidance, and new ideas. 


\section{Table of Contents}

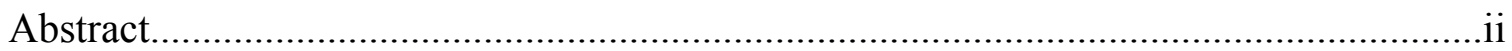

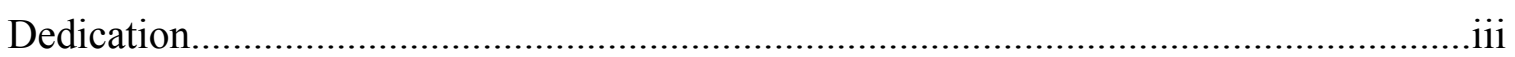

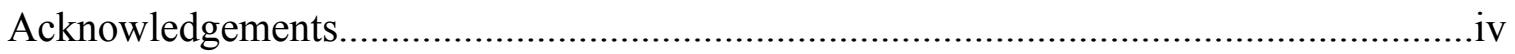

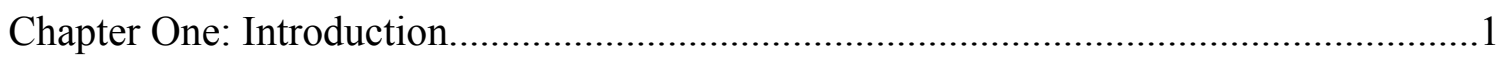

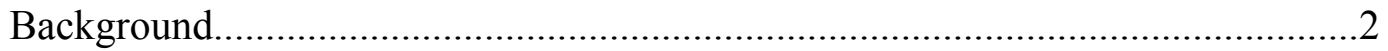

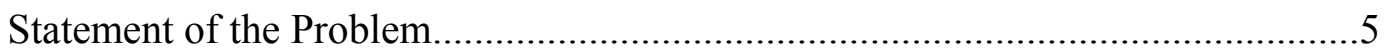

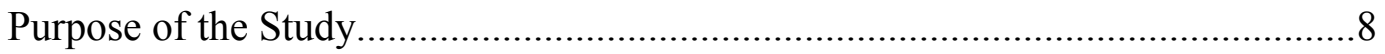

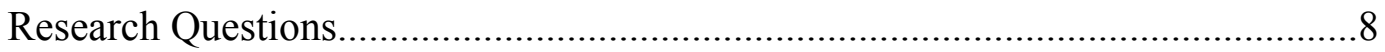

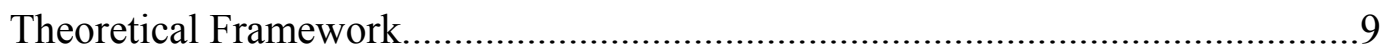

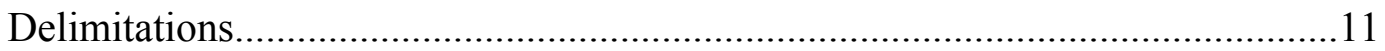

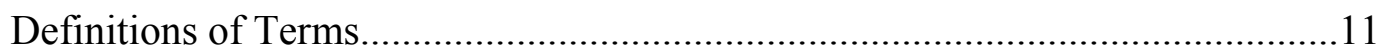

Summary

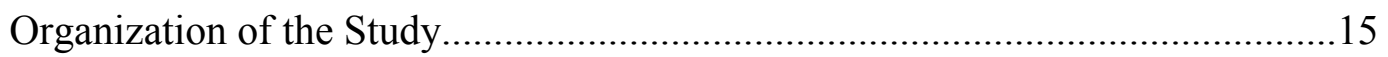

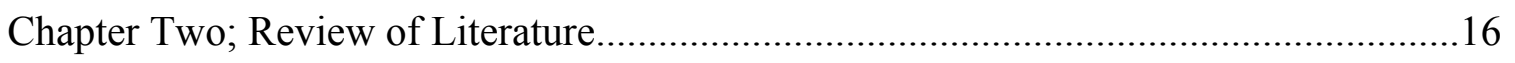

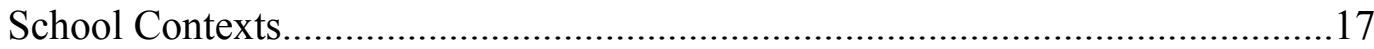

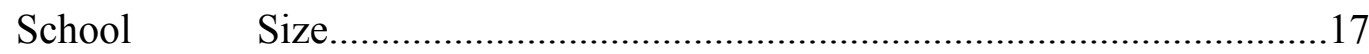

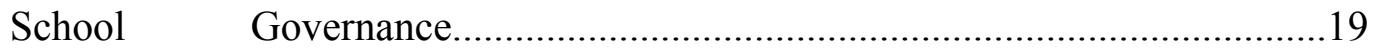

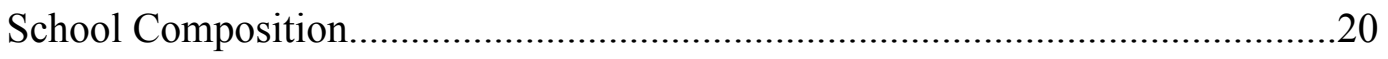

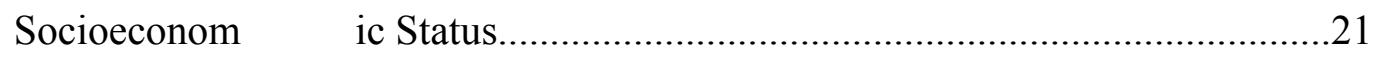

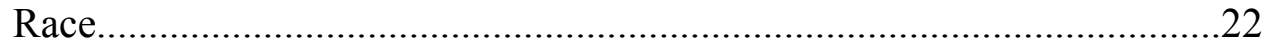

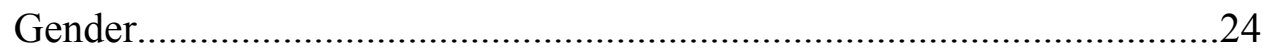

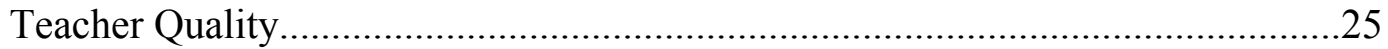




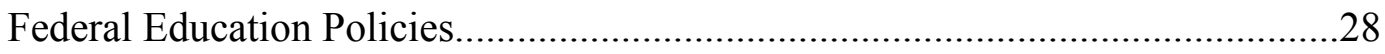

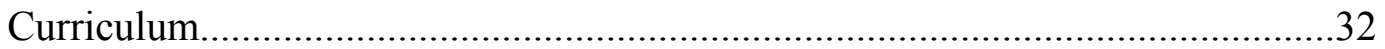

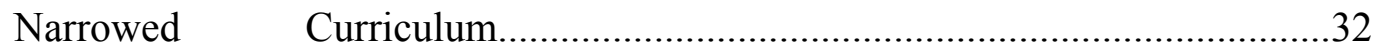

International Curriculum.......................................................................3

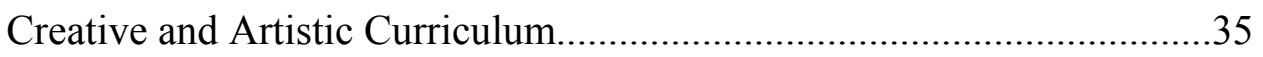

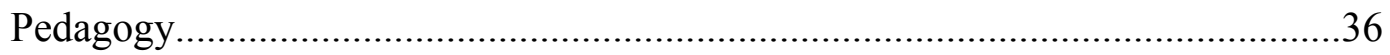

Pedagogical Content Knowledge.............................................................36

Pedagogical Content Knowing.................................................................

Teacher Knowledge Formal and Practical.................................................39

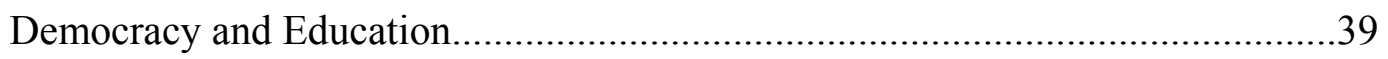

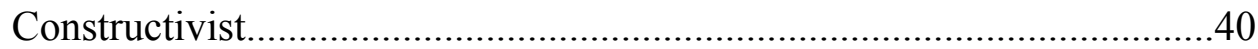

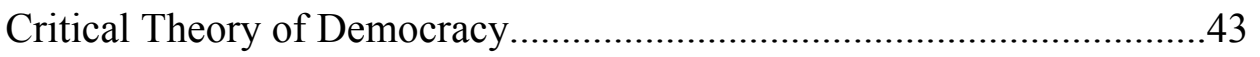

Democracy in the Elementary Classroom...................................................47

Child-Centered Curriculum...................................................................52

Summary

Chapter Three: Research Design and Method................................................................56

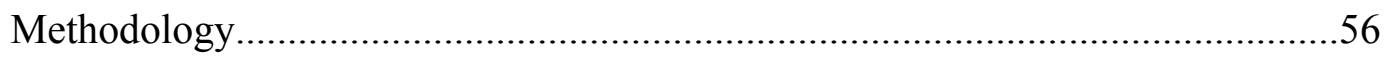

Rationale for Qualitative Research Design.........................................................56

Rationale for Case Study Methodology ..........................................................5

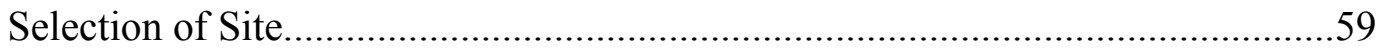

Site $\quad$ Selection Demographics..............................................................60

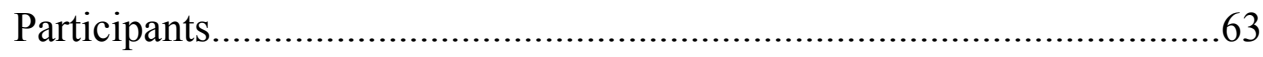

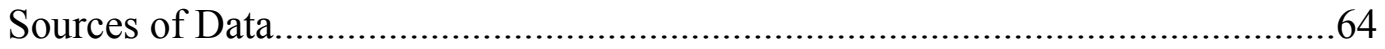




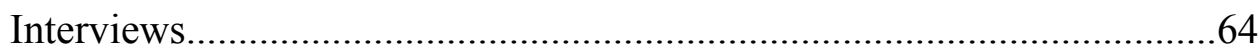

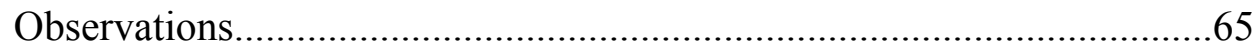

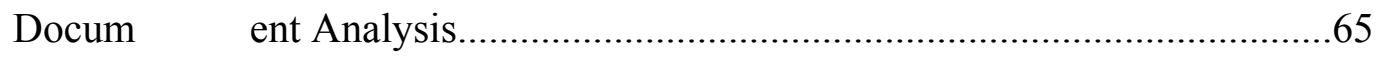

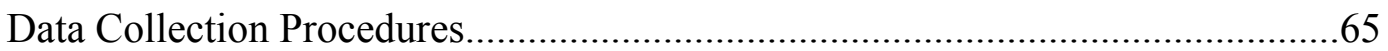

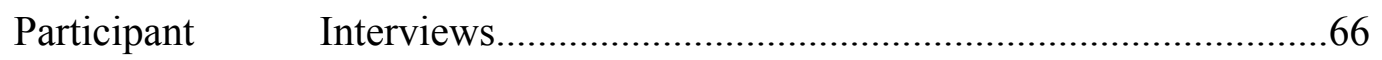

Participant Classroom Observations.........................................................66

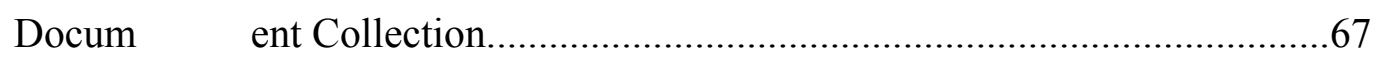

Data Management and Analysis Procedures........................................................67

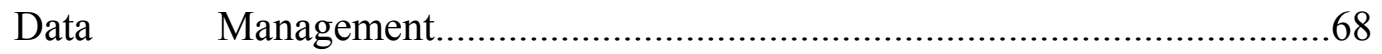

Site and Participant Confidentiality ........................................................68

Trustworthiness and Reliability of the Study............................................68

Dependability and Confirmability of the Study......................................... 70

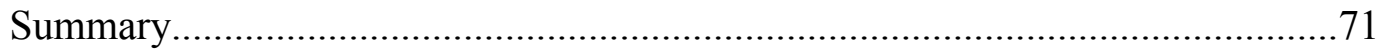

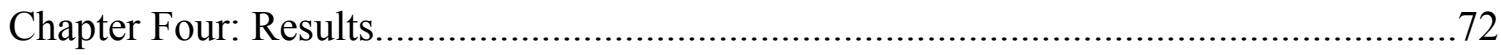

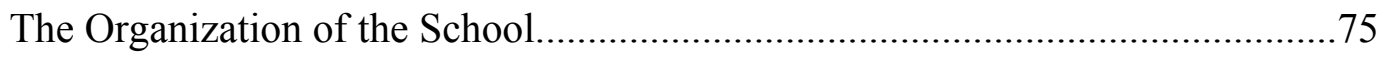

Research Question One: Theme One: Autonomy...............................................75

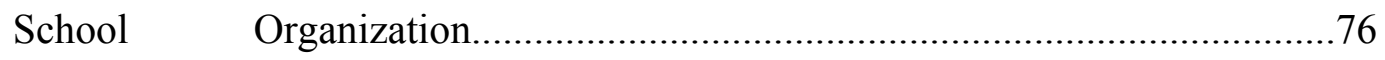

Pilot School Project...............................................................................

Research Question One: Theme Two: Guided Open Curriculum..........................79

Experiential Education......................................................................

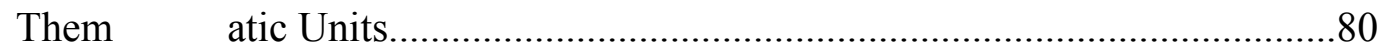

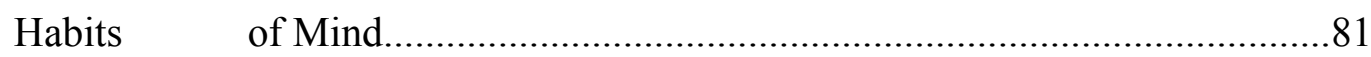

Summary 
Teachers' Perceptions and Pedagogical Practices...........................................83

Research Question Two: Theme Three: Child Centered.....................................83

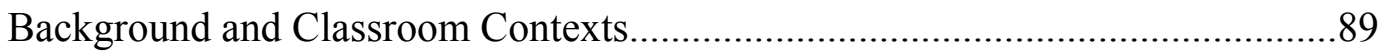

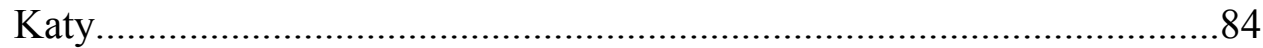

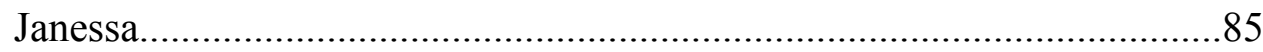

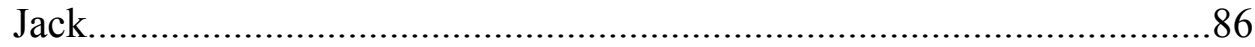

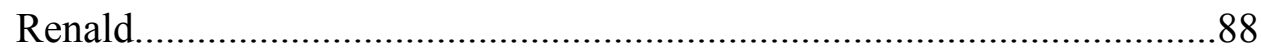

Research Question Two: Theme Four: Voice..................................................89

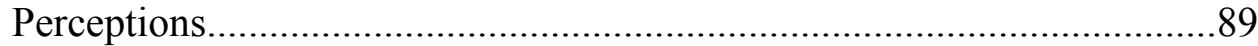

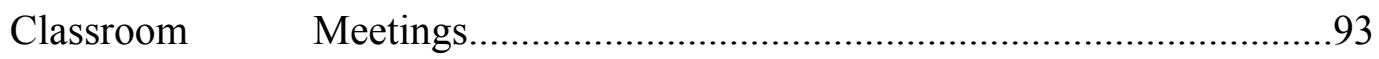

Research Question Two: Theme Five: Time....................................................95

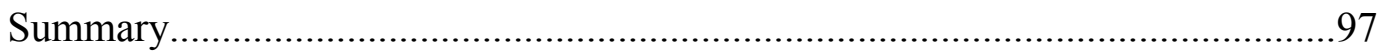

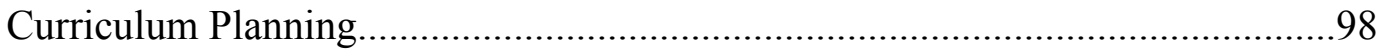

Research Question Three: Theme Six: Child Centered Pedagogical.....................99

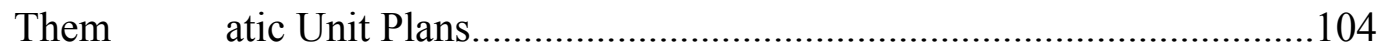

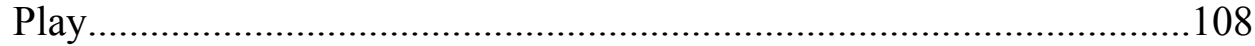

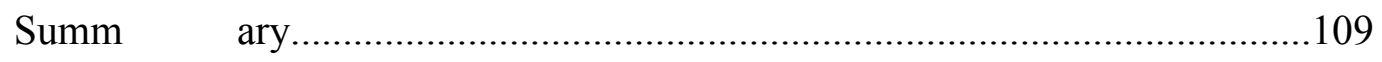

External Classroom Constraints: Educational Policy.......................................110

Research Question Four: Theme Seven: Teacher Centered..............................110

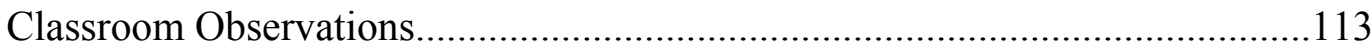

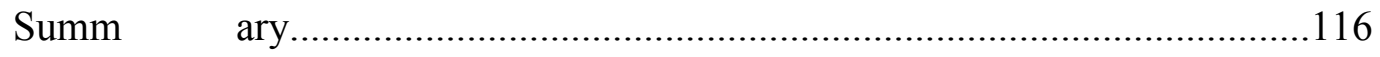

Chapter Five: Discussion of Research Findings....................................................118

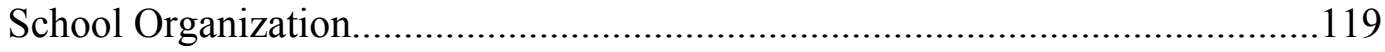




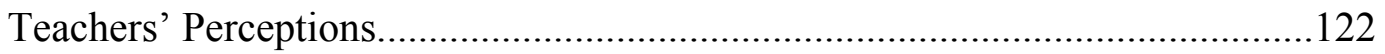

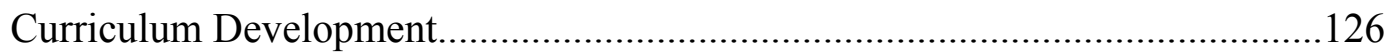

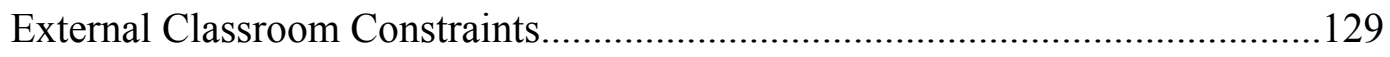

Research Findings Summary .......................................................................132

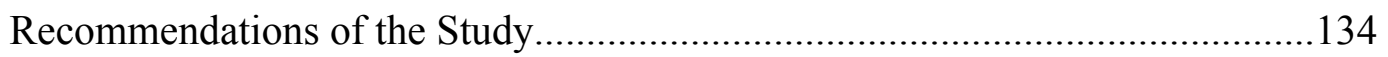

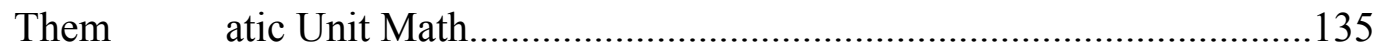

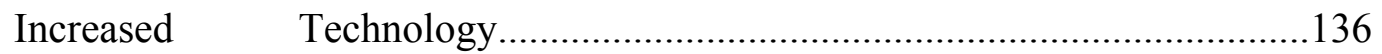

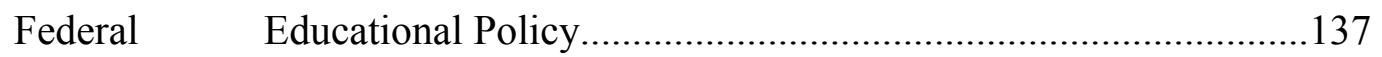

Implications for Further Research...............................................................138

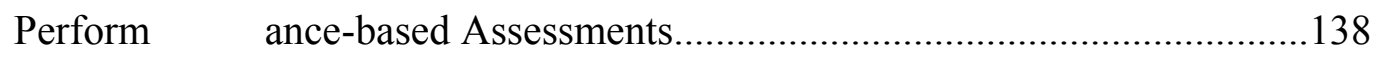

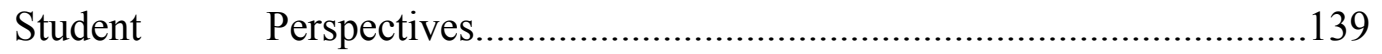

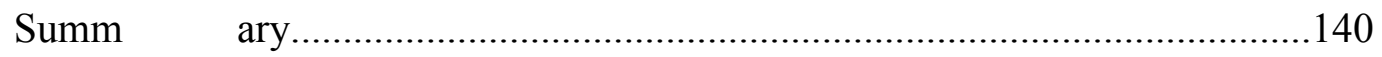

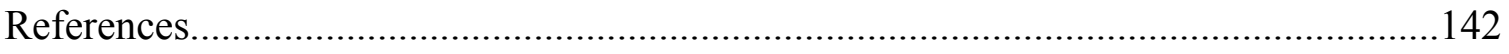

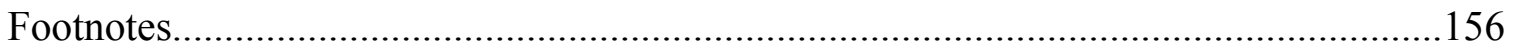

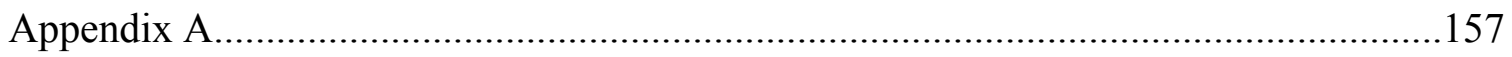

Appendix B

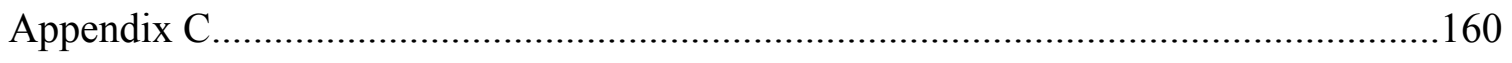

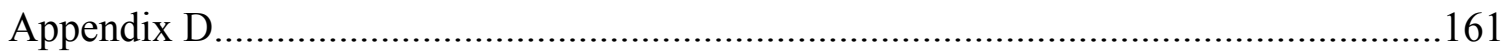

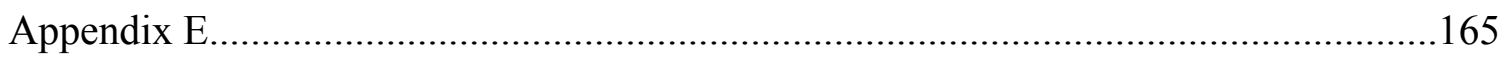

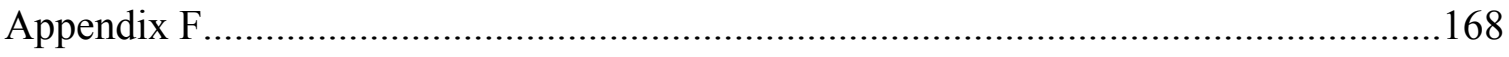

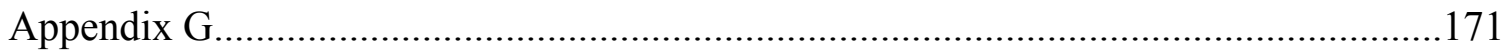

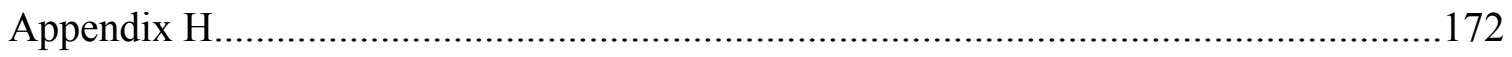

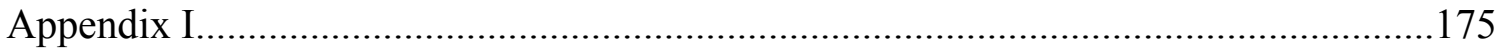




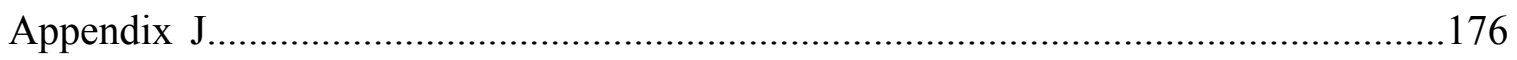




\section{Chapter One: Introduction}

This case study investigated the pedagogical practices of four teachers in one public elementary school whose mission seeks to nurture and maintain democratic habits for participation in a democratic society. As public schools have been argued to be one of the fundamental institutions needed for the survival of democracy, this study focused on how teachers make pedagogical decisions that nurtured such habits (Jefferson, 1778; Rush, 1786; Webster, 1790). Yet with the current educational arena that has placed such an intense scrutiny on student achievement there has become a seemingly disregard for not only what is right for nurturing democracy but for actual student achievement as well. The need to monitor student performance through instructional objectives, competency-based teacher education, and evaluation has significantly impacted pedagogy and curriculum. Teachers are no longer trusted with making decisions regarding curriculum development, pedagogy, and assessment.

In fact much research has revealed that teachers have adjusted their instructional practices and curriculum content in order for students to achieve specifically on administered tests (Darling-Hammond \& Wise, 1985; Goodman, 2004; Hoffman, Assaf, \& Paris, 2001). Teachers abandon what they know to be right for student achievement and democracy—problem solving, critical-thinking, expressing opinion, decision-making, art, and real-life connection—-for testtaking skills, textbooks, worksheets, and tested content curriculum. As such this study investigated the pedagogical practices of teachers within a school that has autonomy over school governance, budget, staffing, and curriculum as shown by research to be key to not only maintaining and nurturing democratic habits but increasing student achievement. However, this autonomy is contingent upon obtaining and maintaining Adequate Yearly Progress (to be later refereed to as AYP). Thus, this study looks at the effects of the various contexts in which the 
teacher made their pedagogical choices for nurturing and maintaining democratic habits students' socioeconomic status, school size, curriculum, teacher quality, school resources and particularly the effect of federal educational policy—these factors research has shown has a significant effect upon teacher practices and student achievement (Crowther, Kaagan, \& Ferguson, 2002; Darling-Hammond, 1985; Howley, 1994; Meier, 1996; Moriyanna, 2010; Opendaker \& VanDamme, 2007). This chapter will begin with the background that frames this study. The statement of problem, the purpose of the study and the four research questions that guided the study will then follow it. The chapter will close with the theoretical framework, delimitations, definition of key terms, and the organization of the study.

\section{Background}

The business of education has acquired a new complexion by the independence of our country. The form of government we have assumed has created a new class of duties to every American. It becomes us, therefore, to examine our former habits upon this subject, and in laying the foundations for nurseries of wise and good men, to adapt our modes of teaching to the peculiar form of our government. (Rush, 1786, "A Plan for the Establishment," para.1)

Historically, public schools have been charged with the duty of preparing young minds to live within a democratic society. This perception is often cited as one of the fundamental justifications for providing public financial support of schools (Glickman, 1990; Barber, 2001). The early pioneers of public education - George Washington, Benjamin Franklin, Thomas Jefferson, Benjamin Rush and Noah Webster-- argued that education was vital to the ability of the American people to continue to govern themselves and thus avoid the tyranny of other nations (Urban and Wagoner, 2004). In his first Annual Message to Congress, George 
Washington advocated that civic education was the first order of business for the national government (Fitzpatrick, 1939). As such citizens of a newly formed county, Washington asserted required an education that would depend on,

Teaching the people themselves to know and to value their own rights; to discern and provide against invasions of them; to distinguish between oppressions and the necessary exercise of lawful authority; to discriminate the spirit of Liberty from that of licentiousness - cherishing the first, avoiding the last; and uniting a speedy, but temperate vigilance against encroachments, with an inviolable respect to the Laws. (as cited in Fitzpatrick, 1939)

In his farewell address he warned that because public opinion influences policy in a democracy, "it is essential that public opinion should be enlightened by schools that teach virtue and morality" (Ellis, 2001, pg. 154). Others, like Benjamin Franklin reasoned that history particularly important, because "questions of right and wrong, justice, and injustice, will naturally arise" as students debate historical issues "in conversation and in writing." Students, Franklin insisted, should also read newspapers and discuss current controversies, thereby developing their logic and reasoning (Franklin, 1749). In 1778, Thomas Jefferson prepared and presented A Bill for the More General Diffusion of Knowledge to the Virginia legislature. This bill sought to secure, what would have been at that time, the broadest form of educational opportunities for Virginia's youth as it called for a statewide school system.

Whereas it appeareth that however certain forms of government are better calculated than others to protect individuals in the free exercise of their natural rights, and are at the same time themselves better guarded against degeneracy, yet experience hath shewn, that even under the best forms, those entrusted with power have, in time, and by slow operations, 
perverted it into tyranny; and it is believed that the most effectual means of preventing this would be, to illuminate, as far as practicable, the minds of the people at large...whence it becomes expedient for promoting the publick happiness that those persons, whom nature hath endowed with genius and virtue, should be rendered by liberal education worthy to receive, and able to guard the sacred deposit of the rights and liberties of their fellow citizens, and that they should be called to that charge without regard to wealth, birth or other accidental condition or circumstance; but the indigence of the greater number disabling them from so educating, at their own expence, those of their children whom nature hath fitly formed and disposed to become useful instruments for the public, it is better that such should be sought for and educated at the common expence of all, than that the happiness of all should be confided to the weak or wicked...(Jefferson, 1778, “A Bill for the More General Diffusion of Knowledge”, Preamable)

Jefferson considered education this to be one of his most if not the most important endeavors (Jefferson, 1779). Although the bill never passed, it did provide a clear outline of Jefferson's thoughts regarding the importance of not only equipping all citizens with the basic literacy and computational skills they would need in order to manage their own affairs but also enabling them to know how to exercise their rights and duties as citizens of a democracy. For Jefferson, education was an investment in sustaining self-governance and human happiness at both the individual and national levels (Urban and Wagoner, 2004).

Although Thomas Jefferson and Benjamin Rush's views varied upon the teaching of religion in schools, Rush's notions and recommendations for a statewide school system for his home state of Pennsylvania ran quite similar to Jefferson's. Rush believed that "A free government can only exist in an equal diffusion of literature. Without learning, men become 
savages or barbarians, and where learning is confined to a few people, we always find monarchy, aristocracy, and slavery. “(Rush, 1786, “A Plan for the Establishment,” para.2). Rush argued that in order to avoid these evils, a tax-supported system of public education for Pennsylvania was needed.

Noah Webster asserted in his 1790 publication, On the Education of Youth in America that "Where government is in the hands of the people, knowledge should be universally diffused by means of public schools. Of such consequence is it to society that the people who make laws should be well informed that I conceive no legislature can be justified in neglecting proper establishments for this purpose" (Webster, 1790, "On the Education”, para.30). While Jefferson, Rush, and Webster wrote of the need for public education, the newly freed thirteen colonies actually created educational institutions. As the new colonies wrote their new constitutions, many recognized that free public schools were essential to democracy (Fraser, 2001). In consideration of these historical roots, democracy and education are intimately connected. In review of current state constitutions, many still recognize the goal of public education as a means of developing democratic citizenship (Glickman, 2009). Thus raises the main question of this study, what is the best way to prepare the nations' youth to live in a democratic society?

\section{Statement of the Problem}

Public schools are the only institutions that serve $90 \%$ of the next generation of adults (Glickman, 2009). But for many educated in the United States, democracy is just a form of political governance which involves the consent of the governed and the right to pursue life, liberty, and happiness. For example, high school seniors learn in their civics class that they should participate in elections as who they vote for 'represents' them in local, state and national 
issues. But democracy is not simply a 'process of voting'; it also comprises of the morals and principles that make up the fundamentals of the democratic way of life:

- Concern for the dignity and rights of individuals and minorities.

- Concern for the welfare of others and 'the common good'.

- Faith in the individual and collective capacity of people to create the possibilities for resolving problems.

- The open flow of ideas, regardless of their popularity, that enables people to be as fully informed as possible.

- The use of critical reflection and analysis to evaluate ideas, problems, and policies.

- An understanding that democracy is not so much an 'ideal' to be pursued as an 'idealized' set of values that we must live and he must guide our life as people.

- The organization of social institutions to promote and extend the democratic way of life (Apple \& Beane, 2007, pg. 7).

Philosopher John Dewey (1916) posited that in order for people to secure and maintain a democratic way of life, they must have opportunities to learn what that way of life means and how it might be led. He contended that knowledge emerges from situations in which learners have to draw out meaningful experiences. As a major contributor to the experiential-education tradition, he wrote extensively on the importance of education to democratic society. In Democracy and Education, he proposed, "since democracy stands in principle for free interchange, for social continuity, it must develop a theory of knowledge which sees in knowledge the method by which one experience is made available in giving direction and meaning to another" (pg. 248). Providing practical guiding principles for such educational 
delivery in Experience and Education, he argued for "a sound philosophy of experience" (Dewey, 1938, pg.91) with educators serving as facilitators connecting learning to students' experiences; helping shape student understanding through "cooperative enterprise, not dictation" (Dewey, 1938, pg. 72); and, ultimately, aiding in group social development as well as the development of individual judgment and exercise of power (Dewey, 1938, pg. 56-58).

Unfortunately, it is argued that the majority of public schools have become models of bureaucratic and hierarchical structures rather than being living examples of democracy (some have argued were never examples of democracy) and has arisen from the need to monitor student performance through series of criterion-referenced tests for all students in Grades 3-12. (Apple \& Beane, 2007, Darling-Hammond, 1985, Meier, 1996) From the 1983 A Nation at Risk (National Commission on Excellence in Education) to the No Child Left Behind Act (U.S. Department of Education, 2001), an outcome of federal mandates for accountability has placed an everincreasing emphasis on standards, benchmarks, proficiencies, and test-oriented classroom pedagogy (referred to as 'teaching to the test'). Although subpart \#3 of the No Child Left Behind Act referred to as the Education for Democracy Act, states, "to foster civic competence and responsibility" (sec. 2342), there is little or no reference given to how to nurture democracy within the contexts of public schools. The mandates seemingly disregard students' and teachers' opportunities to experience a democratic way of life. In addition, research has indicated that various guidelines of democratic education such as providing students with quality teachers, small and democratically organized schools, meaningful experiences, and an intellectually rigorous curriculum has indicated that student achievement could be greatly improved (Crowther, Kaagan, \& Ferguson, 2002, Darling-Hammond, 2010, Howley, 1994, Meier, 1996, Rosenholz, 1987). Thus, the case study explores the dichotomy of what research has stated is 
right and good for democracy and students and what is imposed on public schools from federal educational policy.

\section{Purpose of the Study}

The purpose of this study was to investigate the pedagogical practices of four teachers of one public elementary school whose mission seeks to nurture and maintain democratic habits for participation in a democratic society. Since commitment of teachers to democratic education is a prerequisite for achieving democracy in classrooms, schools, and society (Goodlad, 1996), it was of particular significance to the researcher to explore teachers' perceptions and understanding of democratic habits. Their perceptions, curriculum development, and curriculum implementation have an impact on how democracy is and will be put into action in the classroom and in society. Thus, the exploration of how pedagogical choices and curriculum development were used to create opportunities for experiencing democracy in addition to how and if those pedagogies were affected by school contexts were crucial. Contexts such as student composition (SES, gender, and minority populations), school organization, school size, school resources, and specifically the effects of federal educational policy that research supports all have an impact, direct and indirect, on curriculum and pedagogical choices made by teachers as well as has an effect on student achievement. The main data collection techniques included semi-structured interviews, classroom observations, and document analysis.

\section{Research Questions}

In order to answer the main question, what is the best way to prepare the nations' youth to live in a democratic society, the following questions were utilized to provide in-depth information on the pedagogical practices of four teachers of one public elementary school whose missions seeks to nurture and maintain democratic habits: 
1. How was the school organized that supported democratic habits?

2. How do the teacher's perceptions of democratic habits influence case study teachers' pedagogical practices?

3. How was curriculum developed that promoted democratic habits?

4. How do federal educational policies influence and affect case study teachers' pedagogical practices for nurturing and maintaining democratic habits?

The first question served to gather information regarding the organization of the school based on its status of being a pilot school. It acted as contextual question and whether the school's status, contexts specific to the school, and statement of purpose had any influence on curriculum development and curriculum implementation in the classroom. The second question aimed at learning the teachers' perceptions and their actual pedagogical practices of how to maintain and nurture democratic habits through curriculum development, lesson plans, and classroom structure. The third question focused on the development of curriculum by each of the case study teachers. It explored specific planning and implementation in each of their classrooms. The fourth question was an endeavor to learn how pedagogical practices were influenced from the perspective of federal educational policy that the teachers had no control.

\section{Theoretical Framework}

Education is a social and constructive process (Dewey, 1897). Constructivism as applied to both learning theory and epistemology refers to the idea that learning as an active process where learners construct knowledge for themselves thus the reality of learners is determined by the experiences of the knower (Jonassen, 1991). The learner, thus in this case the researcher, steadily constructs knowledge while striving to make sense of the world on the basis of his or her social and cultural perspective and personal experiences. Specifically social constructivists 
assert that the social context of learning is very important and it is believed that knowledge is the result of social interaction.

Crotty (1998) reasoned that "all knowledge, and therefore all meaningful reality as such, is contingent upon human practices, being constructed in and out of interaction between human beings and their world, and developed and transmitted with an essentially social context (pg. 42). Constructivists believe individuals do not develop in a vacuum, but rather as part of a social and cultural group. They claim that human beings construct meaning as they engage within the environment they are interpreting (Crotty, 1998). Doolittle (1999) asserted that social interaction always happens within a social-cultural context. It is believed that truth is not to be found inside the head of an individual person but is born between people collectively searching for truth through the process of dialogical interaction.

The constructivists' perspective provides a means of examining the pedagogical practices of four case study teachers, as teaching should be accepted as "an uncertain and spontaneous craft situated and constructed in response to the particularities of everyday life in schools and classrooms" (Cochran-Smith \& Lytle, 1999, pg. 262). The role of a teacher thus moves beyond disseminating facts and findings to the incorporation of experience and generation of knowledge with their students. "Teaching then, is understood primarily as a process of acting and thinking wisely in the immediacy of classroom life: making split-second decisions, choosing among alternative ways to convey subject matter, interacting appropriately with an array of students, and selecting and focusing on particular dimension of classroom problems" (ibid, pg. 266). Prior knowledge that teachers use to make these split-second decisions often change from moment to moment and day to day is connected on their experiences and the contexts of their teaching environment. Instructional knowledge is generated from their daily interactions with students, 
administration, parents, curriculum, and pedagogy. Teaching methodologies and theory; therefore, are developed from reflecting on their practice, making adjustments based on outcomes, and constructed from experience.

\section{Delimitations}

The intent of this study was to examining the pedagogical practices of four teachers of one public elementary school whose mission seeks to nurture and maintain democratic habits for participation in a democratic society.

The boundaries considered for this case study included (a) school that serves elementary school aged children; (b) school's mission statement, and (c) willingness to participate in study. These parameters delimited the nature of this case study.

\section{Definitions of Terms}

Below are the key terms used in this study and their definitions.

- Accountability-State or district policies related to holding districts, schools, and/or students responsible for performance. School and district accountability systems typically include efforts to assess and rate schools or districts based on student performance, and to provide rewards and sanctions for schools or districts based on performance or improvement over time.

- Achievement Gap-the disparity in academic performance between groups of students. It is most often used to describe the troubling performance gaps between many AfricanAmerican and Hispanic students whom at the lower end of the performance scale than their Caucasian peers. Similar academic disparity is also revealed between students of different socioeconomic status. 
- Adequate Yearly Progress-based on expectations for growth in student achievement that is continuous and substantial that prepares for all students in every subgroup to be proficient (definitions that assigned by individual state). Final goal is to have all students at or above proficiency by 2013-2014 in both reading and math.

- Curriculum-set of courses and its content at a school

- Democracy- is more than a form of government; it is primarily a mode of associated living, of conjoint communicated experience. The extension in space of the number individuals who participate in an interest so that each has to refer to his own action to that of others, and to consider the action of others to give point and direction to his own, is equivalent to the breaking down those barriers of class, race and national territory which kept men from perceiving the full import of their activity" (Dewey, 1916, pg. 87).

- Democratic Habits-the components of democratic education such as citizenship, democracy, reflection, critical thinking, problem solving, respect, ability to express opinion (voice), analysis, real-life application, and cooperative (Apple \& Beane, 2007; Darling-Hammond, 1997; Dewey, 1938; Glickman, 1998; Giroux, 1988; and Meier, 2002).

- Highly Qualified Teacher-must have: (a) a bachelor's degree, (b) full state certification or licensure, and (c) prove that they know each subject they teach.

- No Child Left Behind Act of 2001(P.L. 107-110)-formally known as the Elementary and Secondary Act (ESEA), requires states to establish academic standards and to use standardized test scores as a means of holding schools accountable. It also requires $100 \%$ of all teachers teaching core academic subjects to be considered "highly qualified" in their field. 
- Pedagogy- the act, process, or art of imparting knowledge and skill

- Performance-based assessment- refers to assessments that evaluate applications of knowledge to real world tasks. They are considered fair and un-biased. Such assessments include oral or written responses to questions or prompts, production of essays, research papers, mathematical problems, or models; and science demonstrations, experiments, or exhibitions in the arts. They can be defined as specific tasks or compilations of a number of tasks, within or across subject areas (Wood, Darling-Hammond, Neill, and Roschewski, 2007).

- Socioeconomic Status-economic and sociological combined total measure of a person's work experience and of an individual's or family's economic and social position relative to others, primarily based on income, education, and occupation. Students must met the following criteria to be considered to have a low socioeconomic status: (a) known to be eligible to receive the free or reduced-price lunch provide through the National School Lunch and Child Nutrition Program, and (b) know to be recipients of or whose guardians are known to be recipients of public assistance.

- School Context-conditions of a particular context—-structures, policies, resources, and student compositions. Influences how teachers think about and/or conduct instruction in their classroom and in turn how students learn. (Talbert \& McLaughlin, 1992)

- Student Achievement- measurement of a students' knowledge. It answers the question, "What does the student know?" Various methods have been used to determine student achievement ranging from outcome measurements standardized testing and GPA to performance-based assessments that include portfolios, multiple writing samples taken over a period of time, and cumulative projects. 
- Teacher Quality-inputs that a teacher bring to the classroom such as demographics, aptitudes, licensure, certification, and experience.

- Quality Teaching-what teachers do to foster learning and achievement (sometimes refer to as pedagogy).

\section{Summary}

This case study investigated the pedagogical practices and activities of four teachers of one public elementary school whose mission seeks to nurture and maintain democratic habits for participation in a democratic society. Through the historical writings of Washington, Franklin, Jefferson, Rush, and Webster the purpose and goal of public education is to develop citizens able to live within a democratic society. The writings of Dewey provide educational theory that security of a democratic way of life is dependent upon opportunities to learn what it is through a living example of democracy. It is only through experience, Dewey argues, that helps shape students' understanding, knowledge, and meaning of democracy.

Since commitment of teachers to democratic education is vital to achieving the living experience of democracy in a classroom, their perceptions, curriculum development, and curriculum implementation were explored through this study. This study also explored the school contexts associated with this case study. Contexts such as student composition (SES, gender, and minority populations), school organization, school size, school resources, and the effects of federal educational policy that research supports all have an impact, direct and indirect, on curriculum and pedagogical choices made by teachers for nurturing and maintaining democratic habits as well as has shown to have an effect on student achievement. 


\section{Organization of the Study}

The following represents the organization of this study. Chapter One provides the rationale and insights of the origin of the study. Chapter Two is a review of the literature related to school contexts, pedagogy, curriculum, and democracy in the elementary classroom. Chapter Three describes the methodology employed and study design of the research. Chapter Four offers the case study findings. Chapter Five, the final chapter, provides discussion of the research findings, recommendations of the study, and implications for future research. 


\section{Chapter Two: Review of Literature}

Seeking an understanding of the case study teacher practices and their roles in the classroom is essential when considering the contexts, curriculum, and pedagogy designed and used in nurturing and maintaining democratic habits for participation in a democratic society. As the curriculum designers, the case study teachers not only made decisions regarding the selection of subject matter but also how it was communicated to the students. Thornton (2005) referred to teachers as 'curriculum gatekeepers' because of the kind of decisions they make regarding the implementation of any planned curriculum in their classrooms. However, as Grant (2003) argued teachers implement curriculum under various external constraints. This chapter will review literature in the context of understanding decisions that teachers make concerning curriculum and pedagogy that nurture and maintain democratic habits for participation in a democratic society. It will provide background literature and research regarding school contexts, curriculum, pedagogy, and the educational concepts of democracy. Thus, there are four sections that will make up this chapter.

The first section examined the literature regarding various context factors that effect teaching and learning. Contexts such as student composition (SES, gender, and minority populations), school governance, school size, school resources, teacher quality, and the effects of federal educational policy that research supports all have an impact, direct and indirect, on curriculum and pedagogical choices made by teachers. This section explored the various contexts that were of issue to this study. The next section reviews literature regarding the process of curriculum and curriculum development. It provides background information regarding curriculum choices, content, and issues regarding making curriculum. The next section focuses on literature regarding pedagogy. Current research indicates the importance of 
answering the question why teachers teach they way they do. The last section explores how context, curriculum, and pedagogy are related to democracy. Two views emerged from the literature constructivist view as democracy as a learned experience and the critical theory of democracy as a transformational process. It will explore research and literature related to both of these views as well as how democracy is enacted in an elementary classroom.

\section{School Contexts}

Research indicates that there are various influences on how teachers think about and/or conduct instruction in their classroom and in turn how it affects student achievement (Talbert \& McLaughlin, 1992). Contexts ranging from school size and federal educational mandates to the basic student composition within a single classroom has been noted in numerous studies specifically its affect on teacher practices and student learning (Crowther, Kaagan, \& Ferguson, 2002, Darling-Hammond, 1985, Howley, 1994, Meier, 1996, Rosenholz, 1987). Two most recent studies Opdenakker and VanDamme (2007) and Heck and Moriyama (2010) revealed that not only were contexts a factor in student achievement, specifically math and reading, and school improvement but also provided evidence for focusing on the environment surrounding instruction.

Contexts that surrounded the case study teachers in this study had a direct influence over curricular development, curriculum implementation, and pedagogical choices for nurturing and maintaining democratic habits for participation in a democratic society. The first section will explore the literature and research related to those contexts: school size, school organization, student composition, school resources, teacher quality, and federal education mandates.

\section{School Size}

Research denoted that in small schools student achievement improves through increased 
student engagement, improved student attendance, higher graduation rates, and increased college acceptance rates (The Center for Collaborative Education, 2003; Conant, 1967; Fine, Pannozzo \& Achilles, 2003; Glickman, 1998; Howley , 1994; Klonsky, 1995; Raywid, 1995; Lee \& Smith, 1996; Rouse \& Barrow, 2006; Sizer, 1996). Literature revealed that the1990's rushed in the era of consolidation that created large schools. Larger schools, specifically high schools, were thought to be more academically advantageous as well as considered to be more cost effective as they were able to provide more academic programs than smaller schools (Conant, 1967). However, Howley (1994) reported that although the student achievements of students of higher socioeconomic status' communities were seemingly unaffected, the achievement of minority and low-income students were greatly affected. Large urban schools and rural consolidated schools reported having lower grade averages, lower standardized test scores, higher drop out rates, and more problems with violence, security, and drug abuse (Klonsky, 1995; Raywid, 1995).

In their study of small schools, Lee and Smith (1996) revealed that because small schools can provide more nurturing environments, the problems that have plagued larger schools could be and were eliminated through enhanced social relationships created by smaller populations. Lee \& Smith additionally found that the promised savings of school consolidation never actually materialized. Because of the considerably large school populations, the schools needed additional layers of academic support and administrative staff to deal with the increased bureaucratic demands.

Glickman (1998) argued that small schools enabled faculty to "sit together around the same table and make plans for and with their students" (pg. 40); to plan opportunities for "team teaching"; to construct an interdisciplinary curriculum; as well as develop "standards and reports of student performance" (pg. 41). He also asserted that small schools allows for individual 
attention and promoted student connectedness to the school. As such, research indicated that an effective size for an elementary school would 300-400 students and for a high school 400-800 students (Williams, 1990).

In addition to smaller school size, research revealed that reducing classroom size has also had a positive affect on student achievement especially for schools with a high population of low-socioeconomic students. Rouse and Barrow (2006) determine that the quality of a school is strengthened when smaller class sizes are available, stating, "Smaller sizes seem to be one promising avenue for improving school quality for disadvantaged students.” (pg.113) Additionally, Fine, Pannozzo, and Achilles (2003) found in their review of research regarding classroom size that the key of small classes resided in student behavior. It revealed findings that indicated that students become more engaged academically and more engaged socially when class sizes are reduced. They also posited that the increased engagement in the classroom led to an increased learning time, thus increased student achievement in all subject areas (pg. 322).

\section{School Governance}

Recent studies have revealed that the traditional notion of a school leader, defined and delegated to the sole responsibility of the principal, has transformed through time (Hall \& Hord, 2001; Katzenmeyer \& Moller, 1996; Marks \& Louis, 1997; Siins \& Mulford, 2002; \& Ovando, 1996). In order to sustain school improvement and effectiveness, the bureaucratic and hierarchical structure of many schools has been replaced with a more distributed form of leadership. In this sense, leadership has been separated from person, role, and status; and is primarily concerned with the relationships and the connections among stakeholders within a school. There has been a shift from a 'singular' leadership definition, practiced by the principal, to different various individuals within a school, specifically teachers (Hall \& Hord, 2001). 
Studies have found that teachers participating in decision making and collaborative teacher principal leadership has contributed to school effectiveness, teaching quality, and improvement in student performance (Blasé \& Blasé, 1994; Katzenmeyer \& Moller, 1996; Marks \& Louis, 1997). Silins and Mulford (2002) and Ovando (1996) found that empowered teachers and distributed democratic leadership have impacted student performance because teachers felt more innovative, invested, and a significant part of the decision-making process. Their argument was based on the notion that if schools were to improve learning experiences for students that the schools must also become better at providing opportunities for teachers. This, Silins and Mulford, (2002) posited, could only be accomplished where leadership is distributed through the school. Another study additionally found that in the most effective schools, leadership was a shared responsibility of teachers and principals. The redistribution of power and re-alignment of authority within a school organization provided enhanced dignity and respect for teachers as well as made teachers part of the collective effort for school improvement (Blasé \& Blasé, 1994).

\section{Student Composition}

Several studies have investigated the effect of student composition on student achievement and school improvement. Factors including socioeconomic status, race, and gender have all been investigated with relation to student achievement. Studies revealed that the general effect on student achievement within a school has been varied to its extent (Coleman, 1966; Gough, 1946; Opdenakker \& Van Damme, 2007; Rose \& Barrow, 2006; Sirin, 2005). Studies have also indicated that the 'hidden curriculum', specifically the attitudes, behaviors, and practices (Anyon, 1980; Apple, 1979; Eisner, 2002), have continued to serve as powerful reinforces of inequities in schools. According to Apple (1979), the 'hidden curriculum' reaches 
beyond pedagogical and teaching practices (considered the formal curriculum) to the informal curriculum that has served as both subtle and explicit messages of gender inequity, racial inequality, socioeconomic inequality, and teacher inequality have continued to exist in many school contexts.

Socioeconomic Status. Studies as early as Gough (1946) found that there is a correlation of .30 between status and achievement, thus showing a slight positive relationship. Coleman's et al. (1966) study on Equality of Educational Opportunity, also investigated socioeconomic status as a predictor of student achievement. Coleman asserted that poverty was the main factor among children in the United States in regards to student achievement (although debated in later research Wenglinsky, 2000). Considering the U.S. Census Bureau (2010) indicated that the U.S. poverty rate rose to 14.3 percent in 2009 from 13.2 percent the year before, bringing the percentage of the population living in poverty to the highest level since 1994. 43.6 million people, or one in seven Americans, lived in poverty in 2009, up from 39.8 million in 2008 and that the poverty threshold for a family of four in 2009 was $\$ 21,954$, the body of research regarding socioeconomic status has been relevant regarding student achievement.

Studies have shown that socioeconomic status is significant when considering school finances and student achievement of low socioeconomic status students (Greenwald, Hedges, \& Laine, 1996; Rose \& Barrow, 2006; Sirin, 2005). Due to that funds for schools are received through property taxes, Sirin (2005) posited that schools whose population is contains a high percentage low income students are likely to be inferior to those schools whose population is of high income. He continued that these schools have less revenue to spend on their students as such these schools do not have to adequate textbooks, computers, facilities, and curriculum offerings. These schools have less income to distribute per student, lowering the per-pupil 
expenditure amount (ibid, 2005). Darling-Hammond (2000) argued that a major side effect of unequal expenditures is unequal access to well-qualified teachers, which is a critical factor in underachievement in minority students. Although research has indicated that increasing resources to school districts with a large population of low socioeconomic status would increase student achievement, the resources should be allocated educationally and efficiently as possible. How monetary resources are spent is significant to student achievement (Greenwald, Hedges, \& Laine, 1996). This argument revisited by Rouse and Barrow (2006) who suggested that school districts with a low socioeconomic status do not efficiently allocate their resources, as many are not managed as effectively or efficiently as those with higher socioeconomic status populations.

Some studies, however, did not find significant relationships among socioeconomic status and student achievement. White, Reynolds, Thomas, and Gitzlaff (1993) found that the knowing a student's socioeconomic status only provided small assistance for predicting a student's performance on a standardized test. Similarly, Nye and Hedges (2002) and White (1982) both found that socioeconomic status is more of a predictor at early stages of education, and much less of a predictor as the students progress into the later stages of education. They argued that other variables become more of a factor in student achievement scores than just being economically disadvantaged.

Race. In the landmark decision Brown v. Board of Education (1954), Chief Justice Warren, wrote education was "perhaps the most important function of state and local governments" $(483,493)$ and repudiated the separate but equal doctrine stating that racially segregated schools were "inherently unequal" (495). This case and Title IV of the Civil Rights Act of 1964 not only led to decades of litigation regarding integration compliance but mass educational studies regarding student achievement of minority students. Integration had created 
the most substantial contact between white students and African American students.

Referenced earlier, Coleman's et al. (1966) study argued that study that the influence of student background was greater than anything that goes on within schools. As such, studies that have often focus on race are more than likely been linked to poverty. True as statistics discussed previously revealed that the poverty rate rose to 14.3 percent and of that 64.9 percent comprised of Blacks, Asians, and Hispanics. Although research and statistics have indicated poverty is an issue, other contextual issues regarding race and ethnicity emerged from the literature.

Studies have revealed that students and teachers are often faced with constricted curriculum that has not adequately accounted for student diversity and has been typically based on the knowledge and experiences of middle-class whites (Darling Hammond, 1985; LadsonBillings, 1994; Ravitch, 2010; Slattery, 2006). Slattery (2006) argued that curriculum and schools have ignored the issues of race, gender, and ethnicity viewed as "controversial and contentious" (pg. 178). He posited that many fear true and open discourse regarding race, gender, and ethnicity, as it would lead to turmoil and unrest in society rather than a greater understanding of society as a whole. However, Ladson-Billings (1994) contended that teachers could increase student achievement by "importing the culture and everyday experiences of minority students" (p. 117). In this theory, minority students are able to relate to the curriculum as well as are motivated to learn the curriculum. Banks (1998) maintained that a significant goal of multicultural education is to "increase educational equality for both gender groups, for students from diverse ethnic and cultural groups, and for exceptional students" (p. 22). Earlier works of James Bank (1988) argued that curriculum that moves beyond heroes, holidays, and contributions; and becomes “...the infusion of various perspectives, frames of reference, and content from various groups" would then "extend students' understanding of the nature, 
development, and complexity of U.S. society" (pg. 2).

Gender. According to Koch and Irby (2002) the term gender equity is defined as " to be fair and just toward both men and women, to show preference to neither, and concern for both," (pg. 4). This definition moves beyond what was previously termed sex equity because gender equity reflects the cultural, social construct of male and female roles and expectations rather than simply biological aspects of sex differences. It accepts that there are some areas in society where both genders have received partiality (Koch \& Irby, 2002). With the passage of Title IX in 1972, it ushered in various programs and studies on the issue of gender equity in schools. Previous studies regarding gender equity issues have focused primarily on the educational disadvantages faced by girls in schools (Bailey, 1992; Sheridan \& Henning-Scout, 1994; Sadker \& Sadker, 1994) A study conducted by The American Association of University Women (to be referred to later as AAUW) (1992) argued that math and science curriculums, standardized testing, and school contexts create environments that are educationally depriving girls. Sheridan and Henning-Stout (1994) posited that teachers interact differently with girls and boys. They argue that historically, gender differences have been interpreted in ways that benefit males. Other studies have noted that girls are viewed to be docile and adaptive while boys are seen as aggressive and problematic, thus girls tend to receive less teacher attention (Sadker \& Sadker, 1994).

More recent studies have concluded there have been some strides in closing the gender gap but assert more studies need to consider not only gender but also family income level and race/ethnicity (Corbett, Hill, \& Rose, 2008; Lubienski,McGraw, \& Stutchens, 2004). Corbett, Hill, \& Rose (2008) argue that tests scores reveal that African American and Hispanic girls have much in common with African American and Hispanic boys in terms of educational 
performance. Understanding gender differences cannot be fully understood without the consideration of family income and race/ethnicity. Using scores from National Assessment of Educational Progress (to be referred to later as NAEP), the authors posit that overall girls and boys are improving by most measures but asserted that the continual achievement gap is more of an indication of a strong relationship between race/ethnicity and family income levels.

Sadker and Zittleman (2005) argue that gender challenges are still an issue in most classrooms. According to their study, teachers tend to still call on boys before girls, provide boys with more precise feedback, and only praise girls for their neatness. Another emerging issue from their study is the issue of bullying. While boys tend to be victims of physical bullying, girls are frequently victims of verbal and psychological, research has shown that both types have bullying have been linked to reduced academic achievement by (ibid, 2005). Research thus supports a continued look at gender equity issues that includes the contexts of socioeconomic status, race/ethnicity, and school governance.

\section{Teacher Quality}

Teacher quality has been a focus of research as student achievement, high-stakes testing, achievement gaps, NCLB highly qualified requirements, and teacher attrition has received increased scrutiny. Research discussed earlier in this review argued that a student's socioeconomic background had more of an impact on student achievement than any other measure (Coleman et al., 1966). Yet, recent research has suggested that how a teacher responds to the social contexts such as socioeconomic status can greatly effect student achievement (Darling-Hammond, 1999, 2000; Wenglinsky, 2000).

To be "highly qualified" according to NCLB (2001) simply means that a teacher holds at least a bachelors degree, has state certification or passed a licensure exam, and has demonstrated 
competence in core academic subjects. However, research has revealed that there is much more to a quality teacher and quality teaching. Kaplan and Owings (2002) defined as teacher quality as "the inputs that teachers bring to the classroom including their demographics, aptitudes, professional preparation, college majors, teacher examination scores, teacher licensure, teacher certification, and prior professional experiences. It is what teachers do with what they know to promote student learning inside the classroom" (pg. 4). In this context, teacher quality implies that there is a set of inputs (as listed above) and a set of conditioned tasks, the task of teaching (what teachers do) and achievement (the student learning that teachers foster). Fenstermacher and Richardson (2005) defined this as successful quality teaching:

Quality teaching could be understood as teaching that produces learning. In other words, there can indeed be a task sense of teaching, but any assertion that such teaching is quality teaching depends on students learning what the teacher is teaching. To keep these ideas clearly sorted, we label this sense of teaching successful teaching. (p. 186) Kannapel and Clements (2005) conducted a study of teacher quality that focused on 26 high-performing as well as high-poverty elementary schools in Kentucky. Their study reported that the teachers in these schools more likely to conduct frequent assessments with student feedback; deliver instruction that was aligned to learning goals, assessments, and diverse learning styles; demonstrate high expectations for student performance; participated in collaborative decision making; participate in job-embedded professional development; and use achievement data for staff development.

Research regarding teacher quality has not been conclusive especially surrounding mitigating factors such as teacher preparation and teacher certification. Various studies have been conducted that have resulted in contradictory conclusions (Darling-Hammond, 2002, 2002; 
Hopkins, Miller, McKenna \& McKenna, 1998; Monk, 1995). Darling-Hammond (2000) conducted a 50-state survey of policies, state case study analysis, 1993-94 school and staff surveys, the National Assessment of Educational Progress that explored how teacher qualifications and other school inputs related to student achievement. Her study identified various teacher quality factors that have been shown to increase student achievement. Factors such as teacher certification, teacher education programs, professional development offerings, and education requirements have made a difference regarding teachers' abilities and their students' outcomes. Her findings also indicated that providing opportunities for teachers to understand how diverse learners learn and make adjustments was key to improving student achievement.

Miller, McKenna, and McKenna (1998) compared the differences in teacher practices between alternatively and traditionally prepared teachers. The alternative certification program required provisionally licensed teachers to complete condensed coursework, participate in a mentoring program, and complete ongoing coursework while teaching in order to meet minimal state certification criteria. Their findings revealed that there were no significant differences between alternatively and traditionally prepared teacher practices. The second part of the study examined the effects of teacher certification on the academic achievement of students. Once more, no differences were noted in average student achievement, based on the student test scores. The most noted of alternate teacher certification is the Teach for America (to be later referred to as TFA). TFA recruits teachers for high-poverty schools in a number of areas around the country. Once corps members are selected, they must attend a six-week summer training institute, operate by Teach for America, prior to being placed in a classroom (Hopkins, 2008). Raymond, Fletcher, and Luque (2001) found that students of TFA teachers in Houston had 
higher test score gains in mathematics than did students of other teachers, many of whom were not certified. Other studies have found that teachers who lack preparation in either subject matter or teaching methods are significantly less effective in producing student learning gains than those who have a full program of teacher education and who are fully certified (Hopkins, 2008).

In a review of her experiences as a Teach for America corps member, Hopkins (2008) revealed that she lacked the necessary content and pedagogical knowledge needed to teach her students effectively. Specifically, she felt as though she did not have a deep understanding of her students' backgrounds or an understanding of the community she was teaching and like 80 percent of other TFA teachers left the field of teaching within three years. Lackso-Kerr and Berliner (2002) investigated student achievement under recently hired under-certified and certified teachers in five low-income school districts. Their results indicate that students of TFA teachers did not perform significantly different from students of other under-certified teachers but students of certified teachers far out-performed students of teachers who were under-certified. The study argued that traditional programs of teacher preparation resulted in positive effects on the academic achievement of low-income primary school children. Recommendations of the study included changing present policies that under-certified teachers, including those from the TFA program, to work with the most difficult to teach children appear harmful. Their study argued that such policies increased differences in achievement between the performance of poor children, often immigrant and minority children, and those children who are more advantaged (Para. 4).

\section{Federal Education Policies}

The need to monitor student performance through instructional objectives, competencybased teacher education, and evaluation became the predecessor to A Nation at Risk. In 1981, under the direction of President Ronald Reagan, Education Secretary T.H. Bell created the 
Commission on Excellence in Education. The commission was directed to examine the quality of education in the United States, report its findings, and make recommendations for educational improvement. Their findings indicated that there was poor academic performance at nearly every level and warned that the education system was being 'eroded by a rising tide of mediocrity' (A Nation At Risk, 1983). This report launched over two decades of tough talk about public schools and reforms that culminated in 2001's No Child Left Behind (to later be referred to as NCLB), the bi-partisan federal education law that pushes schools to improve students' basic skills. NCLB (2001) reauthorized a number of federal programs that aimed to improve the performance of U.S. primary and secondary schools.

The cornerstones of NCLB are high-quality standards and assessment systems. Designed to provide teachers, administrators, and policymakers information that may be used to identify problems, customize and improve education, and target resources and interventions for those students who are in most need of help. It commits that by setting standards, measuring progress, and holding states accountable it will ensure that all children have the basic skills needed to compete in a competitive, global economy (ibid, 2001). States receiving federal funding for public education is required to set a statewide accountability system. The statewide accountability system is based on designing a definition of adequate yearly process (to later be referred to as AYP). The AYP status is based on expectations for growth in student achievement that is continuous and substantial that prepares for all students in every subgroup to be proficient (definitions that assigned by individual state) in reading and math no later than 2013-2014 (NCLB, 2001). Schools are specifically held accountable for minority students as well as low socioeconomic students thus seeking to eliminate the achievement gap between the aboveidentified groups and white students and those of high socioeconomic status. Data collected to 
determine AYP is through statewide standardized testing for grades 3-8 and must meet NCLB minimum standards for statewide accountability systems (ibid, 2001). One-third of the nation's schools did not make AYP in 2009 (CEP, 2010). As of January 2009, 39 states have obtained Full Approval or Full Approval with Recommendations status (US Department of Education, 2009).

Vast studies have been undertaken investigating how accountability measures have impacted pedagogy and curriculum. Most have reported that teachers have responded to the increased pressures created by high stakes testing through teaching test-taking skills, modeling classroom assessments after state tests, and only emphasizing content that is tested (DarlingHammond \& Wise, 1985; Goodman, 2004; Hoffman, Assaf, \& Paris, 2001; McMillan, Myran, \& Workman, 1999; Meier, 1995; Rosenholz, 1987).

In studying teacher responses to district-wide testing, Darling-Hammond \& Wise (1985) revealed that teachers altered their instructional practices as well as adjusted curriculum content in order for students to achieve specifically on administered state tests. Later, Rosenholz (1987) found that teachers altered their instructional practices in order to conform to the content of statewide competency testing. She also found in her interviews with elementary teachers that they also changed the content of their instruction in order to match the content of statewide competency tests. Much research points to the potentially harmful effects of high-stakes testing on students, such as narrowing school curriculum to only that which is covered on exams and/or teachers relied heavily on textbooks for classroom instructions because the textbooks were aligned closely to the curriculum (Korezt, Mitchell, Barron, \& Keith, 1996; McMillan, Myran, \&Workman 1999).

McMillan, Myran, and Workman (1999) surveyed 722 Virginia teachers where more than 
$80 \%$ indicated that the state Standards of Learning (to be referred to later as SOL) test had impacted their instruction, particularly with regard to the content focus of daily lessons. The researchers found that the increased attention toward tested content had led to a decreased emphasis on non-tested curricular areas. In another study, $88 \%$ of Maryland teachers surveyed felt they were under 'undue pressure' to improve student performances on state tests (Korezt, Mitchell, Barron, \& Keith, 1996). Similarly, a review of responses of reading teachers in Texas teachers found that an average of eight to ten hours were spent per week preparing students for the Texas Assessment of Academic Skills (to be later referred to as TAAS). The teachers reported spending this time on test preparation activities that included demonstrating how to mark the answer sheet correctly, providing test-taking tips, teaching or reviewing topics that would be on the test, teaching test-taking skills, and reviewing previously released test questions for practice (Hoffman, Assaf, \& Paris, 2001).

Echoed in Goodman's (2004) antidotal work, he shares two narratives written by teachers regarding the impact NCLB has had in their classrooms. Beginning with the story of Sara, a teacher who began teaching because she wanted to "feel as if I was doing something for my community" (p. 265) however she found herself teaching to the test due to NCLB legislation. Goodman's second narrative visited the classroom of Grace, who expresses her concerns about curriculum and instructional methods that are not meeting the needs of all learners, but her district continues to adopt methods that are in order to prepare for standardized tests

High stakes tests are considered to be the educational vehicles for compensating for social and educational inequalities (NCLB, 2001). Tests are intended to motivate students and teachers to prepare better, resulting in increased achievement. In the case of minority and/or students of low socioeconomic status, the high stakes testing reforms were to serve as a means to close the 
"achievement gap." Research, however, has indicated that the gaps may be widening (Center on Education Policy, 2004) as students may not be learning more under high stakes testing reforms due to consistently poor resources, curriculum, and instruction received by low-income students and minority students (Darling-Hammond, 2000; Greenwald, Hedges, \& Laine, 1996; Rose \& Barrow, 2006; Sirin, 2005). Nichols, Glass, and Berliner (2005) conducted a study using several analyses of National Assessment of Educational Progress test data from 25 states. It revealed that a link between the pressures associated with high-stakes testing and increasing student achievement could not be established. However, the results of their study also demonstrated that the increased testing pressure was related to increased retention in grade and dropout rates.

\section{Curriculum}

This next section discusses issues with the design and implementation of curriculum. It explores research and literature that argues and supports providing a rich-content filled curriculum rather than a narrowed curriculum that has been encouraged through high-stakes testing.

\section{Narrowed Curriculum}

The term curriculum finds its roots in the Latin word 'currere' meaning to run a course (Eisner, 2002). Its modern meaning is defined as a set of courses and its content at a school (Merriam-Webster, 2010). Much research has concentrated on the importance of curriculum content, subject matter, and how each has effected student achievement. Most recently the research has centered on how high-stakes testing has affected curriculum by narrowing the content that teachers teach (Center of Education Policy, 2009; Center of Education Policy, 2006; Common Core, 2009; Darling-Hammond, 2010). As explored in Teacher Quality, mandated standardized testing has greatly influenced instruction. Through this influence, less time is 
devoted to core subjects that other nations embrace (Common Core, 2009).

The Center of Education Policy (2009) conducted case studies of eighteen schools in sixteen school districts in three states Illinois, Rhode Island, and Washington looking at the impact of state and federal accountability systems on curriculum, instruction, and student achievement. One of their key findings revealed that in effort to align curriculum to standards and allow time to focus on tested material in reading and mathematics that it greatly diminished time for social studies, science, and other subjects. In fact the study revealed that often times teachers taught history and science as part of the reading or writing lesson that indicated lack of developed knowledge of history or science content.

An earlier CEP study (2006) surveyed district level administrators regarding districtdeveloped policies. At least half of the districts in the CEP study required elementary schools to spend a specific amount of time on reading (60\%) and on math (50\%), and $71 \%$ of districts reported reducing time on untested subjects at the elementary school level to provide additional time for reading and mathematics instruction. Urban and high-poverty districts reported requiring a certain amount of instructional time on tested subjects, and they also reported spending more time on these subjects than other schools. In fact urban districts reported requiring an average of 113 minutes per day for reading instruction, where the overall average had been reported at about 90 minutes (Center on Education Policy, 2006). In addition, district staff often reported policies that required low-performing students to receive extra instruction in reading or math that normally required the student to miss class time in other subjects.

\section{International Curriculum}

In 2009, the Program in International Assessment (to be referred to later as PISA) found that U.S. 15 year olds ranked $30^{\text {th }}$ out of 65 countries in mathematics, $23^{\text {rd }}$ in science, and $17^{\text {th }}$ in 
reading. The current rankings has launched numerous conversations regarding how and why U.S. have consistently ranked behind countries such as Finland, China, Japan, Australia, South Korea, and New Zealand. Common Core (2009) led by Dr. Diane Ravitch, sought to answer the how and why hence researched the curriculum content of the countries that had consistently outranked the U.S. on the PISA: Finland, territory of Hong Kong, South Korea, Canada, Japan, New Zealand, Australia, Netherlands, and Switzerland (pg. 5). Their key findings indicated that each of the above mentioned nations provided a comprehensive, content-rich education in liberal arts and sciences:

- Fourth graders in Hong Kong visit an artist's studio, study Picasso's Guernica, and analyze the works of modernist sculptor Henry Moore.

- Finish fifth and sixth graders study how the invention of writing changed human life and the impacts of the French Revolution; they trace a topic such as the evolution of trade from prehistory until the $19^{\text {th }}$ century.

- Seventh graders in Korea are expected to know not just about supply and demand, but about equilibrium price theories, property rights, and ways to improve market function (Common Core, 2009, pg. 5).

Darling-Hammond (2010) examined three educational systems Finland, Singapore, and South Korea. Although these countries are fundamentally different historically and culturally they all have staggeringly improved their education systems throughout the last thirty years. These countries have committed resources to rural and urban areas through teacher incentives, smaller class size, teacher collaborative curriculum, and school-based assessments. The majority of the international education systems do not use standardized testing as a form of assessment or as an evaluative tool of teacher performance. Her findings revealed the investment in equalized 
access to an intellectually rigorous curriculum has yielded rankings at the top of education international rankings, a 90\% graduation rate, and an increased college attendance (pgs. 3-4). The findings of Common Core (2009) and of Darling-Hammond (20101) have indicated by using the 'narrowed curriculum' of basics, the U.S. has consequently left behind key elements of curriculum and education that other nations have used to successfully educate their students arts, history, literature, science, geography, civics, and foreign languages. These nations do more than attempt to prepare their students for the labor market (Common Core, 2009).

\section{Creative and Artistic Curriculum}

Eisner (2002) offered that curriculum has historically been defined in a multiplicity of notions as based on ideologies. Ideologies such as religious orientation, Progressivism, Critical Theory, or others can define beliefs about what schools should teach, for what ends, and for what reasons. He argued that curriculum is more than a list of subjects to be taught and that there is an explicit curriculum (the goals and objectives offered by schools) and the implicit curriculum (the pervasive and ubiquitous set of expectations and rules that define schools as a cultural system that teaches important lessons), (pg. 106). Schools have an opportunity, he posited, to offer their students an experience that develops intellectual processes that will be useful in life. Eisner advocated that an ideal school would offer a curriculum that allows teachers the ability to provide optimal growth for the student. Schools must allocate for flexible, creative, innovative, and artistic teaching so that individual learning can occur (Eisner, 2002, pgs. 376-381).

Eisner (2002) believed there should be consideration for the 'art of teaching'. He argued that through curriculum development, textbooks, and materials has created an error proof program that even the most incompetent teacher cannot fail to improve student achievements. Eisner suggested that is has replaced the need for teachers to exercise judgment and has created 
an assembly line of education that is falling short of intended goals. Although Eisner agreed that there are those teachers who required different amounts of support, development, and resources in the end the curriculum and the curriculum materials should minimize a teacher's dependency on them. It should foster a sense of competence in both content delivery and pedagogical matters (Eisner, 2002, pg. 373).

\section{Pedagogy}

This section explores research in teaching that when considering student achievement has not only focused on curriculum but also the mode of delivery. MacLaughlin and Talbert (1993) posited that student success in the end depended on what teachers do in the classroom, the teacher's ability, and the teacher's willingness to offer an educational environment necessary to meet educational goals. Wenglinsky (2000) investigated test scores of over 15,000 eighth graders who took the National Assessment of Educational Progress (NAEP) mathematics and science assessments. The study revealed that teaching higher order thinking skills led to better student outcomes. More importantly, it indicated that teachers with strong content knowledge and those who individualized instruction based on the varying levels of knowledge and skills of students, especially students with limited English proficiency and special needs, were able to produce higher test scores in math for these students. Additionally, Darling-Hammond (1999) argued that, "If teachers are well-prepared in both content and pedagogy, it makes an enormous difference not only to effectiveness in the classroom, but also whether they are likely to enter and stay in teaching" (p. 12). Thus, research has centered on how teachers' knowledge has informed their practice.

\section{Pedagogical Content Knowledge}

Shulman's (1986) postulated that an understanding of subject matter content and an 
understanding of the teaching strategies teachers applied is the 'missing paradigm' in educational research (p.7). By asking thought provoking questions on how teachers gain and use knowledge he revealed that teachers gain knowledge from multiple sources:

"How do teachers decide what to teach, how to represent it, how to question learners about it...? What are sources of teacher knowledge? What does a teacher know and when did he or she come to know it? How is new knowledge acquired, old knowledge retrieved and both combined to form a new knowledge base?" (p. 8)

According to Shulman, there are three types of knowledge required for classroom practice (a) subject matter knowledge, (b) curricular knowledge, and (c) pedagogical content knowledge (to be later referred to as PCK). He defined subject or content knowledge as the principles, theories, and concepts of a particular discipline/subject. He stated that it "referred to the amount and organization of knowledge per se in the mind of the teacher" (p. 9). Thus, Shulman contended that content knowledge is not just knowing facts, but also explaining various propositions of the representation of that fact. Curricular knowledge is an understanding of curricular and instructional resources that are available within various schools and grade levels. Pedagogical content knowledge consisted of knowledge about teaching itself. He describes PCK as "the most useful forms of representation...the most powerful analogies, illustrations, examples, explanations, and demonstrations... the ways of representing and formulating the subject matter that makes it comprehensible for others" (pg. 9). To Shulman, content knowledge and pedagogical knowledge walked hand in hand as pedagogies are the most useful ways of representing subject matter. He observed that PCK developed in stages from the pre-service teacher, to a novice teacher, and to the experienced teacher. 
Continuing his work, Schulman (1987) defined PCK in a larger context as one only one of seven outlined categories that are needed knowledge base of teaching (a) content knowledge, (b) general pedagogical knowledge, (c) curriculum knowledge, (d) pedagogical content knowledge, (e) knowledge of learners, (f) knowledge of educational contexts, and (g) knowledge of educational ends, purposes, values, and their philosophical and historical gains. Within this work, he highlighted pedagogical content knowledge as an emphasis on pedagogy and professional knowledge; and less on subject matter. Schulman (1987) argued that pedagogical content knowledge "represented the blending of content and pedagogy into an understanding of how particular topics, problems, or issues are organized, represented, and adapted to the diverse interests and abilities of learners, and presented for instruction" (p. 8).

\section{Pedagogical Content Knowing}

Building on the work of Shulman, Cochran, DeRuiter, and King (1993) renamed PCK as pedagogical content knowing (to be later referred to as PCKg), based on constructivist views because teaching in specific school contexts is crucial. Finding PCK to be static and not simultaneous, their model not only included subject matter content and specific pedagogical knowledge it added teachers' understanding of the environmental context in which learning and teaching occur (pg. 3). Although, Shulman recognized the environmental context of learning, he placed far more emphasis on the transformation of subject matter for teaching where Cochran et al. emphasized teachers' understanding of student and the context of learning (pg. 6). Their definition of PCKg integrated four components of pedagogy, subject matter content, student characteristics, and the environmental context of learning. Through these key elements a teacher is enabled to create teaching strategies for content that is not only student specific but also context specific (Cochran et al., 1993). 


\section{Teacher Knowledge Formal and Practical}

Also inspired by Shulman, Fenstermacher (1994) conceptualized teacher knowledge formal (to be later referred to as $\mathrm{TK} / \mathrm{F}$ ) and teacher knowledge practical (to be later referred to as $\mathrm{TK} / \mathrm{P}$ ). The $\mathrm{TK} / \mathrm{F}$ are the types of knowledge teachers have gained from their formal training and include subject matter, curriculum theories, instructional techniques, and classroom management skills (Fenstermacher, 1994). He posited that university researchers and professors have based and produced this kind of knowledge on the vast theories of teaching and learning. The expectation from researchers and professors is that training in these types of $\mathrm{TK} / \mathrm{F}$ determines the effectiveness of the teachers in planning and implementation of any curriculum. In addition, he observed that education policy-makers consider $\mathrm{TK} / \mathrm{F}$ as the essential base of knowledge for teachers' classroom practices. As such, curriculum development processes are largely dependent upon this type of knowledge.

Fenstermacher (1994) defined TK/P as the types of knowledge that teachers produce and use through practice in their classrooms. Teachers come to know what works for them through trying out things in the classrooms as well as in the context of their social environment (Thornton, 1994). Fenstermacher contended more can be understood the development of TK/P by engaging teachers in a discourse of how they implemented curriculum within the context of their classroom.

\section{Democracy and Education}

The section explores how context, curriculum, and pedagogy are related to democracy. Two views emerged from the literature constructivist view democracy as a learned social experience and the critical theory of democracy as a transformational process. Dewey argued that not only is education a continuous reconstruction of experience but also the key to 
transforming society (Dewey, 1938, pg, 87). This section is divided into three explorations constructivist view, critical theory, and enactment of democratic education in the elementary classroom.

\section{Constructivist: Learned Social Experience of Democracy}

Much of the constructivist view is founded in the work of educational psychologists Lev Vygotsky (1962/1986) and Jean Piaget (1971). Constructivists view children as the builders of their own cognitive tools and external realities. Knowledge cannot be transmitted, retained, and reapplied; but is constructed and constantly restructured through personal experience. Vygotsky a social constructivist argued that a child's development is guided by the roles of culture and interpersonal communication and that social interaction with significant people was crucial in a child's life (Vygotsky, 1962/1986) He posited that learning is an interactive and constructive activity, and both society and individuals played an essential roles in learning. Social contexts is the both the source and the cultural repository of the learning. Piaget (1971), a cognitive constructivist, theorized that a child constructed knowledge from their experiences through the processes of accommodation and assimilation. Assimilation as described, as a learner will assimilate their new experiences into an existing knowledge framework and accommodation as defined as where a learner will reframe their existing knowledge framework to meet new experiences that alters their understanding. For Piaget, knowledge is not information to be delivered, memorized, and applied at the other end. It is experience that is acquired through interaction with the world, people, and things (Fosnot, 2005).

Research has shown that there have been multiple debates between constructionist who adhere strictly to Piaget's cognitive theory; therefore, rejecting Vygotsky's social contexts of learning (Fosnot, 2005). Thus, Fosnot (2005) postulated a blending of both ideas: 
We cannot understand an individual's cognitive structure without observing its interacting within a context, within a culture. But neither can we understand culture as an isolated entity affecting the structure since all knowledge within a culture...is taken as shared (pg. 28).

Although constructivism is more widely accepted as a learning theory rather than as a theory of teaching, Fosnot argued that analyzing the constructivist theory would inform teacher practice. Through 'constructivist teaching' practice becomes more rigor empowered, and constructed for genuine understanding (Fosnot, 2005, pg. 291).

Constructivist Teaching. According to Fosnot (2005), constructivist teaching affords meaningful, concrete experiences. The classroom becomes a micro-society in which learners jointly engage in activity, discourse and reflection. She proposed several principles of the constructivist view of learning that could be applied to educational practices. Specifically those that seek to provide democratic education:

- Learning is not the result of development; learning is development. It requires invention and self-organization on the learner's part. Teachers should allow learners to raise their own questions, generate their own hypotheses and models as possibilities and test them for viability.

- Disequilibrium facilitates learning. 'Errors' should be perceived as a result of learners' conceptions and therefore not minimized or avoided. Challenging, open-ended investigations in realistic, meaningful contexts will allow learners to explore and generate many possibilities, whether affirming or contradictory. Contradictions in particular, need to be illuminated, explored and discussed.

- Reflective abstraction is the driving force of learning. As meaning-makers, humans seek to 
organize and generalize across experiences in representational form. Reflection through journals, representation in multi-symbolic form, or connections made across experiences or strategies may facilitate reflective abstraction.

- Dialogue within a community engenders further thinking. The classroom should be a "community of discourse engaged in activity, reflection, and conversation." Learners (rather than teachers) are responsible for defending, proving, justifying, and communicating their ideas to the classroom community. Ideas are accepted as truth only as they make sense to the community and thus rise to the level of "taken-as-shared."

- Learning proceeds toward developing structures. As learners struggle to make meanings, they undertake progressive structural shifts in perspectives—in a sense, "big ideas." These learner-constructed, central-organizing ideas can be generalized across experiences, and they often require undoing or reorganizing earlier conceptions. This process continues throughout development (pg. 29-30).

Dewey and Experience. Dewey (1902) posited that order for education to be most effective, subject matter must be presented in a way that allows the child to relate the information to their prior experiences, thus deepening the connection with this new knowledge. Dewey's theory is based on the interaction of two key principles of continuity and interaction. Dewey defined continuity is that each experience a person has will influence his/her future. That influence can be either for better or for worse dependent upon the experience. He defined interaction as the situational influence on one's experience. Thus, one's present experience is a function of the interaction between a person's past experiences and a person's present situation (Dewey, 1938). However, he cautioned that experience itself is not knowledge. Knowledge can only be altered through the process of inquiring, thus knowledge is not a static entity but an activity of inquiry 
(1916). Therefore, knowledge cannot be a mere transfer of knowledge but one that is interactive, constructed, evolving, and transformative (Apple, 1993; Dewey, 1938, 1902; Freire, 1970; Illich, 1971; Giroux, 1985; McLaren, 1998)

\section{Critical Theory of Democracy}

Dewey (1922) posited that children's education must play a central role in societal metamorphosis. Children, he stated, “....are not yet subject to the full impact of established customs; therefore, the chief means of social rectification lies in the utilizing the opportunities of educating the young to modify prevailing types of thought and desire" (pg. 127). Dewey (1916) conceptualized that knowledge is gained from experience and that those experiences should mold and be the mode of a social and political life:

A democracy is more than a form of government; it is primarily a mode of associated living; of conjoint communicated experience. The extension in space of the number of individuals who participate in an interest so that each has to refer to his own action to that of others, and to consider the action of others to give point and direction to his own, is equivalent to the breaking down of barriers of class, race, and national territory which kept men from perceiving the full import of their activity (pg. 87).

However, many critical theorists argue that schools have become havens of ensuring privilege of the dominant culture through political, economic, and social power (Apple, 1993; Freire, 1970; Illich, 1971; Giroux, 1985; McLaren, 1998). McLaren (1998) stated the education institutions:

Serve to reproduce the technocratic, corporate, and capitalistic ideologies that characterize dominant societies. It is, in fact, reasonable to argue that education 
programs are designed to create individual who operate in the interests of the state, whose social function is primarily to sustain and legitimate the status quo (pg. 1).

In analysis of the teacher-student relationship, known critical theorist Paulo Freire argued (1970) that it had become a narrative character, where one narrates subject (teacher) and the other listens (student). The teacher's task has become to "fill" students with content hence the better the "container" has been filled, the better the teacher is considered to be. The more the student permits himself or herself to be filled, the better the student is considered to be. Thus the "banking" concept of education is derived. Through this analogy, Freire posited that education has become an act of simply depositing lifeless, petrified content that is not only detached from reality but has become motionless, static, compartmentalized, and predictable. Knowledge; therefore, has become a gift bequeathed by those whom consider themselves to know everything to those deemed to know nothing (Freire, 1970).

Freire suggested a pedagogy in which the individual learned to cultivate his own growth through situations from his daily life that provide useful learning experiences. The student should build his reality from the circumstances that have given rise to the daily events of his life. The texts that the individual creates permit him to reflect upon and analyze the world in which he lives - not in an effort to adapt himself to this world, but rather as part of an effort to reform it. If education, Freire (1970) described should

Seek to liberate the individual, than it has become a conscious act in which the content is understood and analyzed. It must overcome the dichotomy that has existed between teacher and student. It must leave the unidirectional relationship and allow bidirectionality to contribute to the whole education of both parties, since they both have 
elements to bring to the learning. If this reciprocal meaning is lost, then the learning becomes a unilateral act of deposited knowledge (pg.)

The role of the education, Freire contended, laid in the ability of posing problems of men in their relations with the world, 'problem-posing'. This type of learning helps people to create new expectations and reach a truly reflective state in which they discover their own reality. It incites new challenges that move the students toward a self- construction of the world in which they have real and direct participation in the activities they undertake (Freire, 1970).

Illich (1971) argued that schooling has become the production and marketing of knowledge. The top-down management of schools made students powerless consequently prevented students from learning. Society had been drawn into the trap of thinking that knowledge is hygienic, pure, respectable, deodorized, produced by human heads and amassed in stock. By making school compulsory, people were schooled to believe that the self-taught individual is to be discriminated against. Furthermore, learning and the growth of cognitive capacity require a process of consumption of services presented in an industrial, a planned, and a professional form. Learning is a thing rather than an activity, a thing that can be amassed and measured. The possession of which is a measure of the productivity of the individual within the society and not the measurement of his contributions to society (Illich, 1971). Learning, therefore, becomes a commodity that is marketed and it orients people into a "having mode" where people focus on and organize around the possession of material objects (Fromm, 1979). They approached learning as a form of acquisition and competition. That knowledge is something to have rather than something to be experienced negating education and knowing as a process of inquiry. He argued that schools are designed on the assumption that there is a secret to everything in life; that the quality of life depends on knowing that secret; that secrets can be 
known only in orderly successions; and that only teachers can properly reveal these secrets (Illich, 1971).

In a second writing, Education without Schools (1971a), Illich argued that a good educational school system should have three purposes: it should provide all who want to learn with access to available resources at any time in their lives; empower all who want to share what they know to find those who want to learn it from them; and finally, furnish all who want to present an issue to the public with the opportunity to make their challenges known. He believed that such a system would need the application of the U.S. Constitution in its truest term, as this is the only guarantee to education.

Providing democratic education as stated and defined by Glickman (1998) is a type of learning that promotes:

Freedom of expression, pursuit of the truth in the marketplace of ideas, individual and group choices, student activity and participation, associated living and application, demonstration of learning, and contribution of learning to immediate and larger communities. Such efforts are made in the context of justice and equality for all, consideration of individual liberty and group freedom, and respect for the authority and responsibility of teachers in setting conditions for developmental learning (pg. 29).

Thus, education should enable learners to not only become aware of the conditions of their lives and their lives in society but also be able to acquire the skills, knowledge and resources to be able to plan and create change (Giroux, 1988). It should "promote a better quality of human experience, one which is more widely accessible and enjoyed" (Dewey, 1938, pg. 34). 


\section{Democracy in the Elementary Classroom}

Dewey (1916) envisioned classrooms as learning communities where students experience working together in empowering and culturally democratic ways to solve common problems. Advocates of democratic education posit that the role of the school and the teacher should be to create spaces for students and teacher voices, where the needs of the students are placed above the needs of the adults, work within a content rich curriculum, involve students in collaborative inquiry and problem solving, and expand student understanding of what is means to be part of a culturally democratic community (Apple \& Beane, 2007, Darling-Hammond, 1997; Meier, 2002; Wolk, 1998). It should be collaborative, personal, integrative, and concretized in real world experiences (Homstead \& Pete, 1997). The next section focuses on themes, classroom practices, and curriculum development that emerged from the literature regarding democratic education specifically related to elementary classrooms.

\section{Voice}

Giroux and McLaren (1986) stated, "Voice ...refers to the means at our disposal, the discourses available to us, to make ourselves understood and listened to, and to define ourselves as active participants in the world (pg. 235). Research related to democratic education focuses developing the concept of voice. Students and teachers in a democratic classroom are encouraged to express beliefs, perceptions, concerns, and personal ideals. Guerney and Merriam (1972) argued that in order to have a democratic elementary classroom "free sharing and questioning of ideas are mandatory...it grants equality of opportunity to participate in making group decisions as well as the equality of obligation to abide by group decisions. An individual must be able to question and evaluate his own conduct as well as to participate intelligently in determining the course of his conduct" (pg.376). However, literature revealed that fostering and 
nurturing discussions in the classroom have been viewed as one of the more difficult aspects democratic education (Brookfield \& Preskill, 2005; Apple \& Beane, 2007; Wolk, 1998). Brookfield and Preskill (2005) posited that although true discourse was considered developmentally difficult, it truly exemplified the democratic process. Discussions, they argue, are the most powerful learning tool a teacher can implement to foster and nurture democratic habits. It reveals the most diverse of opinions and yet finds commonality in all its participants. Discussions and democracy are intrinsically intwined as both seek to nurture and promote human growth (Brookfiled \& Preskill, 2005, pg. 18).

Wolk (1998) described 'talk' in his narrative work as the key characteristic in his democratic elementary classroom. Without talk, he revealed, meaningful learning, living democracy, and the idea of community could not take place. He provided descriptions of various forms of talk varying from spontaneous, formal, debate, and choice (pgs. 186-187). He posited that engaging students in discourse allowed teachers to remove themselves as the transmitter of knowledge and become more of a facilitator of constructing new knowledge for their students. Freire (1970) argued:

Yet only through communication can human life hold meaning. The teacher's thinking is not authenticated only by the authenticity of the student's thinking the teacher cannot think for her students, nor can she impose her thought on them. Authentic thinking, thing that is concerned about reality, does not take place in ivory tower isolation, but only in communication. If it is true that thought has meaning only generated by action upon the world, the subordination of students to teachers becomes impossible (pg. 77).

\section{Community}

Dewey (1929) wrote that school is a 'form of community life' and he viewed the 
curriculum as 'a process of living and not a preparation for future living' (p. 18). As a result, if children were to learn about democratic principles, Dewey proposed that they should be living out those principles in their community life at school. The values of social responsibility and that of personal choice that are related to democratic living could not be imposed by the teacher but learned by participation. According to Sergiovanni (1994) schools have become more like organizations rather than communities through dividing content areas into departments, grade levels, and creating rules and programs that convey the message of control. He posits that this has created school atmospheres where each individual involved principles, teachers, and students worked solely for reward and avoidance of punishment. He outlined that communities are different because they seek to join people for a purpose - to connect people through commitment to one another rather on external controls.

As such a variety of definitions emerged from the literature regarding community and the various forms it takes and plays regarding schools, classrooms, and government. Sizer (1996) and Glickman (1998) both argued that state and federal government control over schools have not been responsive to the problems that are truly hindering effective school practices. Each alleged that when local communities comprising of parents, school staff, and students worked cooperatively together that it created the best conditions for educating children and school based decisions. As such, state and federal government should only intervene when direction regarding student attendance and providing resources for equitable racial and socioeconomic balance was needed (Glickman, 1998, pg. 67). Sizer (1996) argued, however, that principles and school staff should have the greatest control regarding issues of curriculum educational policy, and school direction whereas Glickman (1998) believed primary authority should be given to parents'. Both believed, however, that by giving control over the schools back to the local 
participants offered the best opportunity for students to realize democracy. Sergiovanni (1994) asserted that although schools can never replace family or neighborhoods but as they become communities "they facilitate the strengthening of family and neighborhood" (pg.13).

The concept of what school and classroom communities are and how they functioned emerged in the literature. Dewey (1903) argued that democracy is premised on the idea that no select group is wise enough to rule others without their consent. Each has the right to have input to the resolution of common social problems. While not all input is accepted or can be used to solve problems, the greater quantity of ideas increased the likelihood of solving the problem. In democratic schools and classrooms, the teacher and the students are the key participants in decision-making. Their decisions ranged in form from procedural and educational policy to devising classroom rules (Meier, 2000).

Wolk (1998) in his narrative work described community in his classroom with twenty-four terms. Together they addressed the various contests he believed developed and maintained a democratic learning community. The terms sharing, respect, values, movement, bond, common, active, helping, talk, responsibility, trust, caring, thoughtfulness, acceptance, differences, celebrate, friendship, empathy, safety, purpose, inviting, discourse, and democracy guided his lesson development and classroom management. He also revealed in his narrative the process of developing a community and the time needed to develop these certain dispositions in his students. He closed his narrative with the following stating, What if through a school community students were encouraged to think for themselves, to ask questions, to seek the common good, to act on their original ideas, to be critical readers of society, to share their selves and their cultures and their voices, to explore personally meaningful and relevant interests, and to see themselves as creators? What if 
school was about that? What would the world be? (Pg. 202)

Play. Dewey's notion of play and that students should be given real materials such as carpentry tools and cooking utensils to stage and encourage replication of everyday living experiences within a community. Through every day experiences, children are introduced to the "problems of association". As children interact in social groups, Dewey suggested, that children be encouraged to solve their own problems seeking only guidance from teachers, truly "democracy in action"

Literature reviewed four forms of play (a) object play, (b) pretend play, (c) guided play, and (d) physical play. Object play is the ways in which children explore objects, learn about their properties, and transform them into new functions. Pretend play, which can either be alone or with others, is often referred to as make-believe, fantasy, symbolic play, socio-dramatic play, or dramatic play. In pretend play, children are able experiment with different social roles. Guided play is where children actively engage in pleasurable and seemingly voluntary activities under the subtle direction of adults. Physical play, which includes everything from a 6-monthold's game of peek-a-boo to free play during recess (Pellegrini \& Holmes, 2006). Hall (2000) argued that “children's play, like everyday literacy practices, draws meanings from being situated within cultural histories, values and practices and thus generates engagement, involves networks, and is consistently related to the everyday lives of people in their communities" ( $p$. 194). In other words, when children play they create parallel, imaginary worlds from tales they know, their personal stories, things they see in their neighborhood, on television or hear in books. As children play, they engage with, interact to and rely on one another as part of a larger community. Play is important when it is functional or when play is seen as preparation for the work of living in a community (Erikson, 1958; Piaget, 1962). 


\section{Child-Centered, Multicultural Content Curriculum and Assessment}

Child centered curriculum is often presented juxtapose to traditional, teacher-directed approaches. A child-centered curriculum focuses more on individual's differences, interests, and freedom to create their own learning whereas teacher-directed curriculum places emphasis on teacher control over children's learning. Dewey (1938) observed that curriculum should be more child-centered rather than teacher-centered rooted in the ideas of continuity, personal development, and interaction. Moreover, he philosophized that learning is experiencing; therefore, children should develop within schools that functions like a democratic society. Through this, students then learn and develop the ability to function within the larger democratic society (Dewey, 1938). His philosophy, misconstrued often, centered on education as a way to develop children's freedom of intelligence and not as a way for them to act randomly on their impulses. As such, a teacher's role is to build a secure, and socially responsive environment where all individual and group interests are respected. Literature revealed that multicultural thematic units were used to include student prior experience, social responsibility, equal representation in the curriculum, and the inclusion of arts, history, literature, science, geography, civics, and foreign languages.

Multicultural Thematic Units. Peterson (2007) provided an account of specific implementation of thematic units used at the democratic school, La Escuela Fratney. In his narrative he outlined various components of this thematic unit that engaged not only civic responsibility but addressed what Banks (1997) described as a well represented curriculum to include all races, ethnicities, and both genders. His thematic units encouraged his students to understand how African Americans contributed to the nation. His unit explored how as citizens they are shaped by the past but they shape the future. Through research, students were guided to 
create projects aimed at encouraging recycling in their community, which addressed the community issue of littering. Glickman (1998) stressed that student achievement is greatly enhanced when students are actively engaged in problems in the community. As outlined by Peterson students were responsible for generating research, engaging in debate, outlining various projects, and presenting information to the city board of commissioners. In her study, DarlingHammond, et al (2005) stated, an awareness of the educational and social perspectives informing curriculum planning and implementation is necessary, and in America, "curriculum goals are, or should be, shaped by the requirements of preparation for citizenship in a democracy" (p. 170). They go on to add that when considering what is taught and the manner in which it is taught, there must be an eye toward the overarching contribution of education to the development of a productive citizen. In addition, Banks (1997) and Barton and Levstik (2004) argued that a multidisciplinary content curriculum should aim at preparing students to become citizens with the knowledge that can help them participate competently in the social, economic, and political aspects of life and at the various societal levels. In addition, they argued that the curriculum with multicultural content based on race, ethnicity, and gender ensures that all citizens are well represented in the curriculum for instilling in them the spirit of unity and cooperation that are required for civic responsibilities in a democratic civil society.

Performance-based Assessments. Meier (2000) argued the importance of using performance-based assessments for it is "culturally relevant using cultural knowledge, prior experiences, frames of reference, and performance styles of and for culturally device students" (p. 86). A teacher committed to true student achievement, she posited, should also embrace a student centered assessment pieces that clearly show what the student has learned, such as projects, work portfolios, performances, teacher observation, and antidotal records. Wood, 
Darling-Hammond, Neill, and Roschewski (2007) argued that performance based assessments offers a way to move beyond the limits and negative effects of standardized testing by providing locally controlled and multiple assessments of achievement. In addition, they argued that performance based assessments actually met federal guidelines as provided by NCLB that called for "multiple up-to-date measures of student academic achievement, including measures that assess higher-order thinking skills and understanding" (NCLB, Sec. 1111, b, 2,I, vi as cited in Wood et al., 2007, pg. 2). Citing studies that focused on examples of performance-based assessments used in Nebraska, Wyoming, Connecticut, and New York, Wood et al. (2007) stated that "using performance-based assessments schools can focus on higher order skills, provide a more accurate picture of what students know and can do, engage students more deeply in learning, and provide more timely feedback to teachers, parents, and students in order to monitor and alter instructions" (pg. 2)

\section{Summary}

This chapter provided research evidence and literature regarding the context of decisions that teachers make concerning curriculum and pedagogy. Specifically it focused on contexts that surrounded the participants of this case study that affected the choices they made to nurture and maintain democratic habits for participation in a democratic society. Kelly (1995) defined democratic society as "one where reasons are continuously put forward to justify behavior and where public spaces exist to permit free and un-coerced debate over questions of cognitive, normative, or aesthetic truth" (Kelly, 1995, pg. 120) thus if democracy was to flourish, teachers and students needed a forum for debating issues pertaining to classroom learning, interactions, and atmosphere. As such, it was necessary to review contexts such as student composition (SES, gender, and race), school organization, school size, school resources, and the effects of federal 
educational policy research indicated has impacted how teachers engaged, presented, and developed lessons based on provided curriculum. This section also addressed how student achievement has been impacted by these choices as well as revealed how student achievement can be greatly improved by providing students with quality teachers, small and democratically organized schools, and an intellectually rigorous curriculum. The next chapter will present the findings of the study about the curricular and pedagogical practices of four teachers at one public elementary school whose statement of purpose seeks to nurture and maintain democratic habits for participation in a democratic society. It will look at the organization of the school, teachers' perceptions of democratic habits, curriculum development, and the affects of federal educational policies. 


\section{Chapter Three: Research Design and Method \\ Methodology}

This study used a descriptive research design to explore the pedagogical practices of four teachers at one public elementary school whose statement of purpose seeks to nurture and maintain democratic habits for participation in a democratic society. Specifically, a qualitative approach was used to examine and build understanding of curricular and pedagogical practices and decisions that were used to promote democratic habits. In addition, the qualitative research sought to examine school contexts and how they affected curricular and pedagogical choices. Using this design, the following questions guided the study:

1. How was the school organized that supported democratic habits?

2. How do the teacher's perceptions of democratic habits influence case study teachers' pedagogical practices?

3. How was the curriculum developed by each of the case study teachers that promoted democratic habits?

4. How do federal educational policies influence and affect case study teachers' pedagogical practices for nurturing and maintaining democratic habits?

\section{Rationale for Qualitative Research Design}

An inquiry in qualitative research is the understanding the world from the point of view of those who live in it. This study was particularly suited to qualitative research as qualitative research is a multi-method in focus, involving an interpretive, naturalistic approach to its subject matter (Creswell, 2007). In a qualitative study, the researcher must study things in their natural settings, attempting to make sense of, or interpret, phenomena in terms of the meanings people 
bring to them. Qualitative research involves the studied use and collection of a variety of empirical materials - case study, personal experience, introspective, life story, interview, observational, historical, interactional, and visual texts - that describe routine and problematic moments and meanings in individuals' lives. Accordingly, the researcher would deploy a wide range of interconnected methods, hoping to get a better fix on the subject matter at hand (Denzin \& Lincoln, 2005).

According to Patton (2002), qualitative data is produced through three types of data collection: (a) in-depth, open-ended interviews; (b) direct observation; and (c) written documents. Interviews generate direct quotations from people about their experiences, opinions, feelings, and knowledge. Direct observations describe people's behaviors, activities, actions, and the full range of interpersonal interactions and organizational processes that are part of observable human experiences. Documents provide information regarding organizational, clinical, and program records; memoranda and correspondence; official publications and records; personal diaries; and open-ended written responses to questionnaires and surveys. Using various combinations of methodological practices, empirical data and multiple perspectives in a single study adds rigor, breadth, complexity, richness and depth to an inquiry, (Flich, 2002). Thus, as Patton (2002) further explains this qualitative data is typically driven from fieldwork. In fieldwork he describes we discover the "themes, patterns and understandings of our qualitative inquiry" (p. 5). In this, he continues, that "fieldwork is more than a single method or technique" in such that multiple sources of information are used because no single source can be trusted to provide a thorough perspective on a program (p. 6). Again, by using a mixture of open-ended interviews, direct observations, and various public documents, the researcher is able to use different data sources to validate and crosscheck findings--triangulation. 


\section{Rationale for Case Study Methodology}

The case study is one type of qualitative research that is particularly interested in investigating a contextual phenomenon of limited number of people, events, and their relationships. Case study is the ideal methodology when a holistic, in-depth investigation is needed (Feagin, Orum, \& Sjoberg, 1991). Case studies are designed to bring out the details from the viewpoints of the participants by using multiple sources of data. Therefore, case studies are multi-perspective analysis, as the researcher considers not just the voice and perspective of only one but of all relevant members of the site and the interaction between them. Research in the field of education often utilizes case study as it assists in understanding the processes of events, projects, and programs. Insights gleaned from case studies can "directly influence policy, practice, and future research" (Merriam, 1998, pg. 19).

The definition of case study can vary dependent on the focus of the study. Merriam (1998) and Wolcott (1994) saw a case study in terms of its end product and defined a case study as an intensive description and an analysis of a unit or set, rather than a strategy or method. Yin (1994) defined case study as an empirical inquiry that investigates a contemporary phenomenon within its real-life context, especially when the boundaries between phenomenon and context are not clearly evident. Even though definitions regarding case study varies, it holds true of all definitions that the phenomenon to be studied must be intrinsically bound. If there is no end to the number of people who could be interviewed or there is a field with no limit on the number of observations that could be conducted, then the phenomenon is not bounded enough to qualify as a case study (Merriam, 1998). Since the focus of this case study is of four teachers within a school that seeks to nurture and maintain democratic habits and building an understanding of the pedagogical practices and decisions that are used to promote maintain democratic habits for 
participation in a democratic society, it met the intrinsically bounded specification of case studies.

In summary, this case study methodology serves as a modus to illuminate the pedagogical practices of four lead teachers within a public school whose mission seeks to nurture and maintain democratic habits (Merriam, 1998).

\section{Selection of Site}

Selection of the chose research site was made purposefully based upon the following criteria: (a) serves elementary school aged children; (b) school's statement of purpose; (c) site visit; and (d) willingness to participate in study. In December of 2009, the researcher had contacted the founding member of Demey Elementary School seeking permission to contact the school regarding this study. Emails were exchanged that resulted in the founding member contacting the principal of Demey School on my behalf. The researcher made contact with the school publicists/coordinator and scheduled a pre-study visitation. The visitation was set to establish whether Demey School would be willing to participate (as a permission letter was required for Institutional Review Board of West Virginia University), establish its status as a potential democratic school, and to observe Friday share. No data was collected at this time although a classroom observation was permitted as part of an open school visitation as provided by Demey School.

Arrangements for actual data collection were initiated once receiving exempt status from the Institutional Review Board (IRB) of West Virginia University on March 4, 2010. After exempt status had been established, the researcher sent a letter to five potential teacher participants. The researcher contacted the principal of Demey School to notify her of the four participating teachers, the process of collecting the intended data, and setting the researchers 
arrival date to the school. Although classroom observations were part of the study, the researcher did not seek consent from students, as they were not participants of the actual study.

\section{Site Selection Demographics}

Demey School (pseudonym) is a pilot school of Trent Public Schools (pseudonym) located in the center of a large urban city. As a pilot school, the school has complete autonomy over areas of budget, staffing, governance, school calendar; and curriculum and assessment. The Pilot Schools Program of Trent Public School System was founded under the theory that student engagement and achievement increases when schools are small, personalized, mission-driven and have autonomy over their decisions and resources in exchange for increased accountability (Trent Public Schools, 2008). Specifically a key component of the Pilot Schools Program is the implementation of experiential education. The Program was constructed under the four key characteristics of experiential education curriculum, pedagogy, school culture, and structures (Table 1). 
Table 1

\section{Characteristics of Experiential Education}

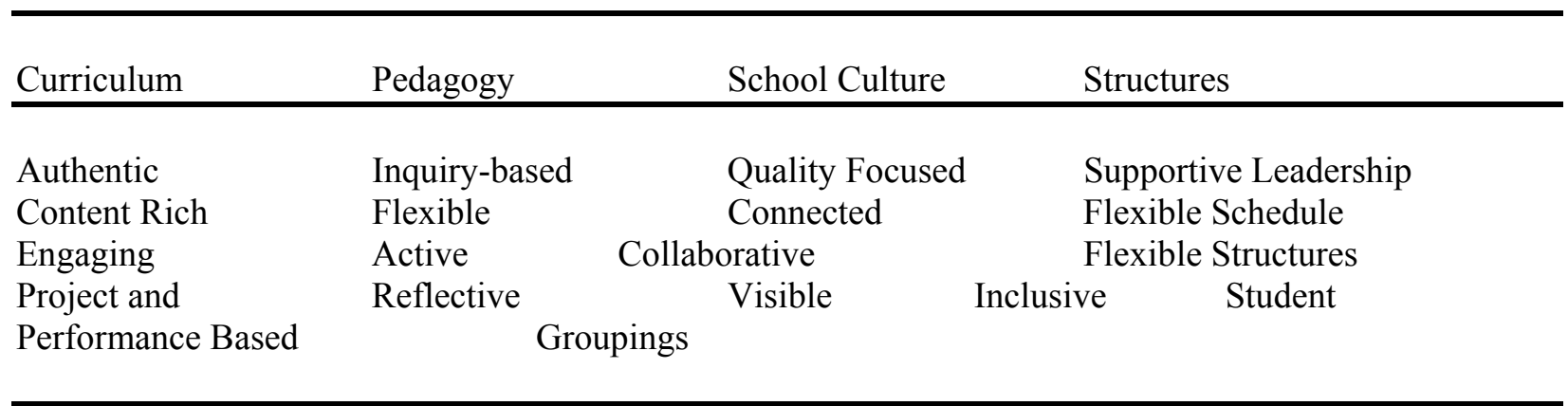

Demey School's statement of purpose (See Appendix C) was primarily used to determine its alignment with the study's definition of a democratic school. Specifically,

The task of public education is to help parents raise youngsters who will maintain and nurture the best habits of a democratic society be smart, caring, strong, resilient, imaginative and thoughtful. It aims to produce youngsters who can live productive, socially useful and personally satisfying lives, while also respecting the rights of all others. (Demey School's statement of purpose, 2010, para.1)

City Demographics. Trent Public Schools is a school district serving a large city in the east coast of the United States. The population of Trent was 589,141 (US Census Bureau, 2000). Trent is a uniquely diverse city—specifically when compared to other similar metropolitan areas. According to the US Census, the racial distribution of Trent is 54 percent White, 25 percent Black, 14 percent Hispanic, 7.5 percent Asian, .4 percent American Indian or Alaska Native and 4.4 percent two or more races. ${ }^{1}$ In addition, Thirty-three percent of Trent's population reported speaking a language other than English at home. Trent also reported having had a 19.5 percent poverty rate (15.3 percent of this were of two-parent households and 29 percent were of single parent households), 4.6 percent unemployment rate with a medium household income of $\$ 39$, 629 (US Census Bureau, 2000). 
School District. Trent Public Schools consists of 137 schools: 56 elementary schools, 29 middle/K-8 schools, 25 high schools, 2 alternative schools and 25 pilot schools (Trent District Profiles, 2009). Trent Public Schools (2009) reported their total student population as 56,168. There were 4,372 teachers in the district; therefore, student to teacher ratio was 12.8:1 for the school year 2008-2009. The racial distribution for the school year 2008-2009 was 39.3 percent Black, 36.7 percent Hispanic, 13.4 percent White, 8.5 percent Asian, .4 percent American Indian, .1 percent Pacific Islander and 1.5 percent of more than one race. Of the total Trent Public School student population, 71.4 percent are of low-income homes and 37.7 percent live in homes where English is not the first language.

School/AYP Standing. Demey School serves 165 students (Trent District Profiles, 2009). The school had a 47.3 percent poverty rate and had a school wide Title I program. The racial distribution for the school year 2008-2009 at Demey School was 44.4 percent Black, 27.5 percent Hispanic, 23.4 percent White, .6 percent Asian and 4.1 percent one or more race. Demey School (SY 2008-2009) included grades K-8 and had 12 teachers; the student to teacher ratio was 1:14 for the 2008-2009 school year. According to the 2008-2009 Trent District Profile, $100 \%$ of the teachers are assessed as 'Highly Qualified' as determined under No Child Left Behind.

During the 2008-2009 school year, there were two classrooms at the K-5 grade levels with subject-oriented classrooms for the 6-8 grade levels (i.e. math, science, humanities). Demey School's average student daily attendance was 94.8 percent while the district's was 91.7 percent. The total number of students in each grade level for the 2008-2009 school year; there were 16 in Kindergarten; 25 in grade one; 23 in grade two; 21 in grade three; 19 in grade four; 18 in grade five; 16 in grade six; 13 in grade seven; and 14 in grade eight. Twenty-nine students at 
Demey School received special education services and 11 students come from homes where English is not the first language.

According to Trent Public Schools District Profiles, Demey School under No Child Left Behind (NCLB) has been categorized in English Language Arts as Improvement Year 1 as the school met adequate yearly progress 'AYP' in 2007 and 2008 in aggregate and all subgroups but failed to meet 'AYP' in 2009 and 2010 in both aggregate and in the sub groupings; low income and Black. In Mathematics, the school's 2010 status is Restructuring Year 2 for failing to meet 'AYP' in 2006, 2007, 2009, and 2010 in aggregate and failing to meet AYP in the sub groupings of low income and Black in 2008, 2009, and 2010. Under this No Child Left Behind designation, families in Demey School are entitled to the following services: option to transfer to another school in the district and supplemental education services for low-income students.

Demey School's 2009 mobility rates indicated an 11 percent aggregate churn with 13.8 percent of the churn in the sub grouping low-income and 4.4 percent in the sub grouping Black.

\section{Participants}

Purposeful sampling was used in the selection of the participants of this study. This type of sampling was used based on the assumption that the researcher wanted to discover, understand, and gain insight; therefore, the sample was selected to generate the most knowledge (Merriam, 1998). There were five teachers selected for this study with four of the five teachers willing to participate (the 6-7-8 math teacher declined to participate). The participants in the study were teachers from each represented grade level K-1, 2-3, 4-5, and 6-8 Humanities. Of the four willing participants, two were women and two were men. One of the four teachers has taught at Demey School since the creation of the school with the other three having taught at the 
school an average of 9 years. The teachers' overall experience ranged from 5-16 years and ranged 4-14 years at their current grade level (Table 2).

Table 2

Teachers’ Demographic Information

\begin{tabular}{lccccc}
\hline Teacher & $\begin{array}{c}\text { Grade } \\
\text { Level }\end{array}$ & $\begin{array}{c}\text { Years of } \\
\text { Experience }\end{array}$ & $\begin{array}{c}\text { Highest Degree } \\
\text { Obtained }\end{array}$ & $\begin{array}{c}\text { Years Teaching } \\
\text { at Grade Level }\end{array}$ & $\begin{array}{c}\text { Years Teaching } \\
\text { at Demey School }\end{array}$ \\
\hline Teacher 1 & K-1 & 12 & Masters & 12 & 12 \\
Teacher 2 & $2-3$ & 9 & Masters & 9 & 9 \\
Teacher 3 & $4-5$ & 16 & Masters & 12 & 12 \\
Teacher 4 & $6-7-8$ & 8 & Bachelors & 8 & 4 \\
\hline
\end{tabular}

\section{Sources of Data}

This case study explored the curricular and pedagogical practices of four teachers at one public elementary school whose statement of purpose seeks to nurture and maintain democratic habits for participation in a democratic society. This study used a triangulation of data collection procedures involving various sources of data that included interviews, classroom observations, and documents, interviews. This section details the choices made for data sources used in this study.

\section{Interviews}

Interviewing is considered one of the most widely employed methods in qualitative research (Denzin, 2005; Patton, 2002). Creswell (2007) posited that the major benefit of collecting data through individual, in-depth interviews is that it provides the opportunity for the researcher to capture a person's perspective of an event or experience. Patton (2002) describes 
that the qualitative interview "begins with an assumption that the perspective of others is meaningful, knowable, and able to me made explicit" (p. 341).

\section{Observations}

Observation is a significant means of collecting data in qualitative research. When it is combined with interviewing, it allows for a more holistic interpretation of the phenomenon being investigated, (Merriam, 1998). Patton (2002) describes five key advantages to direct observations: (a) the inquirer is better able to understand and capture the context, (b) allows the inquirer to be open, discovery oriented, and inductive, (c) inquirer has the opportunity to see things that may routinely escape awareness among the participants in the setting, (d) chance to learn things that the participants may be unwilling to discuss during an interview, and (e) permits the inquirer to draw on personal knowledge during the formal interpretational stage of analysis, (p. 263).

\section{Document Analysis}

According to Merriam (1998), a major source of data in qualitative studies is documents. Document collection in this study served as a means for uncovering meaning, develop understanding, and discover insights relevant to this study. It also served as a supplementary source for data triangulation to increase research reliability.

\section{Data Collection Procedures}

The researcher made arrangements with each of the four participating teachers for a semi-structured interview. Following the first semi-structured interview the researcher conducted two classroom observations, followed by a second semi-structured interview. During this interview, the researcher requested documents such as curriculum plans, lesson plans, examples of project plans, and math textbooks/worksheets. The researcher was also allowed per 
principal's permission to collect documents regarding the school organization included newsletters, Trent Public school district studies, AYP status, and information pertaining to pilot schools. The researcher conducted two more classroom observations to allow for observation all subject areas.

\section{Participant Interviews}

Two semi-structured interviews were conducted. Merriam (1998) purposed that semistructured interviews allow participants to define the world in their perspective. In these interviews, the researcher encouraged the participants to discuss their pedagogical reasoning and actions by posing questions. The first interview was about an hour long and addressed relevant study issues including background demographics of the teacher and their classroom, perceptions regarding democratic habits, curriculum development, strategies, equity issues, classroom activities, perceptions, and pedagogical practices (see Appendix B). In addition, the dialogues sought to understand any challenges or constraints the teachers felt in their curriculum planning, implemented lessons, and their everyday classroom practices. The researcher (if permission was granted) took various pictures of the classroom (see Appendices D, E, \& F).

The second semi-structured interview occurred after two participant classroom observations that to sought bring deeper understanding of observed practices. Interviews varied in length from an hour to an hour and a half as each interview specifically addressed questions related to each teacher's decisions, lessons, practices, strategies, teaching resources, and choices in their specific classrooms. The researcher asked for copies of curriculum plans, report cards, project samples, and worksheets during this interview. The researcher digitally audio taped each interview session. Following each interview, the researcher then transcribed each digital recording via Dictate to produce a precise, word for word account of each interview session. 


\section{Participant Classroom Observations}

The researcher observed four classroom sessions in each of the participant's classrooms. Observations were divided between classroom subject (math, language arts science), activity (morning meetings, direct instruction, student led instruction, group and project work) and time of day (morning and afternoon). The objective of each the observations were (a) to determine to what extent democratic habits were enacted in classrooms, (b) to determine to what extent how democratic principles were enacted through language, behaviors and interactions between the teacher and his/her students, and the classroom contexts; and (c) to determine to what extent teacher expressed external constraints affected curriculum and pedagogical practices. In these observational sessions, the researcher's role was of complete observer. Using the Classroom Observation Protocol (see Appendix J) as a guide, accounts of observations generated field notes that also included initial impressions and interpretations of observed classroom practices. These notes were typed, analyzed, and triangulated with other sources of other collected data to draw conclusions.

\section{Document Collection}

Documents collected included instructional materials, unit plans, assessments, pictures, rubrics, pilot school documentation report, lesson plans, student report cards, school mission statement, school newsletters and the 2008, 2009 and 2010 Adequate Yearly Progress data. Each teacher provided various documents as well as documents were obtained from Demey School administration.

\section{Data Management and Analysis Procedures}

Following data collection, there was a considerable amount of data that were generated from the interviews, participant classroom observations, and document collection. The 
following information provided will explore management of data and data analysis procedures utilized and discussed in Chapters Four and Five.

\section{Data Management}

The researcher obtained various forms of data ranging from participant interviews, classroom observations, and document collection. Following each participant interview, totaling eight, verbatim transcriptions were created through a replay of digital audio-recorded dialogues. A total of sixteen classroom observations were made throughout the course of this study. During each observation period, field notes were generated of all activities occurring in the classroom. Various observations were transcribed into vignettes and/or presented as classroom observation summaries in Chapter Four. Documents collected were filed under respective teacher participants and/or school documentation after various field marks relating to the evidence and/or lack of evidence of nurturing and maintaining democratic habits.

\section{Site and Participant Confidentiality}

The site's city, school district, school name are represented with pseudonyms through out the entire paper. All names of the teacher participants have also been changed in accordance with the standard requirement of the Institutional Review Board (IRB) of West Virginia University.

\section{Trustworthiness and Reliability of the Study}

Data was collected in a six-week period created by thorough interviews, extensive classroom observations, and collection of various forms of documents. Thus the researcher's goal was to achieve accuracy and precision when analyzing the data between the three sources. The first step taken to achieve this was through rigorous and numerous readings of interview transcriptions, lesson vignettes, lesson plans, curriculum plans, newsletters, and school AYP 
reports. The second step involved an analytical guide to provide means of coding, categorizing, and capturing themes that emerged from the data. Categories are described as words and phrases used by participants and/or presented through classroom observations while themes are the major threads that connect patterns and categories implied (Merriam, 1998; Patton, 2002; Yin 1994)

The third step involved highlighting data and labeling categories with a code theme for each case study teacher. Words and short phrases such as voice, autonomy, and mandated were used to represent various issues and categories. The above examples and others were used to label across all three of the data sources. Through this process, the researcher created the code theme. The coding ensured the reliability and trustworthiness of the study by as they were derived through the triangulation of the sources (Merriam, 1998; Patton, 2002; Yin 1994).

In order to accurately detail and discuss findings, the researcher created a category and theme chart for each case study teacher. Using the four research questions as a guide, the coding schemes were used for analysis of data that represented what occurred in each of the four case study teacher's classrooms. Each case study teacher's chart was then used for a cross-case analysis, where data from each individual chart was examined for similarities, differences, and patterns. Through this process, the researcher was able to interpret broader themes as well as identify themes that were specific to one or more case study teacher. As presented in Chapter Four, one theme and category chart was created and used in discussing research findings. Thus, the researcher recognizes that with autonomy comes the variant of interpretation and key issues and perspectives of each case study teacher is presented in their own voice. Their voice is presented in vignettes, verbatim answers to questions, and their provided verbatim lesson plans. The following table provides a timetable of data collection and data analysis (Table 3). 
Table 3

Time Table of Data Collection and Data Analysis

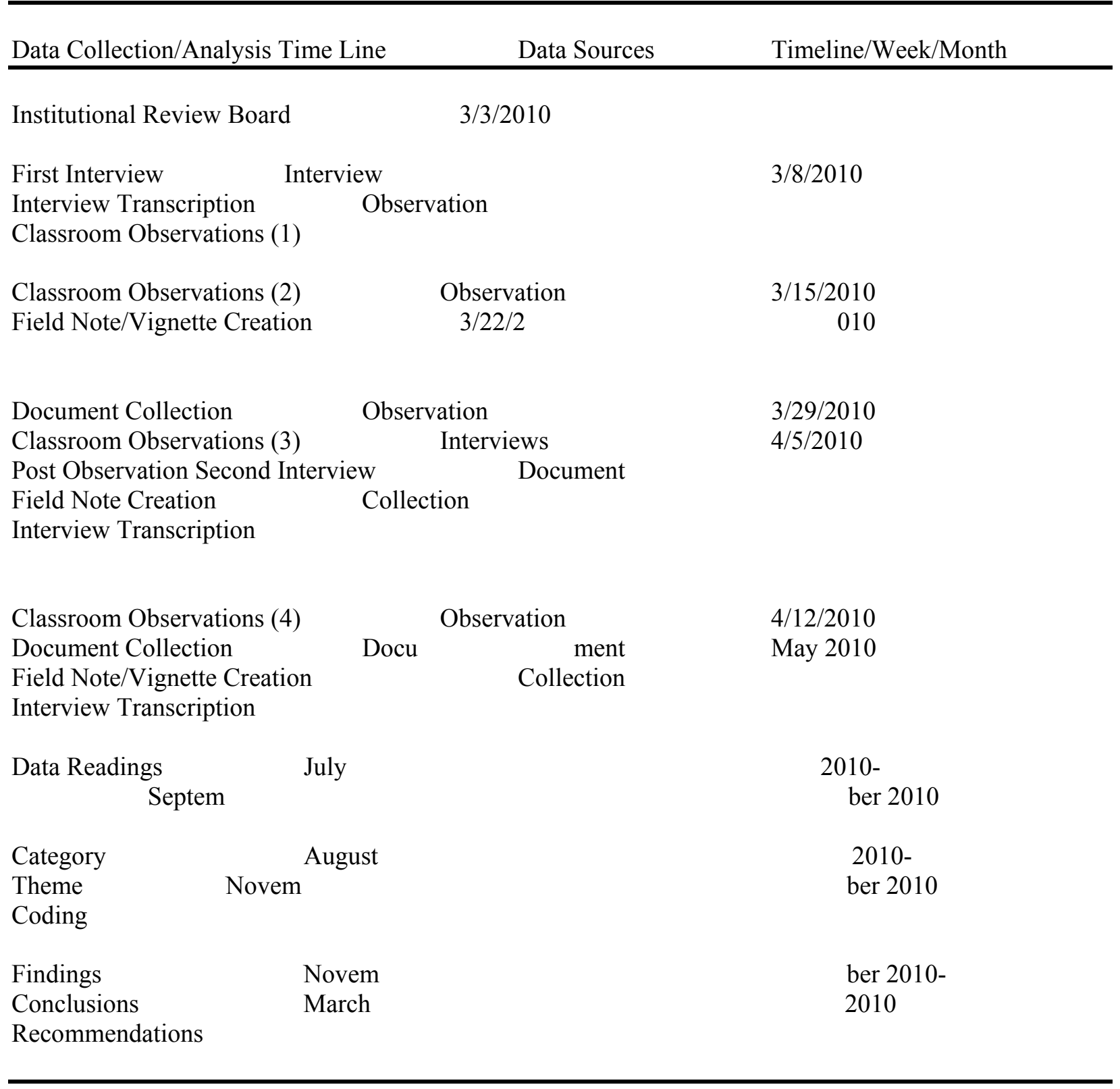

\section{Dependability and Confirmability of Research Findings}

The credibility and trustworthiness in data analysis determine the dependability and confirmability of research findings. Lewis and Ritchie (2003) posited that dependability is representative of the thorough and comprehensive procedural analysis of issues, categories, and 
themes that are close enough to denote the studied group, whereas the confirmability relates to closeness of the generated data to the parent population. It is within this consideration, the researcher meticulously and consistently analyzed the data in this study using a coding theme that was generated from the various data sources of interviews, classroom observations, and document collection. The coding theme helped in the interpretation of the data leading to inferences and conclusions about pedagogical practices for maintaining and nurturing democratic habits. Thus argued and implied is that if the equivalent methods of interviews, classroom observations, document collection and data analysis were applied to a different sample of the same parent population, the research results would lead to similar conclusions of this study (Lewis \& Ritchie, 2003).

\section{Summary}

This research study used a qualitative case study to explore the pedagogical practices of four teachers within a democratic learner-centered public school. Data was collected through interviews, observations and document analysis. Data analysis occurred through the triangulation which categories, themes, and patterns were identified to answer research questions. Consistent triangulation also served as the tool to increase researcher reliability, dependability, and confirmability. 


\section{Chapter Four: Results}

This chapter reviews results of the study about the pedagogical practices of four teachers at one public elementary school whose statement of purpose seeks to nurture and maintain democratic habits for participation in a democratic society. Four research questions were used to guide the collection of data from a triangulation of sources. The first question served to gather information regarding the organization of the school based on its status of being a pilot school. It acted as contextual question and whether the school's status, context, and statement of purpose had any influence on curriculum development and curriculum implementation in the classroom. The second question aimed at learning the teachers' perceptions and their actual pedagogical practices of how to maintain and nurture democratic habits through curriculum development, lesson plans, and classroom structure. The third question focused on the development of curriculum by each of the case study teachers. It explored specific planning and implementation in each of their classrooms. The fourth question was an endeavor to learn how pedagogical practices were influenced from the perspective of external classroom constraints that the teachers had no control. Based on these questions, the data collected from semi-structured interviews, classroom observations, and document analysis were transformed into themes that cut across the four case study teachers.

This chapter, therefore, is organized into four sections based on each of the research questions. Each section is further divided further into the subsections based on the developed themes and categories for each of the research questions. The following four research questions guided this study:

1. How was the school organized that supported democratic habits? 
2. How do the teacher's perceptions of democratic habits influence case study teachers' pedagogical practices?

3. How was the curriculum developed by each of the case study teachers that promoted democratic habits?

4. How do federal educational policies influence and affect case study teachers' pedagogical practices for nurturing and maintaining democratic habits?

Based on these questions, basic themes and categories were derived from the data as shown on the next two pages in Table 4 for the discussion of research evidence. 
Table 4

Themes, Categories, and Evidence of the Study

Themes Categories Evidence

Q1. School Organization

Theme One: Autonomy

school

its

providi

regarding:

populati

interviews:

Teacher

Theme Two: Guided Open The curriculum was organized Curriculum within

tain

Experiential

Them

Mind, interviews:

Teacher

the guidelines of being
a pilot school and with a broad spectrum to nurture and maindemocratic habits: Education, atic Units, Habits of and Habits of Work. was based upon ng various options location, layout on, guidelines.
The organization of the status as a pilot school

ut

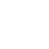




\begin{tabular}{|c|c|c|}
\hline $\begin{array}{l}\text { Challenges } \\
\text { external } \\
\text { Teacher }\end{array}$ & $\begin{array}{c}\text { by case study teachers were } \\
\text { constraints: Time }\end{array}$ & $\begin{array}{l}\text { Semi-structured } \\
\text { interviews: Case Study } \\
\text { s. }\end{array}$ \\
\hline Q3. Curriculum I & pment & \\
\hline $\begin{array}{l}\text { Theme Six: Varity of } \\
\text { Child Centered } \\
\text { Pedagogical Choices } \\
\text { study } \\
\text { KWL, } \\
\text { Decision } \\
\text { teacher }\end{array}$ & $\begin{array}{l}\text { Curriculum Development } \\
\text { in all areas except math were } \\
\text { contingent upon each case } \\
\text { teachers chosen method: } \\
\text { BCD, Real Life, } \\
\text { making, and Play }\end{array}$ & $\begin{array}{c}\text { Document Analysis: } \\
\text { Course and curriculum } \\
\text { documents such as unit } \\
\text { descriptions, standards } \\
\text { developed by the } \\
\text { teachers and school, } \\
\text { and class } \\
\text { generated rubrics, } \\
\text { sample lesson plans, } \\
\text { ments, and } \\
\text { ssments. } \\
\text { m Observations } \\
\text { Semi-structured } \\
\text { Case Study } \\
\text { s. }\end{array}$ \\
\hline
\end{tabular}

Q4. Federal Education Policies

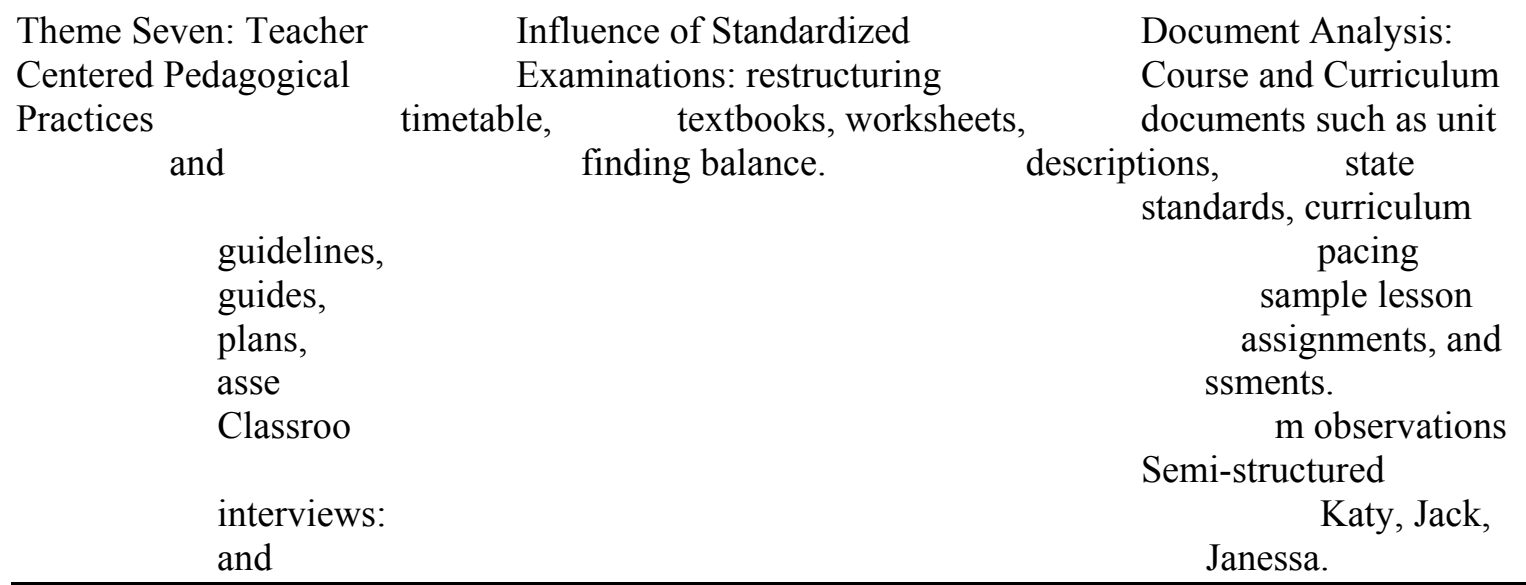

The Organization of the School

Research Question One: How was the school organized that supported democratic habits?

Theme One: Autonomy

Document analysis and observation revealed that as a pilot school Demey School operates with autonomy within the Trent Public School District (TPSD). The five key features 
of the school's autonomy included the ability to make decisions regarding budget, staffing, governance, school calendar, and curriculum. As part of the pilot school program, Demey School also served as part of research and development laboratory with the foremost purpose of identifying, creating, and assessing strategies known as 'best practices'. Analysis revealed that the school's characteristics such as the location, layout and student population of the school also served as a contributing factor to curriculum development, decisions, and implementation.

\section{School Organization}

School Location. The school is located in the center of Trent that statistically shows as the city's highest poverty percentage at 33.7 percent. Although the neighborhood statistically shows the city's largest population under the poverty rate, it only shows a 5.8 percent unemployment rate. The racial distribution of the neighborhood is 63 percent Black, 5 percent White, 24 percent Hispanic, 1 percent Asian, and 4 percent of more than two races. The school is located on the second floor of an old abandoned parochial high school that is shared with another pilot school (Please see Chapter Three: Methods for a full detailed description of the city's population).

School Layout. There are eleven classrooms that are divided into to two 'houses', East House and West House. Each house includes a classroom of every grade level with the middle school grade levels being split between the two. As one walks down the hallway of Demey School, one notices its uniqueness as the hall is filled with art work, couches, tables and chairs, a rolling kitchen, interactive bulletin boards, sand boxes, water centers, and student work. Mostly the hall is filled with chatty students working on projects, creating maps, or simply working oneon-one with a teacher. It is loud and seemingly chaotic. 
The school's main office was once an old classroom. It is a wide-open area that not only houses the principal and the secretary but also a tutoring area, an eating area (always filled with food), a copier, mailboxes, instructional resources, and computers. These are all things found in any school's main office but here nothing is divided by walls or behind dividers. Students, teachers and parents tend to walk freely in and out of the office.

Student Population Selection. Students who attend Demey School are selected through a lottery system. The lottery system has changed periodically from preference of neighborhood students to the current status of being open city wide to all students of the TPSD. Students are not required to submit to testing or other screening measures prior to enrollment (Please see Chapter Three: Methods for a detailed description of the racial distribution and socioeconomic status of the school's population).

\section{Pilot School Project}

Document analysis revealed that Demey Elementary School is a pilot school. Considered to be the hallmark of the pilot schools program is the shared leadership and decision-making by the people closest to the learners. As such, Demey School has autonomy over (a) staffing, (b) budget, (c) curriculum and assessment, (d) the school calendar, and (e) governance and policies (TSPD Pilot School Executive Summary, 2008). Part of maintaining autonomy over the listed areas is the obligation of the school to obtain and maintain Adequate Yearly Progress (to be referred to later at AYP). The following is a summary of each area that school has autonomy over.

Staffing. In order to create a unified school community, Demey School is allowed to staff their school with those which meet the academic, social, and emotional needs of their students. In a reached agreement with the TPSD Board of Education and the Trent Teacher's Union, they 
are not required to hire the senior teacher interviewed and are allowed to excess staff that do not fulfill the needs of the school. In addition, teachers are required to sign an election to work that outlines added responsibilities including additional allocation of time, participation in governance board, curriculum development, and professional development. They maintain all other union negotiated rights, benefits, and guidelines.

Budget. Demey School is allotted a lump sum per pupil budget equal to other TPSD schools within the same grade span. They have total discretion to spend in the manner that best supports the school's mission, programs, and services for their students and their families. In addition, the school is free to purchase identified discretionary district services or not. ${ }^{3}$

School Calendar. Demey School is allowed to create longer school days and calendar years for both students and faculty. Examples of the increased school day and calendar year at Demey School include additional mathematical instructional time, increased planning and instructional time, and organized Friday share time. The faculty also attends a weeklong retreat every summer that focuses on professional collaboration and professional development.

Governance and Policies. Part of being able to make budgeting and staffing decisions is the school's ability to create their own governance structure. The increased decision making power includes principal selection and firing, initiating educational programs and policies, teacher supervision, and setting graduation policies. Although policies and guidelines are set at the school level, the school must obtain final approval by the TPSD's superintendent.

Demey School purports to be a democratically run school under the direction of the principal. All staff is involved and attends weekly meetings to make and review decisions together. Teachers often chair committees such as the School Improvement Plan and Professional Development (Renald, personal communication, March 10, 2010). The school has 
two associations that make decisions for the school, the Governing Board and the Family Council.

The Governing Board meets quarterly and whose task is to insure that the school's mission is in safe hands. It consists of five parents, five staff members, five community members, three eighth graders and two seventh graders, plus one alternate. The board's functions include (a) evaluating the school's leadership, (b) selection of the school's principal, (c) approving the annual staffing and budget plan presented by the staff, and (d) assisting in the development of long range assessment tools for the school and its graduates.

Demey School also has a family council that consists of every parent, guardian, and family member with a child in the school. They meet every month to share information and discuss timely issues, coordinate parent volunteer opportunities, arrange school events and fundraisers, and provide orientation support orientation for new parents.

\section{Theme Two: Guided Open Curriculum}

Document analysis showed that as a pilot school, Demey School is freed from local district curriculum requirements thus able to structure their curriculum and assessment practices that the school believes best meet students' learning styles and needs. However, analysis did reveal that the school must include the use of experiential education practices that best fits their mission statement. They may set graduation standards that emphasize competency-based and performance-based assessments (portfolios, observations, interviews) rather than evidence-based assessments (standardized-testing).

\section{Experiential Education}

The Association for Experiential Education (2010) defined experiential education as "a philosophy and process in which educators purposefully engage with learners in direct, relevant 
experience and focused reflection in order to increase knowledge, develop skills, and clarify values and ways of thinking" (p. 3). Demey School is one of twenty schools that participated in a program initiated by the Trent Public School District (TPSD) that sought to enhance student engagement and performance through the use of experiential education. Believing that student engagement and achievement increases when schools are small, personalized, mission-driven, and have autonomy over their resources, there is also an increased accountability by all shareholders. Each pilot school focuses on content that is either related to technology, environmental education, health education, arts education, and physical education dependent upon alignment with their school mission (Trent Public School District, 2008). Seeking to nurture and maintain democratic habits, Demey School content focused on arts education, physical education, and environmental education.

\section{Thematic Units}

Again, document analysis revealed that Demey Elementary School structured their curriculum under the belief that students learn best when they are engaged in meaningful topics. Demey School utilized thematic education that is covered over a trimester school year as the core of their curriculum, (Demey School, 2008). Rotated over a four-year curriculum cycle, students study three multicultural thematic units. One trimester is devoted to science, technology, and the impact each has on students' lives and alternates between life and physical science. The second trimester is a study of Ancient Civilizations and the Struggle for Freedom and Justice in American History. During this trimester students explore what is to be free, how history has shaped who they are, and how the political system works. The final trimester is left open for teachers and students to design the study together. Teachers and students are free to further explore previous themes or create an entirely new theme based on class interest or need. All 
instruction within the thematic study is integrated with the exception of math. All though the themes are predesigned, curriculum approach and implementation is left to the discretion of the teachers.

The faculty of Demey School annually participates in curriculum reflection that occurs at the end of each school year. During this time, faculty discusses both at a grade level and again as a whole what worked well and what didn't work well with each thematic unit. Issues such as time lines, student interest, resources, encouraging more reflection, changing themes, creating more project-based units, and preparing for standardized-testing were discussed, evaluated, and adjusted (Demey School, 2008).

\section{Habits of Mind}

According to document analysis and semi-structured interviews, the thematic units/topics are designed in order to encourage the use of Demey School's Five Habits of Mind. The Five Habits of Mind are designed to further the school's belief that learning should be depth over breadth. This supports the idea that learning should be about some things deeply rather than a lot of little things with little understanding (Demey School, 2008). Thus the school's instructional philosophy and practice supports what Demey School considers being the definition of a welleducated person who is capable of living and functioning in a democratic society. Thematic units and classroom discussions are designed to deliberate use the Five Habits of Mind. The five habits are summarized as:

1. Evidence: How do we know what's true and false? What evidence counts? How sure can we be? What makes it credible to use? This includes using the scientific method and more. 
2. Viewpoint: How else might this look if we stepped into other shoes? If we were looking at it from a different direction? If we had a different history or expectations? This requires the exercise of informed empathy and imagination. It requires flexibility of mind.

3. Connections/Cause and Effect: Is there a pattern? Have we seen something like this before? What are the possible consequences?

4. Conjecture: Could it have been otherwise? Supposing that? What if? This habit requires use of imagination as well as knowledge of alternative possibilities.

5. Relevance: Does it matter? (Demey School, 2008, pg. 5).

The Five Habits of Mind are supplemented by the Habits of Work. The Habits of Work were developed as a guideline to encourage students to meet deadlines, establish guidelines, being on time, sticking to a task, and listening to differing viewpoints. This rationale implies that both sets of habits are needed in order to gather appropriate knowledge and skill in and out of school (Demey School, 2008).

\section{Summary}

This section focused on data gathered regarding the school's organization and development of the school's curriculum. Theme one focused on the autonomy associated with being a pilot school. It discussed the organization through location, layout, and student population) as well as the school's status as a pilot school. Theme two focused on the school choices for curriculum development. Document analysis revealed that the school curriculum is broad enough for teachers to develop curriculum and lessons that maintain and nurture democratic habits to become contributing members of a democratic society. But as teachers are free to develop curriculum, units, and lesson plans independently the next section focuses on data 
gathered regarding teachers' perceptions of democratic habits and its influence on curriculum development, unit planning, and lesson planning.

\section{Teachers' Perceptions and Pedagogical Practices for Democratic Habits}

Research Question Two: How do the teacher's perceptions of democratic habits influence their pedagogical practices?

\section{Theme Three: Child Centered Classroom Contexts}

This study explores pedagogical practices of four teachers at one public elementary school whose school mission seeks to nurture and maintain democratic habits for participation in a democratic society. This study defined democratic habits as the components of democratic education such as citizenship, democracy, reflection, critical thinking, problem solving, respect, cooperative learning, analysis, real-life application, and ability to express an opinion (voice). The study also defined teacher quality as "the inputs that teachers bring to the classroom including their demographics, aptitudes, professional preparation, college majors, teacher examination scores, teacher licensure, teacher certification, and prior professional experiences. It is what teachers do with what they know to promote student learning inside the classroom" (Kaplan \& Owings, 2002). In addition, research has suggested that how a teacher responds to the social contexts such as socioeconomic status, race, gender, and ethnicity can greatly effect student achievement (Darling-Hammond, 1999, 2000; Wenglinsky, 2000). As each case study teacher enjoys autonomy (with guidelines) over curricular decisions, unit planning, and lesson planning, it was vital to explore the background of each teacher as well as explore the context of each of their individual classrooms. Much of what a teacher believes and is committed to is revealed in the design and organization of his or her classroom. 


\section{Backgrounds and Classroom Contexts of the Four Case Study Teachers}

\section{Case Study Teacher One: Katy}

Katy teaches the 5-6-7 year old multiage classroom traditionally known as kindergarten and first grade in the East House of Demey School. She holds an undergraduate degree in education, a master's degree in education, an administration certification, and has additional educational course work in the areas of special education, English language learners, and math. She is currently pursuing a second master's degree in zoology. Katy has been teaching for 12 years and they have all been at the Demey School. She is considered to be 'highly qualified' as outlined by NCLB.

\section{Katy's Classroom}

Upon entering Katy's classroom, one notices that the traditional set-up of most classrooms is absent. Specifically, the primary established pieces of furniture, student desks, have been replaced with rugs, pillows and low setting tables. The wall to the right of the entryway there is long wooden shelving system that contains cubbies for student belongings and storage for instructional materials. Further into the classroom are bookshelves, a white bulletin board and an easel. These all frame a large area rug designated as the 'meeting area'. Upon the easel, one finds student names placed next to morning activity choices and there are numerous bookshelves containing reflection journals, reading books and resource books. On the others side of the meeting area is a low setting table surrounded by large pillows and a 'napping' area also with large pillows and blankets.

In a far corner, one finds the cooking station, which accommodates a refrigerator, a toaster oven, griddle and various other cooking utensils. Past the cooking station, one finds the class turtle asleep in its habitat created by the students from a previous thematic science unit. A 
large part of the classroom is donated to the 'play' area where an assortment of blocks, dress up clothes, kitchenette, tent and additional reflection journals can be found. Also visibly absent was a teacher's desk and classroom computers. Katy's classroom is not contained within four walls. The hallway outside of her classroom houses a water station, a sand box, a greenhouse and a painting station. The hallway walls as well as the classroom walls are covered with student work, drawings and writings (See Appendix D for classroom photographs).

Katy had fifteen students in her multiage classroom seven are classified as kindergarten and eight are classified as first in traditional labeling. The racial distribution of Katy's classroom is six Black, five White, three Hispanic and one Asian. Her classroom is also considered to be an inclusion classroom with one-third of her students having an Individual Education Plan. Onethird of her students speak a language other than English at home. Katy has one full time student teacher and three interns assigned to her classroom. Additionally, one of the school's cooks volunteers in her classroom during reading. At no time are there less than two adults present in the classroom.

\section{Case Study Teacher Two: Janessa}

Janessa teaches the 8-9 year old $\mathrm{m}$ ultiage classroom traditionally known as second and third grade in the W est House of De mey School. She holds an undergraduate degree in psychology and two Masters degrees, one in sociology and the other in education. Janessa was a student teacher at Demey School and then was subsequently hired by the school nine years ago. She is considered to be 'highly qualified' as defined by NCLB.

\section{Janessa's Classroom}

Upon entering Janessa's classroom, one first notices the openness and organization of the room. As in Katy's classroom, there are no student desks but rather two rectangular desks, one 
circular table and one low setting table surrounded by pillows. To the right of the doorway is a series of bookshelves, which sit under a series of bulletin boards and one dry-erase board. The dry-erase board as well as another series of bulletin boards frame a large area rug designated as the 'meeting area'. Under the second series of bulletin boards, one finds a fish tank, bookshelves and the students' clay representations of Wampanoag housing. Opposite of the doorway is a series of windows where underneath one finds a beehive, resource materials and posters. In the center of the classroom are four bookshelves filled with math manipulatives and resources. Attached to the classroom is closet that is the length of the classroom. Inside one finds the teachers desk, students' coats and backpacks and a listening station. There are various teacher created instructional posters hanging throughout the classroom and numerous student drawings, writings and work displayed in the classroom. Outside Janessa's classroom, there are interactive posters and displays that align with the incoming thematic unit, Struggling for Justice: Peopling of America.

Janessa has twenty-three students in her multiage classroom eleven are classified as second and twelve are classified as third in traditional labeling. Of Janessa's twenty-two the racial distribution was six White, eleven Black, four Hispanic and one Asian. Janessa has one full time paraprofessional, one full time student teacher and two interns assigned to her classroom. Additionally, one resource teacher travels to her classroom during math. Janessa is responsible for math instruction for all students traditionally considered third grade (See Appendix E for classroom photographs).

\section{Case Study Teacher Three: Jack}

Jack teachers the 9-10-11 year old multiage classroom traditionally known as fourth and fifth grade, which resides in the West House of Demey School. He holds an undergraduate 
degree in fine arts and a Masters degree in education. Jack has been teaching for 15 years with 11 of those years having been at Demey School. Prior to teaching, Jack worked as a freelance illustrator, an after-school program volunteer, paraprofessional and a teacher assistant. Jack also taught in Aruba providing him with international teaching experience. He is considered to be 'highly qualified' as defined by NCLB.

\section{Jack’s Classroom}

There are very few teacher made or store purchased posters that hang in Jack's classroom; rather the classroom is adorned with five model habitats, clay masks, student made posters, multicultural flags and an extremely large student made mural. The wall to the left of the entrance houses student cubbies and various educational posters. The model habitats can be found running along the back wall followed by the meeting area, an easel, a white board and storage. The wall opposite of the entry accommodates more storage, the mural, a worktable and Jack's desk. His desk appears to never be used as it is piled with books, papers and student work that have spilled onto his desk chair. ${ }^{2}$ The entrance to the classroom closet can be found to the right of the entryway. Here students keep their belongings as well as the closet serves as additional storage for projects, student work and reference materials. The center of the classroom holds five large worktables, four computers, and a meeting area. The meeting area is a large area rug surrounded by five benches, pillows, the easel and the white board. The room has also been painted green. Jack did not display student work in the hallway or use the hallway to post-instructional material (See Appendix X for classroom photographs).

Jack had 18 students in his multiage classroom with ten traditionally classified as fourth grade and eight as fifth grade. The racial distribution of his classroom denotes ten Black, 5 White and 3 Hispanic. His classroom is considered to be an inclusion classroom with one student 
identified with an Individual Education Plan and one-third of the classroom speaking a language other than English at home. In addition, Jack is responsible for all math instruction for all students traditionally considered fourth grade. Jack has one full time student teacher and two interns assigned to his classroom. The student teacher is responsible for various instructions in math, language and thematic unit construction. (See Appendix F for classroom photographs).

\section{Case Study Teacher Four: Renald}

Renald teaches $6^{\text {th }}, 7^{\text {th }}$ and $8^{\text {th }}$ grade Humanities in the East House of Demey School. He holds an undergraduate degree in history and completed an alternative teaching preparation program to earn his teaching certificate. Before Demey School, Renald taught at a high school charter school for four years. This is his fourth year at Demey School. He is considered to be 'highly qualified' as defined by NCLB.

\section{Renald's Classroom}

Renald's classroom is sparsely decorated and very open. Rather than being filled with student desks, the students assemble at four clusters of tables. The wall to the left of the entryway holds a supply table, water fountain and bulletin boards. The classroom meeting area is situated in the back of the classroom surrounded in park benches, chairs and beanbags. To the right of the meeting area are two computers, a white board, a worktable and a large bookshelf filled with various novels. The wall opposite of the entryway holds two more large bookshelves and a series of windows. On the wall to the right of the entryway there are more computers, an entrance to the storage closet, storage shelves and the teacher's desk. Students who may store their belongings as well as any additional reference materials use the storage closet. There are few store bought or teacher made posters that hang in the classroom. Two bulletin boards are 
used to display student work. Renald does not use the hallway to display student work or instructional material.

Renald has sixteen students in his $6^{\text {th }}$ grade class and 14 in each of his $7^{\text {th }}$ and $8^{\text {th }}$ grade classes. Of Renald's thirty-four students the racial distribution was 16 black, 9 Hispanic, 8 White and 1 Asian. Renald has one full time student teacher assigned to his classroom. Renald opted not to have photographs taken of his classroom.

\section{Theme Four: Voice}

Teacher's perceptions of democratic habits for participation in a democratic society should necessitate that teachers fully understand its ingredients such as citizenship, democracy, critical thinking, reflection, problem solving, and decision-making (Apple \& Beane, 2007, Darling-Hammond, 1997; Meier, 2002; Wolk, 1998). A solid understanding of these concepts is likely to help teachers in the development and implementation of a curriculum designed nurturing and maintaining democratic habits. This section is provides data collected regarding each of teacher's perceptions of democratic habits and how it influenced his or her pedagogical practices. It will be divided into two parts that explores the teacher's stated perceptions and one key practice of their stated perceptions of democratic habits, classroom meetings.

\section{Perceptions}

During the semi-structured interviews with the four case study teachers, each shared what they considered democratic habits to be. Each was guided by the concept of creating a community where students felt free to express their voice. In addition each touched upon the idea of creating a learning community where knowledge is gained as members of a democratic community. When explaining their perceptions of democratic habits through voice, many touched on other democratic habits such as reflection, critical thinking, problem solving, 
cooperative learning, and citizenship. When asked specifically about her understanding of democratic habits, Katy stated:

It is first and foremost about voice. Democratic habits is key in being able to give value to everybody, give each student a voice, and requires my students go be reflective about what they are doing and what they are thinking. You can't have a voice though until you critically think about something or problem solve your way through. So learning itself should be a democratic activity, so it should be constant discussion. (Katy, personal communication, March 10, 2010)

Janessa replied:

It's learning about voice. Creating a community where voices are welcomed and heard. They may not necessarily be included in the final decision but definitely heard. Learning democratic habits is learning to be part of a community. We do a lot of reflecting and talking. I make sure I create projects where they have to be part of group and be a responsible member of that group. . (Janessa, personal communication, March 18, 2010) In response to the same question, Jack provided:

To me, democratic habits are about teaching students that they have the power to participate in the process of learning. So it is about developing their voice. If a teacher is not doing this than they are not creating human beings who grow up to be capable of participating in a democratic society. (Jack, personal communication, March 10, 2010) Renald responded:

Democratic habits are about going out of my way to make sure to include student voice. Voice is a priority at this school. So even when I am creating my lessons, I make sure allow for some sort of choice. It is also about teaching about a collective and majority 
opinion. I think also that part of that voice is learning to be reflective of our work and engaging in work that is responsive to the world around them (Renald, personal communication, March 10, 2010)

Engaging and developing voice was central to each teacher's understanding of nurturing democratic habits. Specifically, each felt the classroom should be filled with continuous talk, discourse, and social interaction. All believed this practice allowed for an infinite number of voices to be heard. When asked how their understanding of democratic habits influenced their teaching and student learning, Jack emphasized:

I believe it makes me create activities where students have to think about whom they (students) are and what role they (students) play. It makes me consider how as part of a community my students have to be aware-aware of choices, aware to be informed, and aware enough to talk to people. It brings meaning to really learning how to work with others, having a sense of the world around you, having a sense of right or wrong, a sense of history, and a sense of justice. Students have to know what they are capable of and what they need to learn. They (students) have to make a conscious decision to be part of that, part of that knowing, and part of having a sense of something. I tell them they can't sleep walk through life. (Jack, personal communication, March 10, 2010) Janessa believed making sure to allow for reflecting had influenced her idea of democratic habits. She expressed that reflection should be part of not only the academic aspects of school but all the decisions the students make through out the day:

I make sure that we do a lot of reflecting. I want them to explain why they think a certain way or why they did what they did. Every project and a majority of assignments include a reflection. I ask them what they think of their work, what was challenging or 
interesting about their work, what they learned from the work, and what they would change about their work. Through reflections, students begin to thin about their work and begin to make connections. I also use student rubrics so that their reflections are used as part of the assessment. Rather than just me reflecting on their work, it is a shared voice in assessment. Reflecting is an activity I use a lot to develop voice in my classroom. (Janessa, personal communication, March 18, 2010)

At the age of five, Katy believed her students were just beginning to understand the power of their voice to she believed this influenced her to provide every a lot of opportunities in the classroom to create, question, and learn together as critical thinkers:

I spend a lot of time in the beginning of the school year starting conversations. I ask them a lot of questions to get them to start thinking about why they chose that activity or why they agree with that student. I put talking on the table. This leads to the idea that they have a place here and then they learn they have a place in the world. I think it is also important as beginning critical thinkers that they also realize not everyone is going to agree with them or do what they want to do. Or that maybe their idea won't work but I say 'let's try it' and maybe it will, maybe it won't. It leads to the idea they have a presence in this classroom and I like I said a presence in the world. (Katy, personal communication, March 10, 2010)

As a humanities and language arts teacher Renald found that he was influence to use writing as a tool to teach voice but to engage his students voice in learning as well:

I try to focus on teaching kids how to express themselves through writing. When my students work on creative writing, it seems their voice comes out quite easily. My job is to find their voice when working with expository writing, responding to historical fiction, 
or responding to nonfiction. Using their voice seems to be a little more difficult for them in these areas. I concentrate on building research skills that provides the facts for forming an opinion or helping them to just present the facts so others may form an opinion. It is a different way to look at voice. (Renald, personal communication, March $10,2010)$

\section{Classroom Meetings}

In the semi-structured interviews, each case study teacher was asked to provide an activity that they incorporated whether in a lesson or just classroom practice that focused on their understanding of democratic habits. Each commented regarding that they incorporate classroom meetings in their daily schedules. Each commented that this was one key practice that is vital to the development of voice in the classroom. The following is based on classroom observations and semi-structured interviews regarding classroom meetings.

Each observed instructional day in each of the case study teachers' classrooms began with a morning meeting and ended with a classroom meeting. The meetings ranged in time from twenty to forty minutes and took place in a large circle on the rug, grouping of various chairs, or on benches in the front of the classroom (See Appendices X-X for photos). All participants either sat on the rug or within the various types of seating including the adults. Katy believed that open democratic discussion could not occur if her students were sitting on the floor and she and the other adults were in chairs, (Katy, personal communication, March 23, 2010). During morning meeting, normal morning business were addressed such as attendance, daily schedule and morning greeting. Depending on the observational day, different topics were then discussed following morning business. 
Students during one of the observed morning meetings in Katy's classroom had shared personal experiences. Students discussed movies, travel plans, sick relatives and how the weather affected their commute to school. Katy shared during a post-observation interview part of developing her students both personally and socially is to demonstrating that she values their lives outside of the classroom. She believes it is very important to keep abreast of the happenings in her students lives and that many times her students will reveal things in morning meeting that may even explain behavior issues. She also communicated that morning meeting was an important time to practice listening. She expressed that listening is very important to developing democratic habits, as it is the prelude to understanding differing viewpoints, (Katy, personal communication, March 23, 2010). Classroom observations revealed that students concurred with fellow classmates' opinions by placing their thumb to their chests or they could disagree by raising their hands and presenting an opposing or differing thought. Students easily communicated with one another in this manner.

During another observed morning meeting in Janessa's classroom, Janessa had shared happenings of her own life following morning business. She openly discussed her plans for the evening, restaurants she loved to eat at and why she was late for class. Students appeared engaged, interested and responded to Janessa with various questions regarding what she ate or whom she ate with. Janessa replied to each question openly. Janessa expressed that this practice allows her students to see her as a human being that has emotions, feelings, passions and a real life (similar to her student's) outside the school walls. Other observations revealed that morning meetings would also include a review of instructional material or an introduction of a thematic unit. 
Classroom meetings occurred at the end of the instructional day. Classroom meetings are designed to address happenings of the day, problems of the day and things to think about at home. Students were encouraged to share the best part of their day as well as encouraged to express any problems they may have encountered during the day. These meetings are examples of how Jack believed he is able to recognize the value of each student's individual contribution and participation. He saw this as an attitude that all teachers should have to "value every student's voice and effort regardless of their race, class, gender, or religion" (Jack, personal communication, March 23, 2010). He also discussed the importance of how these meetings translated into thematic units and other instructional periods throughout the day. Students continue to develop the ability to learn together and how important it was for them to listen to other people but also how to show respect for other people when they disagree.

\section{Theme Five: Time Challenges}

When asked what they perceived to be the challenge of promoting and nurturing democratic habits, commonalities discussed by all of the case study teachers was the lack of time needed to nurture and maintain democratic habits were lost to mandated state and federal educational policies. Katy expressed:

Time. Democracy takes time and without time we cannot fully discuss or listen to nurture problem solving, critical-thinking, reflecting, and all the other skills needed to live in a democratic society. I am lucky, my students at this age don't take the high stakes testing, but we are starting to feel the pressure here. I can't imagine the immerse pressure in the third, fourth, and fifth grades. Having to say, 'I hear your voice, but let's move on' in order to check something off for a test would go against everything I believe. If you 
make more time for math or test review then something else has to go. If you look at pictures of the school ten years ago, you see a completely different school. (Katy, personal communication, March 10, 2010)

When asked the same question, Jack replied:

It is harder now to maintain the same values we had in the beginning. Our school is slowly having our time absorbed. Our time is being forced to address adequate yearly progress, test preparation, and making kids conform to external standards. We no longer have time to discuss where our learning can take us. Now, especially in math, I am just cramming things down their throats to get them to pass a test. I can't take the time to build an understanding like I once did. I want them to be crating a mathematical understanding. It should not have to happen on one specific date but that is the point now unfortunately. I do still try to build that understanding, but now I am behind in my pacing guide. So I am faced with pulling time from our thematic unit to give more time to math so they can get a few more answers right on the test. (Jack, personal communication, March 10, 2010)

Because Renald was not a founding teacher of Demey School as well as does not teach math, he believed he could be a little more philosophical than perhaps other teachers who were feeling the pressures of external classroom constraints. He, however, did address this issue and the subject of time when asked about the challenges of promoting and nurturing democratic habits:

Each year I have been here we have met to discuss what we did that year and ways we can improve. We seek to find if we are being true to our progressive ideals and whether we need to make changes. However, in the last four years the conversation has included 
that if we make these changes will we meet adequate yearly progress? How do we find the time to do both? We are not anti-tests but we do value other things more and want to remain true to those. For me, if we prepare our students well, they should do well.

However, I am not responsible for teaching math (laughs), so I can be very philosophical about it. (Renald, personal communication, March 10, 2010)

For Janessa, she believed the external classroom constraints were just another form of voice that should simply be considered in the classroom schematic. She did express her concern with the lack of flexibility as each student is different and learns differently. She believed that the standardized tests were important but some students may need more time to grasp concepts: I know most teachers would say the standardized testing is a challenge but I believe they should be meshing somehow. I think in a lot of ways they do mesh well. Sometimes when you think about voice and expressing your opinion, we have to accept sometimes our voice is heard but not always included in the decision. I like standards and standards are important. I actually look at the standards while creating my curriculum. My concern is the blanket the standards put over all kids. I think some flexibility should be maintained because every student is different. How do you put a blanket on all of these students? Right now we are juggling between our educational beliefs and philosophy versus what really needs to change for our students. Schools change and grow. We have to learn how to change and grow as well. That takes time. (Janessa, personal communication, March 18, 2010)

\section{Teachers' Perceptions Summary}

This section focused on data collected as guided by the second research question of this case study. It explored the four case study teachers' perceptions regarding their understanding of 
democratic habits. Based on their responses and classroom observations, three themes emerged in the data child centered classroom contexts, voice, and time. The first theme primarily focused on the classroom environment. Classrooms were designed, organized, and decorated to be specifically centered on students. The participants used the specific term voice to define their understanding of democratic habits but other terms used in the case study's definition emerged in their responses to questions. Their responses included other terms such as critical thinking, citizenship, cooperative learning, and community but were all placed under the same voice umbrella. The participants were asked to describe an activity that they considered implemented what they understood democratic habits to be. Each specifically stated classroom meetings to be one activity that they each used to develop voice. When discussing the challenges incorporating democratic habits into their classroom the theme time emerged from the data. Because each felt the need to develop democratic habits took time, scheduling conflicts that resulted from the loss of autonomy over math made it difficult to carve out time in their daily schedule to do so. Although all the case study teachers agreed that the external classroom constraints were having an impact on the school and specifically for this study their pedagogical practices, there was not an overall consensus whether the impact was a negative, positive, or serves as a means for improvement. The second section focuses on research question three that explores curriculum development of the four case study teachers.

\section{Curriculum Planning}

Research Question Three: How was the curriculum developed by each of the case study teachers that promoted democratic habits? 


\section{Theme Six: Variety of Child Centered Pedagogical Approaches}

This section discusses how the case study teachers planned for curriculum that promoted and nurtured democratic habits. As discussed in chapter three and in chapter four of this study, the case study teachers have autonomy over curriculum planning. Through semi-structured interviews and document analysis, the study revealed that teachers use a variety of methods in developing curriculum for their students. When asked how they begin curriculum planning for their classrooms Katy provided:

I will give you an example. Right now we are beginning our thematic unit on the Peopling of America. First, I thought about what I wanted my students to understand, be able to do, and skills I can introduce and build upon. So for this unit I thought it would be fun to look at who was here before looking at when people started coming to the United States. So then I started looking around for resources like books, videos, and anything having to do with the Wampanoag Tribe. I then contacted the local public library and they had this great investigation kit about the Wampanoag Tribe. I arranged for it to be delivered. Even though I have my ideas of what students to should learn, I know I am not the only voice in my classroom. Right now I only have an outline of what I want to do, I want sure I ask my students what they want to know and do. I believe it builds greater interest in a unit of study as well as helps my students build their voice when they can explore questions of their own. So before anything is truly set in stone, I guess, I talk to my students about the next unit and what we are going to be exploring. After, I use a simple KWL chart and find out what they are curious about. For instance, they are curious about what the Wampanoag ate and if they rode horses. So those are two things I will be incorporating into the unit study. From there I think about art projects, 
field trips, speakers I can bring in, and how or if any parents have anything to contribute. (Katy, personal communication, March 10, 2010)

Regarding curriculum development, Janessa described using Backwards Curriculum Design:

I normally sit down with my paraprofessional, Missy (pseudonym) and we decide what we want our students to learn and what do we want to accomplish. We start backwards from that. We create some guiding questions as part of the design. What are the things we want them to be thinking about through out the course of the curriculum that doesn't have a definitive answer but something that can be revisited through the course of the study. I also reference the state curriculum standards to help give me some guidance. I start with that and then begin to think about how I want that to play out in the classroom. For example, with the Peopling of America I really wanted them to think about themselves as we talk about immigration, so I think how can they do that? I answer that question with well they can do that by writing about oneself and that is how my curriculum begins to take shape. We usually just have one solid idea like for this unit I want them to do scrap books so I put the focus there. What skills can I build from that or an art project like in the study of the Taino people? (Janessa, personal communication, March 18, 2010)

When Jack was asked about how he begins his curriculum development, he explained that his units are specifically designed to set up opportunities for students to make decisions. $\mathrm{He}$ believes his job is to facilitate decision-making through a creation of a general plan and provided expectations. He believed less detail provided more opportunity for students to grow as critical thinkers, problem-solvers, and decision makers: 
Part of preparation for unit planning is considering where students will have opportunities to make decisions. I understand that my unit has to be flexible and I have to let go of control. My units are not so detailed that I control every aspect of that unit. It is a general outline where students are going to have to make some decisions during various moments of the unit. In those moments my job is to facilitate the decision-making process. Sometimes I explain material or options. Sometimes I have to poke them to get moving on a project. I don't provide the answer that is their job as problem-solvers or answer finders. I live for the moments when they say, “I understand!” So I basically have one essential question I ask about a unit. I think about some curricular and academic goals but then most of my unit is open. (Jack, personal communication, March 10, 2010) Answering the same question, Renald discussed an approach similar to Jack's. It was important to Renald that his units and individual lessons remain open to student interpretation. As a humanities and language arts teacher, he seeks to foster a love of a writing, reading, and learning through the use of student voice. However, he also touched upon those students who lack motivation and or find it difficult to work with too much freedom:

I think about the outcome of the unit or lesson plan. What do I want my students to be able to do at the end? I try to keep the task broad enough so each student would be able to do it the way they want to do it. This is an area that as a teacher I am trying to develop. I am struggling with how much scaffolding is too much and how much is not enough. I find when I give my students a lot of examples, rubrics, and guidelines that the work lacks their voice and tends to be quite rigid and formulaic. When I just give the concept or the idea, then the student's use more of their voice and produce far more creative work. I do have reluctant and in some cases struggling learners. I think all 
classrooms have those. They can get overwhelmed with unlimited choice so I am struggling with finding the right balance. I try to give them a little structure and lately I have been giving checklists to help my students that are having difficulty finishing assignments (Renald, personal communication, March 10, 2010).

Research indicated that school contexts are a contributing factor regarding decisions regarding curriculum development and lesson planning. When asked specifically when planning the curriculum what strategies and materials they used to ensure that all races, ethnicities, and both genders were represented in their curriculum and if they believed democratic habits helped develop curriculum, Katy responded:

Our thematic units are designed specifically for our school population. For example, the unit People of America, we are specifically looking at where our students come from. I also choose books that are of interest to my students and they have a say in that. . (Katy, personal communication, March 10, 2010)

Janessa's response was very similar to Katy's:

We meet as group (teachers) and discuss changes that need to be made in our curriculum. We used to study the Mayans as part of our Ancient Civilizations theme but we noticed this year that our population really didn't reflect that study anymore. We changed it to the Taino because we have a lot of Caribbean student or family ties to the Caribbean. So based on the school cultures we changed it. We also study the ancient civilizations of Egypt, China, and Greece. But we also look at the African American experience and immigration. (Janessa, personal communication, March 18, 2010)

Jack's approach attempts to connect his student's home life to the their lives at school: 
I try to make my curriculum is real as I can possibly make it. With my unit on the elections, I try to connect it to their real life and then bridge it out to the bigger picture of the country and the world. I encourage them to discuss issues with their parents and then bring what they discuss with their parents back here. We also spend a lot of time talking about their 'name' and their heritage. So we spend a lot time building those connections. (Jack, personal communication, March 10, 2010)

Renald believed that it was still just part of including student voice:

It is just part of our make-up to include student voice. This way student's background is included in the curriculum. Since voice is fused into everything we do, it is just natural for those items to be addressed.

Case study teachers were also asked regarding how they prepare their students for civic understanding or community participation in their classroom. There were also encouraged to discuss how experiential education guided their curriculum planning and how arts, music or other disciplines were encouraged. In consideration of these questions, Jack responded:

Our school runs on community and everything we are is about being a community. We participate with the local community by bringing in speakers, going on field trips to the museums, or going to the local businesses...Civic participation goes back to including student voice and encouraging them to have an opinion and say it! Right now my students are working on a mural that represents the Peopling of America. Each student is designing an aspect of the mural that represents his or her heritage (Jack, personal communication, March 10, 2010). Janessa expressed that many times art is what drives her unit. In response to an earlier question she discussed her desire for students to make scrapbooks that included various aspects 
of drawing, painting, and design. She also discussed her unit on the African American experience. Her curriculum was designed to look at it through art but her students caught onto the freedom songs, “ so instead of doing the paintings I had planned we started looking at poetry, listening to songs, and performing songs.” (Janessa, personal communication, March 18, 2010) She also revealed that her students participated in a local ballet class. It was only offered to students who did not have the opportunity to participate in outside activities or the opportunity to attend a ballet recital. She had three boys who had traveled every Tuesday to work with the local ballet company.

Katy revealed that her students have the opportunity to draw, paint, sculpt, build, cook, and listen to music every day as she incorporates this into her project time. In addition to this time, she expressed that an art project is involved in every unit. She also revealed during the interview that she encourages all members of the school community to be part of her classroom:

I have a lot of boys in my class this year and well the majority of them are African American. Our cook agreed to come up every Wednesday to take one of my reading groups. He works here part time while he is working on his degree. He does such a great job with them and they really like being with him. I wanted my students to know we all play a role and it is about respecting that role. I think it is good for them to have such a good role model. It is all about community. (Katy, personal communication, March 10, 2010)

\section{Thematic Unit Plans}

To further illustrate and clarify curriculum planning by case study teachers, a completed thematic unit plan was provided (See Appendices G, H, \& I for thematic unit samples). The thematic unit plans provided varied from science units to social studies units. Appendix G is a 
thematic unit designed by Janessa (8-9 multiage group) that focuses on the theme 'Peopling of America'. The unit plan highlights specific aspects of democratic habits ranging from critical thinking, decision-making, reflective thinking, and citizenship. For example, students were asked to consider what is an American and why? In a classroom observation of this lesson, Janessa, her students, and student teachers gathered on the morning meeting rug where Janessa presented various photos through a power point of people of all nationalities, color, and religious backgrounds. As each picture was introduced students were asked whether they believed this photo to be of an American. Once students answered, Janessa would ask questions such as:

1. How do you know this?

2. What makes you think that?

3. What is your evidence?

4. Why did you change your mind?

Students were encouraged to share their thoughts and feelings but were also encouraged to 'change their mind' regarding what they thought an American should look like. During this observation, students were engaged and actively participated by asking and answering questions. At the end of the classroom observation, students were asked to write a reflective piece about what is an American regarding what they thought, learned, and were still curious about (Classroom Observation, March 31, 2010).

Appendix $\mathrm{H}$ is a thematic unit provided by Jack (9-10-11 multiage group) regarding life sciences, Animal Habits and Where We Live. This unit plans emphasized application of knowledge as well as decision-making. During a classroom observation of one of the lessons of this unit, students were engaged in making decisions regarding the formation of their habitats. Students were arranged in four research team clusters dependent on their chosen living organism. 
Group formations were also represented both genders. Within the groups, one student served as a field note taker while the various groups discussed items needed for their living organism's habitat. In a pre-observation discussion, Jack revealed that students were allotted a certain budget to purchase the items needed to create and maintain their living organism's habitat. In addition, students had previously engaged in background research activities regarding their living organism. During this lesson observation, students were required to create a list of items needed based on research completed prior to this discussion. Students were engaged and excitedly discussed needed items and challenges to creating and maintaining the habitats. Jack circulated around the classroom asking students various questions such as:

1) How will you represent that in your habitat?

2) Why is that needed in your habitat?

3) If you spend your entire budget building the habitat, how do you intend to feed your living organism?

After such questions, Jack would circulate to another group asking the same or various other questions that resulted in further group discussions, further research, and at times heated debates. The 45-minute lesson concluded with Jack reminding students to continue to work on their animal folk tales and that they should be ready for peer editing the following week (Open School Visitation, November 9, 2009).

At the time of the study, Katy's classroom had just completed their KWL chart and Katy admitted that she had yet to create the unit plan for Peopling of America only an outline of what she wanted to accomplish. As discussed earlier, she referenced that she begins to look for and think about resources, art projects, field trips, and various other aspects of lesson planning that she can begin to incorporate. She stated that she uses a KWL chart, as she is not the only voice 
in her classroom. During a classroom observation, students were engaged in project time. As one of their options, Katy had contracted with the local museum for information regarding the Wampanoag Tribe. In the morning meeting, she pulled out various items and then reminded students that exploration of the kit should be one of their choices today. As students completed their choices, students were observed exploring the kit. Many played with the items, some read books included with the kit, and others quickly looked and moved to their preferred choices that day. At the end of project time, Katy pulls an item from the kit. She questioned the students probing to find out what they thought the item was used for. Various answers were given where students were able to concur or not but evidence to support either decision. She concluded the lesson with adding to the KWL chart whether they had answered any questions posed and what they had learned.

Appendix I was a project assigned by Renald (6-7-8 Humanities) to his $8^{\text {th }}$ grade Humanities class (because subjects are divided in 6-7-8 middle school, other thematic units are include). The culminating project was created for the thematic unit on Consummation. This project emphasized decision-making, analysis of production methods, and art design. Renald had revealed in a pre-observation interview that this unit previously explored sweatshops, the working class, trade unions, and for profit margins. During lesson observation, students were engaged in numerous activities ranging from shoe design, research of production methods, and writing. Students freely walked in and out of the classroom and were often observed talking, sharing designs, and resource materials. Renald spent the observational period circulating the tables, providing feedback to both genders, and posing questions for students to consider in their design. At the end of the lesson, Renald asked for students to share the progress they had made. 
Most students were reluctant to share but three presented early sketches and beginning thoughts to their response papers (Classroom Observation, March 25, 2010).

\section{Play}

In a semi-structured interview with Katy, she revealed how Play is vital component of her instructional time especially in consideration of developing democratic habits. Katy implemented all four versions of play in her classroom (a) object play, (b) pretend play, (c) guided play, and (d) physical play. Object play, pretend play, and guided play are implemented through morning activity choices whereas she stated physical play is implemented through a scheduled and daily half-hour recess (Katy, personal communication, March 10, 2010). Classroom activity choices varied between block makings, a listening center, dramatic play (dress-up clothes, kitchenette center, camping tent, grocery store and hospital), the science center, cooking, a water center, the sand box, painting, thematic unit projects, and a writing center. Students are encouraged to make four different activity choices with the writing center and the thematic projects as two of their prescribed choices.

During a classroom observation, the researcher observed four students engaged in block makings. It was during this observation that students created a pizza shop using various kinds of blocks. Beginning as object play, the 'pizza shop' quickly developed into a form of pretend play as students created menus, signs and created order pads as part of their activity. The four students pretended to take orders, make pizzas, take payments, answer phones and deliver pizzas.

Following their block making, students were then encouraged in the writing center to reflect upon their block making experience through narratives. Two students simply described what they did and how the pizza shop was created while one student chose a more creative approach by writing a story about an imaginary pizza place. The final student, an emerging 
writer, chose to create a picture with a written translation by Katy.

In a post observation interview, Katy (personal communication, March 23, 2010) discussed how play is utilized for creating and maintaining democratic habits but also for how it allows students to work on a developmentally appropriate level. Her description included how play enables her students to collaboratively imagine and actively carry out activities that they could not do on their own. In this, she stated that play creates contexts where her students engage in events and practices that are part of everyday life, which is integral part of social development. It also allows her students the opportunity to build self-confidence; face challenges and is a building block of problem solving.

The students are not in perpetual play. I know that when people come into my classroom there is a misconception that the classroom activities lack structure or content to the curriculum, especially during our instructional mornings. But I truly need to know my stuff. I have to predict the needs of my students and really know my students so when they ask for something or need something, I can respond. I also have to unafraid of not having everyone doing the same thing and I have to trust that I know where everyone is (Katy, personal communication, March 23, 2010).

\section{Curriculum Planning Summary}

This section reviewed the various methods used by the case study teachers in curriculum development. It reviewed data collected regarding how the participants created curriculum, how curriculum represented all races, ethnicities and both genders; and explored how art, music, and community were integrated. This section also reviewed provided thematic unit plans as well as how play was incorporated into Katy's classroom. The next section explores data collected 
regarding the final research question. It primarily focuses on the area of curriculum planning and instruction for math.

\section{External Classroom Constraints: Educational Policy}

Research Question Four: How do federal educational policies influence and affect their pedagogical practices for nurturing and maintaining democratic habits?

\section{Theme Seven: Math-Teacher Centered Pedagogical Practices}

Document analysis, semi-structured interviews, and classroom observations revealed that although Demey School operates with autonomy within the Trent Public School District, it is still required to obtain and maintain adequate yearly progress (to be later referred to as AYP). The state assesses AYP through the administration of standardized norm-referenced tests where a student group in the areas of Mathematics and English Language Arts must meet (a) student participation requirement, either (b) the State's performance target for that subject of a fixed school year or (c) the group's own improvement target of a fixed school year, and (d) an additional attendance or graduation requirement. Unfortunately, Demey School has been categorized in English Language Arts as Improvement Year 1 as the school did meet adequate yearly progress AYP in 2007 and 2008 in aggregate and all subgroups but failed to meet AYP in 2009 and 2010 in both aggregate and in the sub groupings; low income and Black. In Mathematics, the school's 2009 status is Restructuring Year 2 for failing to meet AYP in 2006, 2007, 2009, and 2010 in aggregate and failing to meet AYP in the sub groupings of low income and Black in 2008, 2009, and 2010.

Due to their Restructuring Year 2 status in Math, the Trent Public Schools Board of Education required that Demey School make the following instructional changes in the area of math $^{4}$ (a) set one hour math instructional time in every grade level, (b) grade level split 
beginning in second grade for set math instructional time, (c) mandatory use of school board approved curriculum and textbook, Math Investigations, (d) mandatory use of school board approved assessments, (e) professional development in math instruction, and (f) additional remedial math instruction for identified students.

This section discusses the effects of failing to meet AYP, current status as a restructuring school, and the culminating effects upon the pedagogical practices for nurturing and maintaining democratic habits. It will review specific responses from the case study teachers when asked regarding external classroom constraints, curriculum planning in the area of math, and classroom observations. Semi-structured interviews revealed a vast response to the external classroom constraints. As referenced earlier, some of the case study teachers viewed it as simply another voice in the schematic of the classroom context where other case study teachers found it to be quite a hindrance to their pedagogical choices for nurturing and maintaining democratic habits. This was revealed when asked previously regarding the challenges of nurturing and maintaining democratic habits. The triangulation of the data revealed teachers taking a more teacher-centered pedagogical approach in the area of math. The semi-structured interview with three of the four case study teachers responsible for math instruction revealed that mandated examinations affected their pedagogical choices:

I don't object to standardized testing. I don't object to making sure students are learning. I just think it should be relevant especially since I have students with various backgrounds. I don't even object to the content of the test. It is stuff they should know. I just think it is used inappropriately and it makes teachers teach to the test. When we teach to the test then it corrupts the purpose of the test. Accountability is fine if you are a bank. But I don't work in a bank. We are dealing with human beings. However, I have 
a responsibility to my students, their parents, and the community we all live in. We will not be able to continue to do the things we believe in without meeting AYP As much as I want my students to think mathematically, I have to make decisions based on a timetable set by a test. (Jack, personal communication, March 10, 2010) Although Katy's students are not active participants in the mandated examinations, she believed the math instruction she provides is the base for all students at Demey School. While she doesn't consider the standardized test an authentic assessment, she felt as a school they had to explore why the students were not performing well:

I know my students are mathematicians so I don't know why they are not doing well on the test. So upset as I was that we had to make the changes to how we teach based on a test I don't consider being authentic, I had to consider my students. This is serious. Is it the assessment, our teaching, or is it both? Ideally, if we are doing our job well then whatever is put in front of ours students they should be able to tackle? We should be teaching math in a variety of ways. They should know word problems, how to read a simple algorithm, and be able to answer any kind of mathematical question. It is just a different way to see it. So although I am not a supporter of standardized testing, it did force us to look at ourselves. That is a good thing. It has to be about the students and not the teachers. I wish I could still teach math as part of our project time but I have to find ways around it.

In response to a previous question, Janessa had referred to the external classroom constraints as simply another active voice in her classroom. Janessa references the state curriculum through out all of her curriculum planning, yet when specifically asked about the external classroom constraints she voiced: 
People were doing their own thing before AYP and I don't know if we were doing the best for our students. We have always had Math Investigations but it was more of a resource. It was intended that math was to come through the theme and we would have all of the students together in our classrooms. Now, the district wants us to follow the scope and sequence and divide our students by grade level. We still have a little freedom such as we can create a game instead of using the flashcards they suggest. By like I said before, it is about balance. Trying to find the balance is a little more difficult now. As a school we are trying to hold true to our educational philosophies but now we have another and sometimes-louder voice to contend with. If we stay focused on our students, I think we will be all right.

\section{Classroom Observations}

Classroom observations during set math instructional time revealed teachers wanted to cover as much content material as possible to help students gain the much-needed knowledge for mandated examinations. Classroom pedagogical choices used during thematic unit instruction like discovery, play, analysis, discussions, reflection, questioning, and exploration were abandoned for teacher centered pedagogical choices such as whole group lecture, explanation, worksheets, question and answer, and recitation.

During a classroom observation of Jack's fourth grade math lesson, it was apparent that both Jack and his students were uncomfortable with the pedagogical choices being made during math instruction. Using whole group instruction, Jack reviewed the various methods for solving addition story problems by writing problems on a small white easel that had been moved from the meeting area to the center of the classroom. As students do not have assigned seats or even desks, it was difficult for many of his students to see the math problems placed on the board. As 
Jack modeled the various components of solving addition story problems, students were disengaged from the lesson and spent most of the lesson talking, doodling on paper, or finding other methods to avoid the lesson at hand. During this lesson, Jack attempted to engage the students by asking leading questions such as, "How do you know when it is an addition story problem" or "What clue words are used?" unfortunately very few students responded to such prompts which lead to a lengthy lecture regarding the importance of doing well on the approaching standardized test. Following the end of the lesson, Jack provided each student with a 10-page packet that reviewed the entire unit on addition story problems. Each student was handed the same packet regardless of individual ability level. (Classroom Observation, March $16,2010)$

A second classroom observation of Jack's fourth grade math instructional time revealed similar teacher-centered pedagogical choices as observed in the first classroom observation. Jack modeled various ways in which to find the fractions of numbers by using square units. During this lesson, Jack attempted to engage students by having the students come to the easel to demonstrate the various ways they solved assigned problems. He equally asked for volunteers from both gender groups. He attempted to use various classroom management techniques common to whole group instruction such as addressing individual students, reviewing established classroom rules for listening, and encouraging disengaged students to participate at the easel. Concluding the lesson, Jack again provided each student an 8-page review packet. (Classroom Observation, March 15, 2010)

During an observation of Janessa's third grade math lesson, Janessa also implemented a more teacher centered pedagogical approach but seemed more at ease with this approach than Jack. Once traditional grade levels divided students, students were asked to move to the 
classroom-meeting rug. She then instructs her third grade students to put their math hats on and solve for the story problem that has been written on the large white board in the meeting area. The story problem read:

Dogs usually have four legs.

At the park there were 32 legs altogether. How many dogs are at the park?

Janessa asks for volunteers from both gender groups to solve the problem and once a correct answer is established they discuss the various methods that each student used to solve the mathematical story problem. During story problem time, Janessa and/or the paraprofessional corrected student behavior often. Students are uninterested and easily distracted. In addition, during this observation, two students were separated to avoid physical confrontation. Following this incident, students were redirected by being provided with small clocks. Using the clocks she asks the students an assortment of mathematical story problems dealing with the concept of elapsed time. During this review, behavior of the two students is addressed again. At this time clocks are collected and students are asked to solve division story problems using unifix cubes. Majority of the students use the unifix cubes to solve their problems, a few seemed confused on how to use the cubes to address the problem. It is never addressed by any of the adults in the classroom. Upon completion of the four story problems, students are provided with a 2-page worksheet with 24 division story problems. Students are asked to move to one of the tables in the classroom to begin working on their worksheets that completed the 60 -minute math lesson

Katy's students are not yet required to split into traditional grade levels although they are still required to use the Math Investigations textbook as in the other grades. During a classroom observation of Katy's multiage math lesson, she revisited various mathematical concepts that the students had been working with all year story problems and patterning. She asked her students 
to join her on the morning meeting rug and asked them what they thought great mathematicians do. Students eagerly raised their hands and provided answers that included:

- Read the problem out loud

- Write your name

- Cant get angry

- Think before you write it down

- Try different ways

- Share when you are supposed to share, don’t when you are not supposed to

Following this discussion, she reviewed story problem key words that indicated whether the students were to add, subtract, or multiply. After the discussion, she reviews the three activities the students may choose from. Their three options range from pattern making, story problems, and reading math books (each student has a reading cubby with various books at their individual reading levels). Students chose various areas in the classroom to work on their activity choices. Students who selected story problems were assigned story problems based on their mathematical level. The rest of the math instruction time was spent working on the activities. During this time, Katy, her student teacher, and her pre-service teacher circulated around the room answering questions, providing positive feedback, and keeping students on-task.

\section{External Classroom Constraints: Educational Policy Summary}

The discussion in this section focused on the external constraints of school board decisions, state and federal educational policy, and their influence on pedagogical choices of the case study teachers. Apparent in teacher responses to questions as well as through classroom observations that most of the case study teachers modified, often to their discomfort, their instructional practices. Practices such as discovery, discourse, reflection, decision-making, problem solving, and choice were replaced with whole group lecture, explanation, worksheets, question and answer, and recitation. Although not a focus of this study, classroom observations revealed that students responded to the adjusted instructional practices through disengagement, disruptive 
classroom behavior, and avoidance.

The next chapter will discuss and interpret the findings of this case study. It will be divided into three sections interpretations of the findings, recommendations of the study, and implications for future research. 


\section{Chapter Five: Discussion of Research Findings \\ Introduction}

A constructivist view guided this study as the researcher wanted to learn and understand the pedagogical choices of four teachers in a public school whose mission sought to nurture and maintain democratic habits for living within a democratic society. The constructivist perspective provided a means to examining the constructed knowledge of teachers through an examination of experiences that had emerged from interviews, classroom observations, and document analysis. Experiences created from the curricular and pedagogical decisions made by teachers and through various interactions between students and teachers within a specific social context helped bring meaning to this study, the intended goal of this chapter.

The first section is the interpretation of the research findings. It will discuss each research question through the themes and categories identified in the previous chapter as well as tie in literature and research from Chapter Two. The second section is a discussion of recommendations of the study and the last section reviews implications for future research. The four research questions that guided this study were:

1. How was the school organized that supported democratic habits?

2. How do the teacher's perceptions of democratic habits influence case study teachers' pedagogical practices?

3. How was curriculum developed that promoted democratic habits?

4. How do federal educational policies influence and affect case study teachers' pedagogical practices for nurturing and maintaining democratic habits? 
Through categorization of the research data, seven themes emerged from the four guiding questions of this study that details various perspectives, practices, and choices made by the case study teachers to maintain and nurture democratic habits. This section will be a discussion based on the four guiding research questions, themes, and categories.

\section{School Organization}

Research Question One: How was the school organized that supported democratic habits? Research Question One Themes: Autonomy and Guided Open Curriculum

Research question one of the case study focused on the how the school was organized. Literature reviewed in chapter two indicated that successful democratic schools have had control over decisions regarding how the school governs, the school and class size, curriculum development, and direction of learning experiences (Dewey, 1938; Meier, 2000; Sergiovanni, 1998, Glickman, 1996) as needed in consideration of the interests of the students intended to

serve. Specific findings of the school organization revealed that as a pilot school, Demey School did have autonomy over various decisions such as those mentioned previously that made it possible to maintain and nurture democratic habits. However, as will be detailed further in research question four, autonomy is contingent upon obtaining and maintaining Adequate Yearly Process (to be later referred to as AYP). Study findings have demonstrated that failing to do so has resulted in loss of autonomy over various items such as curriculum development and implementation methods in math, instructional time, and math assessments. Study findings have also indicated that this has had undesirable affect on various other areas as well such as student engagement, student discipline, and the inability to incorporate student voice. It also revealed 
that the case study teachers' acceptance and/or rejection of loss of autonomy varied throughout the themes.

Currently, Demey School retains autonomy over school size and class size (considered small) that research has indicated is most beneficial for a school population such as Demey Schools (The Center for Collaborative Education, 2003; Conant, 1967; Fine, Pannozzo \& Achilles, 2003; Howley , 1994; Klonsky, 1995; Raywid, 1995; Lee \& Smith, 1996; Rouse \& Barrow, 2006) whom serves only 165 students with a 47.3 percent poverty rate in addition to the 76.9 percent minority racial distribution. In addition, analysis of school organization documents revealed that the school still maintains the ability to make decisions regarding budget and staffing which is another key component of not only supporting democratic habits but student achievement. As addressed in previous research, how monetary resources are spent is significant to student achievement (Greenwald, Hedges, and Laine, 1996). In addition, participants involved in the case study are considered to be 'highly qualified' and also fit the definition of teacher quality as defined by this study. Provided research argued that a major side effect of unequal expenditures is unequal access to well-qualified teachers, which is a critical factor in underachievement in minority students. Demey School receives the same allotted per pupil equal to all other TPSD schools. Because the school retains autonomy over these two area, it has greatly enhanced the school's ability to allocate resources based on student need as well as obtain and retain highly qualified and teacher quality within their staff.

Document analysis of the school's curriculum revealed that the school curriculum was broad enough for teachers to develop curriculum and lessons that maintained and nurtured democratic habits. In fact, the analysis of curriculum documents showed that teachers are able and even encouraged to use various techniques, lesson activities, and resources that specifically 
addressed democratic habits. Guided under the principles of experiential education, thematic units, habits of mind, and habits of work curriculum development integrated critical thinking, problem solving, and relevant learning experiences. For instance, experiential education purposively engages learners with direct, relevant experience that students use to form and clarify opinions. McLaren (1998) posited the nucleus of any curriculum should emphasize student experience because knowledge acquired in school that voids personal relevance is tainted and thus deeply rooted in power relations. Additionally, Freire (1970) suggested that an individual who is able cultivate his own growth from his daily life situations provided the most useful learning experiences. The student should build his reality from the circumstances that have given rise to the daily events of his life. The texts that the individual creates permit him to reflect upon and analyze the world in which he lives - not in an effort to adapt himself to this world, but rather as part of an effort to reform it. As such the habits of mind and habits of work both function as a method and means of instructing students how to question, evaluate, and consider apposing viewpoints. In addition, students are asked to consider reasonable alternatives, consequences, empathy, and imagination. The development of these skills is essential in helping student understand multiple perspectives for critical and compassionate analysis of relevant societal issues (Giroux, 1988).

Triangulation of data revealed that thematic units are designed to specifically meet the needs, interests, and demographics of the school's population. Although document analysis and semi-structured interviews revealed that perhaps more guidance is needed in formation of actual curriculum and lesson planning that is not only in consideration of race and ethnicity but also representative of both genders. Although adjustments were made in consideration to the changing school population as indicated by exploring the Taino rather than Mayan, Banks (1988) 
argued that true multicultural curriculum should be representative in all forms of the presented curriculum. Based solely on gathered data, gender identification is one area that the researcher did not find true representation. This will be discussed further under research question three. However, the school's curriculum is designed to include what Darling-Hammond (2010) argued to be key elements of curriculum and education that other nations have used to successfully educate their students arts, history, literature, science, geography, civics, and foreign languages.

\section{School Organization Summary}

The ability to nurture and maintain democratic habits resides in the school's ability to organize the school based on key factors such as governance, school and class size, curriculum development, and direction of learning experiences. This discussion explored that because Demey School maintains status as a pilot school and retains autonomy over these key factors that has made it possible to nurture and maintain democratic habits. However, due to failing to maintain AYP has resulted in loss of autonomy over the area of math. The loss of this one area has affected various programs, daily schedules, and nurturing democratic habits.

\section{Teachers' Perceptions of Democratic Habits}

Research Question Two: How do the teachers' perceptions of democratic habits influence their pedagogical practices?

Research Question Two Themes: Child Centered Classroom Contexts, Voice, and Time The second research question focused on how the teachers' perceived what democratic habits to be and how it was engaged in the classroom. As discussed in chapter two, strength in delivering any curriculum is largely dependent on the teacher's commitment to and understanding intended curricular goals. For this specific case study, it is a commitment and 
understanding of democratic habits. Based on their responses and classroom observations, three themes emerged in the data, classroom contexts, voice, and time.

Much of what a teacher believes and is committed to is often revealed in the design organization of his or her classroom. In review of the case study teachers' classroom, each were organized, designed, and decorated to be specifically centered on students. Classroom observation revealed the replacement of student desks with tables, pillows, and rugs that signified a certain commitment to discourse, cooperative learning, interactive lessons, and safety. Three out of the four case study teachers did not even have desk, a symbolic feature of power relations in classrooms or the desk used as simply storage (Freire, 1970; McLaren, 1998). The classrooms supported student work on the walls rather than traditional store bought content posters as well as classroom rules were created by students and displayed through student posters. Katy's classroom was filled with 'play' items and everything was stored to be within reach of students. The tables used in Janessa, Jack, and Renald's classroom were all facing each other and provided ample opportunity for students to engage in discussions or cooperative learning. Classroom meeting areas were all designed based on age level such as Katy's students sat on a rug with pillows where in Renald's room students sat on park benches, beanbags, or stools. Lacking in many of the classrooms was the availability of updated technology. It should be noted that there were no interactive white boards, updated computers, or classroom projectors. Although each classroom supported some type of desktop computer, they appeared older and lacked current software. Internet and portable laptops are available but was only observed being used once in a classroom observation. This will be further addressed under recommendations of this case study. 
When participants were asked specifically to provide an understanding of democratic habits each used the specific term voice. If fact, this term was often used interchangeably with the other key terms used by this case study to define democratic habits such as citizenship, cooperative learning, and community. Each case study teacher expressed a commitment to enacting voice in the classroom as well as discussed above encouraged it through the classroom design and organization of the their classroom. Their definitions often echoed those of Giroux and McLaren (1986) who stated, "Voice ...refers to the means at our disposal, the discourses available to us, to make our selves understood and listened to, and to define our selves as active participants in the world (pg. 235). As Jack stated in his response, “...it is about teaching students they have the power to participate in the process of learning...developing voice.... and creating human being capable of participating in a democratic society." (Jack, personal communication, March 10, 2010) When participants were asked to reflect upon how their understanding of democratic habits influenced their teaching, Katy responded, “...I put talking on the table...they learn they have a place in the world...they become critical thinkers about the world around them.”

Critical to understanding the participants were their expressed differences to what voices should be included in the classroom. Janessa specifically stated, "We have to accept sometimes our voice is not heard. That is part of democracy". Whereas Katy expressed regarding standardized testing and voice, “...I hear your voice but lets move on in order to check something off for a test would go against everything I believe." Jack expressed, "We no longer discuss where learning can take us". Renald provided, "If we are being true to our progressive ideals then we have to make changes when needed." In review of the case study teachers' backgrounds, opinions often differed based on when they were employed by the school. 
Specifically, Katy and Jack expressed more contempt for the inclusion of the external voice of standardized testing and mandated math curriculum hired before NCLB whereas Janessa and Renald employed after the implementation of NCLB were more at ease with the external voice. This difference is also indicated under theme seven to be discussed later in this chapter.

Important to note was that each of the participants used classroom meetings as a strategy to develop and include voice in their classrooms. Wolk (1998) stated that a healthy nation is dependent on our ability to talk and listen to each other. He posited that this practice also validated outside school experiences and student opinions that created positive classroom atmospheres.

When specifically questioned regarding challenges of implementing democratic habits theme five of the study emerged, time. Participants reported struggling with the imposed external constraints that affected the amount of time they had to nurture democratic habits. In reflecting upon democratic habits, two of the participants regarding mandated testing as an intrusion especially in the ability to provide a rich content curriculum that is part of nurturing democratic habits. Jack described this feeling in his statement:

It is harder now to maintain the same values we had in the beginning. Our school is slowly having our time absorbed. Our time is being forced to address adequate yearly progress, test preparation, and making kids conform to external standards. We no longer have time to discuss where our learning can take us.

Katy expressed, "If you make more time for math or test review then something else has to go." She also expressed that, "Democracy takes time." Both of these statements illustrated to the researcher, that the two case study teachers who were employed by school prior to NCLB felt more pressure regarding time and how it was used. During interviews, there tended to be more 
of an urgency to recommit to their mission and what they began to do at the beginning.

Janessa's concern regarding time was being able to provide more time for her students to grasp concepts. She expressed that she liked standards and used the standards to guide her curriculum; however, in reflection of her varying students' abilities admitted that many of her students needed more time to academically develop. This demonstrated to the researcher that Janessa was grappling with how standardized testing; time, and democratic habits were in her words 'meshing'. Renald additionally expressed that standardized testing has absorbed the time that was once for activities that the school values such as field trips, projects, and learning exploration. But also noted that he felt if they were truly doing their job the students should do well. He admittedly stated that he does not have to teach math that has been the key issue for obtaining and maintaining AYP so his opinion was perhaps more philosophical than others.

\section{Teachers’ Perceptions Summary}

Finding of this case study revealed that the case study teachers had a clear understanding of democratic habits. Instructional strategies varied between the case study teachers used to nurture and maintain democratic habits. Their classrooms were designed, organized, and decorated to encourage discourse, cooperative learning, and interactive lessons. Although the definition used in this study to define democratic habits included various other terms, it was determined through out observations and interviews that these terms were used interchangeably with voice. They unanimously agreed that student voice was the key ingredient of democratic habits as well as the need for time to develop democratic habits.

\section{Curriculum Development for Democratic Habits}

Research Question Three: How was curriculum developed by each of the case study teachers that promoted democratic habits? 


\section{Research Question Three Theme: Variety of Child Centered Pedagogical Choices}

The third question of this case study focused on specific curriculum planning for democratic habits. Through semi-structured interviews, classroom observations, and document analysis theme six emerged from the data, variety of child centered pedagogical choices that supported democratic habits. As Demey School is freed from the local district curriculum requirements, it is still guided by experiential education guidelines that best fit the school. In fact, experiential education as defined, "philosophy and process in which educators purposefully engage with learners in direct, relevant experience and focused reflection in order to increase knowledge, develop skills, and clarify values and ways of thinking" is directly connected to nurturing democratic habits. Direct and relevance experience is key to what many supporters of democratic education state is needed. Giroux \& McLaren (1999) important aspect of proving students with skills in critical thinking and development of positive attitudes about the real world, greater connections to the outside world he higher the likelihood that the students can transfer the classroom experiences to real life situations.

Overall each case study teacher had a relative understanding of how to include democratic habits within their curriculum planning although their approaches varied. While some participants used direct student voice prior to planning others used voice in the decisions that students made through out the curriculum unit. The researcher concluded that based on specific age levels, ability levels, and goals of the curriculum who necessitate what role teachers and students had in curriculum planning. As students mature, the ability to communicate clearly through writing becomes more relevant than in the formative years of schooling. As such, Renald uses voice as way to encourage students to read literature they would not normally select or attempt different forms of writing other than creative. In this way, Renald introduces other 
viewpoints, opinions, and knowledge into his student's lives as Dewey considered the role of the teacher (Dewey, 1938). Dewey argued that by presenting new problems and new experiences it stimulates new way of observing, thinking, and reflecting (pg. 75-78).

This is also apparent in Jack's classroom, as he views himself as more of a facilitator of decision making rather than a supplier of information. He encourages his students to find the answer rather than seeking him to give them the answer. Janessa's approach tended to have more structure and a complete outline. She uses the local district curriculum to guide her but believed she also left her curriculum open enough to include her student interests as well. Katy's curriculum essentially was designed around the use of a KWL chart. She truly attempted to bring her students into every decision to build interest and a love of learning.

When asked specifically about school contexts and what strategies and materials each incorporated to ensure all races, ethnicities, and both genders were represented in the curriculum, teachers' responses indicated an over reliance on the thematic units. Each believed that the inclusion of student voice assured that representation occurred. Upon document analysis there were no clear indications whether gender was even a contributing determinant in curriculum planning. Specifically in review of provided curriculum plans (Appendices G-I), teachers did not specifically address inclusion of resource materials, discussion topics, or perspectives that included or encouraged the female viewpoint. Classroom observations did reveal that because voice was key factor for providing opportunities for self-expression, specifically in classroom meetings, inclusion of play in Katy's classroom, inclusion of African American role models, and the use of gender-inclusive language that case study teachers to a degree address this issue within their classrooms. 


\section{Curriculum Planning Summary}

Overall each case study teacher included democratic habits within their curriculum planning. Each used various strategies such as KWL charts, backwards curriculum design, and open units to include student voice in their planning. Each believed that the thematic units also addressed all races, ethnicities, and gender as being represented in the curriculum planning. Although, gender was never directly addressed in provided curriculum documents.

\section{External Classroom Constraints: Federal Educational Policy}

Research Question Four: How do federal educational policies influence and affect the case study teachers' pedagogical practices for democratic habits?

Research Question Four Theme: Math Teacher-Centered Pedagogical Practices

Research question four focused specifically on how state and federal educational policy affected the teachers' pedagogical choices. This research study often found that teachers abandoned learner center pedagogical practices that support democratic habits for more teachercentered pedagogical practices to accommodate changes in required by the Trent Public School District Board of Education for failing to meet AYP. Responses to questions regarding the required accommodations were somewhat varied yet reflective. When asked specifically regarding curriculum development prior to the required changes and post case study teachers revealed that while some considered it another voice to contend with in the classroom others considered it a direct intrusion to the learning environment. The responses were almost indicative of their employment date. As referenced earlier, frustrations with the mandated examinations differed dependent on when the teacher began working at the school. While Jack and Katy were hired previous to NCLB tended to be more aware of the time constraints the additional instructional requirements added to their curriculum planning and their ability to foster 
democratic habits. While Janessa and at times Renald were more accepting of the additional requirements. Researcher considered that their teacher preparation education might have been geared more to evidence based teaching than the others.

Participants were also quite very reflective about their answers as the failure to make AYP made them consider perhaps they were not doing the best they could do for their students. Katy had expressed, "I don't know why they are not doing well on the test...is the assessment, is it our teaching, or is it both?" This response as well as Janessa's response, "I don't know if we were doing the best for our students" revealed a commitment by the case study teachers to their students. It was obvious to the researcher that each case study teacher wanted their students to excel in every area including on the mandating examinations but was unsure how to accomplish it and remain true to their mission statement as well as meeting the learning needs of each of their students. Previous research echoed these same findings, where Goodman (2004) found that the impact of NCLB had forced teachers to adjust their teaching practices to accommodate district guidelines for instruction in preparation for mandated examinations.

Classroom observation revealed an abandonment of learner center teacher practices for what research considers being teacher-centered practices. The researcher observed large group instruction, lectures, question and answer, as well as worksheets. In addition, curriculum lacked any attention to race, ethnicities, or gender. Even though Katy is not required to split her classroom based on traditional grade levels for math instruction, she is still required to a set math instructional period. The researcher observed Katy attempting to include individual attention based on the varying abilities in her classroom by adjusting word problems, providing activity choices, and leveled reading material. However, students are required to meet the same objectives, complete the same assessments, and receive the same group instruction. Classroom 
observation, interviews, and document analysis revealed that Katy's ability to meet the needs of her students was often hindered by these requirements.

Students in Jack and Janessa's classrooms are required to be separated based on traditional grade levels for math instruction. During observed classroom instruction, both case study teachers directed their instruction based on the tested content material. Teachers used lecture, question and answer, and textbook worksheets as their main instructional tools. These instructional practices findings were similar to previously conducted studies (McMillian, Myran, and Workman, 1999; Mitchell, Barron, \& Keith, 1996; Hoffman, Assaf, \& Paris, 2001) that also identified the same adjusted teacher practices when preparing students for mandated examinations. Although slightly different in expression, both case study teachers expressed that the adjusted curriculum and instructional methods are not meeting the needs of their students regardless if it is a voice they need to contend with. They also revealed that their decisions are now based on a time table that does not provide flexibility and adaptability based on individual student needs. Similar to the findings of the Center on Educational Policy (2004) students are not learning more under high stakes testing reforms due to the consistently poor curriculum and instructional practices especially received by low-income and minority students. Strength in delivering any curriculum is largely dependent on the teacher's commitment to and understanding intended curricular goals. Overall, the researcher found that the case study teachers' truly did not have a commitment to the math curriculum nor faith in its ability to increase student achievement.

Although students were not a focus of this study, classroom observation revealed certain student passivity during math instruction was too apparent and relevant not to mention within this case study. Most students were observed doodling, chatting, and appeared off task the 
majority of the math instructional time observed. This was a stark difference to observations made during thematic instructional time where students were openly engaged, debated, and were actively involved in the instructional unit. In addition, at times students tended to display disruptive behavior during math instructional time. This behavior was mostly observed during periods where teachers were attempting to explain mathematical concepts through use of a white board or question and answer. The reaction by students was one of interest because it demonstrated how students are aware of the difference in chosen teacher practices during math instructional time and thematic units.

\section{Federal Educational Policy Summary}

Findings of the last research question are similar to findings of other studies that focused on high stakes testing. Teachers in this case study abandoned their beliefs, learner centered teaching practices, and student voice to accommodate preparation for mandated examinations. The findings have indicated a lack of commitment on part of the case study teachers to the math curriculum and as a result have had an effect on student achievement. Based on the findings of this case study the next section discusses possible recommendations.

\section{Research Findings Summary}

Seven themes emerged from the four guiding questions of this study that detailed the various perspectives, practices, and choices made by the case study teachers to maintain and nurture democratic habits. Research question one focused on the organization of the school and acted as contextual question and whether the school's pilot status, context, and statement of purpose had any influence on curriculum development and curriculum implementation in the classroom. Autonomy was revealed to be a key ingredient to the school's ability to maintain and nurture democratic habits Previous literature indicated that the more decisions made at the 
school level by those parties most involved with students was the most effective regarding democratic habits as well as student achievement. Loss of autonomy in the area of math not only effected mathematical instruction but also was increasingly affecting all areas of the school up to and including the inclusion of student voice, teacher voice, student behavior, and teacher effectiveness because of the amount of time and effort designated for math instruction.

The second question aimed at learning the teachers' perceptions and their actual pedagogical practices of how to maintain and nurture democratic habits through curriculum development, lesson plans, and classroom structure. Data collected revealed that case study teachers had a clear understanding of democratic habits. They varied their instructional strategies and decisions based on their perceptions and varied regarding how much and when student voice was included. The third question focused on the development of curriculum by each of the case study teachers. It explored specific planning and implementation in each of their classrooms. Each used a variety of methods to include democratic habits in their planning. Each relied heavily on thematic units to address race, ethnicity, and gender that are significant components of democratic habits.

The fourth question and perhaps the most revealing question was an endeavor to learn how pedagogical practices were influenced by federal educational policy constraints that the teachers had no control. In an attempt to accommodate changes required by Trent Public School District Board of Education for failing to meet AYP, data collected revealed that teachers abandoned learner center pedagogical practices for more teacher-centered practices. Responses to questions regarding federal educational policy was indicative of their employment date with teachers hired prior to NCLB being more aware of the constraints then those after. Each revealed a commitment to their students and a desire for each of their students to perform well on 
the state assessment. None of the case study teachers truly believed the current math curriculum was flexible or adaptable enough for the varied student abilities in their classrooms. The most revealing data was lack of engagement displayed by the students during math instruction time.

\section{Recommendations of the Study}

Public schools have traditionally been charged with the duty of preparing young minds to live within a democratic society. As such, this perception has often been cited as one of, if not the one, fundamental justifications for providing public financial support of schools (Glickman, 1990; Barber, 2001), yet the question remains what is the best way to prepare the nations' youth to live in a democratic society and if/are schools truly attempting to?

Reorganization efforts of the Elementary and Secondary Act (to be later referred to as ESEA Act) continue to emphasis on standards, benchmarks, proficiencies, and test-oriented classroom rather than providing intellectual inquiry, hands-on projects, and an activity based curriculum that is the core of living in a democratic society, (Darling-Hammond, 2011).

Research has indicated that the previously listed as well as of providing students with quality teachers, small and democratically organized schools, and commitment to meeting the needs of students rather than what is cost effective have shown that student achievement could be greatly improved especially for low socioeconomic students. Although the premise behind No Child Left Behind sought to increase student achievement, it nonetheless ignores the fundamental truth that could accomplish this task, nurturing and maintaining democratic habits.

Touted by their own district school system as a model of change for student achievement, Demey School is still mandated by Trent City Public School District the to conform to the federal guidelines of AYP. Thus, what do we make of this school that is considered the model to follow when in fact the school district mandates various changes to the curriculum and the 
changes proposed by the reorganization of ESEA alters the a fabric of their mission and of K-12 public education in general. If the notion of truly preparing young minds to live in a democratic society is no longer held as the fundamental justification for providing a tax supported school than not only is the future of Demey School uncertain but all American schools.

To this truth, recommendations of this case study are provided in two fold. The first set of recommendations speaks to the ability of Demey School to work within federal education policy. This case study revealed that much success was found when the case study teachers were able to pursue the school's mission statement that sought to nurture and maintain democratic habits when freed from the district curriculum guidelines. However, obtaining and maintaining AYP is essential for keeping autonomy and continuing the school's mission. As such, the researcher makes the following recommendations.

\section{Thematic Unit Math}

This case study revealed that the strongest instructional tool that the case study teachers' implemented was the nurturing and maintaining democratic habits through thematic units. Teachers displayed a commitment to as well as students demonstrated a true interest when engaged in thematic unit learning. Case study teachers freely admitted that adjustments in mathematical instruction were required and although Demey School is required to provide a separate math instructional time, this case study revealed that students are not engaged if they are not actively part of the lesson. Based on this evidence, it is recommended that case study teachers not only provide the mandated instruction but to include once again math instruction within the thematic units. This will not only increase the amount of instruction time students receive but provide instruction that includes democratic habits which this study has demonstrated to be the school's strongest instructional practice especially for low socioeconomic students. By 
providing meaningful experiences in math, students are able to build the needed connections for achievement, understanding, and mathematical advancement.

In addition, this case study revealed that the majority of the case study teachers are uncomfortable with whole group instruction. This case study revealed that teachers failed to and in fact completely abandoned instructional practices known by them and stated in school's mission statement to be best for student achievement. The case study teachers should incorporate hands-on activities, technology, and cooperative learning within mathematical instructional time that are within school district mandated guidelines. The listed strategies can be included and although limitedly based on democratic habits would advance mathematical instruction. In addition, providing the ability for students to manipulate objects, visualize outcomes, and work together could decrease the lack of interest shown by students and increase student achievement. Additionally, case study teachers revealed that they are not required to use worksheets. This provides the case study teachers ability to develop games, math projects, and other performancebased assessments could greatly increase interest as well as meet individual student needs.

\section{Increased Technology}

This case study also revealed that classrooms lacked relevant and current technology. Items such as interactive white boards, upgraded computers, social networking, and updated software were absent from the majority of the case study teachers' classrooms. The ability to use and incorporate technology is vital to living in a democratic society today as well as to student achievement. Technology has changed how members of a society interact with one another and exploring, using, and participating in different forms of discourse is important to the ability to nurture and maintain democratic habits. Allocated funds should be directed towards purchasing and maintaining technology for each classroom. In addition, curriculum review and professional 
development should include discussions of incorporating technology that benefits thematic units, math instruction, and the school community.

Discussion in this section focused on recommendations for improvement in pedagogical practices that nurtures and maintains democratic habits based on evidence from this case study. However, there is a need for more rigorous studies for guiding policy that has implications for pedagogical practices with continued nurturing and inclusion of democratic habits could have a marked affect on student achievement.

\section{Federal Educational Policy}

The second set of recommendations speaks to reorganizational efforts of the ESEA. In a recent 10-year study, Hout and Elliot of the National Academies of Science (2011) concluded that accountability mechanisms implemented under current legislation NCLB have generated minimal improvement in academic learning. It determined that the accountability measures used are too narrow to accurately gage progress and has led to focusing on behaviors that only seek to improve test scores rather than providing elements of curriculum and education that other nations have used to successfully educate their students (Common Core, 2010; DarlingHammond \& Wise, 1985; Darling-Hammond, 2010, Goodman, 2004; Hoffman, Assaf, \& Paris, 2001; McMillan, Myran, \& Workman; Meier, 1995; Rosenholz, 1987).

Other issues highlighted in the recently produced documentary "Waiting for Superman" asserted that teachers are the most important and at times the only factor determining student achievement. That the over abundance of 'bad' teachers who were supported by teacher unions were the main contributors of poor student achievement in public schools. Yet, the documentary failed to acknowledge as noted in chapter two, although teachers have a profound effect on student achievement, teachers alone can not over come the effects of student poverty, a poor 
curriculum, poor teacher preparation, and lack of equitable funding. In addition, countries such as Finland, China, Japan, Australia, South Korea, and New Zealand that consistently outrank the U.S. and used as comparison in the film have committed resources to rural and urban areas through teacher incentives, supporting teacher unions, funding school equitably, invest in highquality teacher preparation, organize curriculum around key democratic habits such as problemsolving and critical thinking, reduced class sizes, and most importantly do not use standardized testing as a form of assessment (Common Core, 2010; Darling-Hammond 2010). Based on reviewed literature and the findings of this study, the following recommendations are made:

- Invest in and improve teacher incentives as well improve teacher and school leadership evaluations based on performance measures not solely connected to test scores.

- Develop and provide more effective teacher and leadership education founded in the principles of democracy.

- Create a more thoughtful and rigorous curriculum as well as instructional strategies that support democratic habits.

- Provide equitable funding for public schools.

- Allow for school created performance-based assessments of learning that include challenging projects, investigations, and performances.

\section{Implications for Further Research}

Based on the above recommendations, there are various implications for future research.

\section{Performance-based Assessments Research}

There is need of further exploration of performance-based assessments for evaluation of student achievement especially in consideration of the increased achievement gaps of students of low socioeconomic status and the ability to prepare students to live in a democratic society. 
Federal legislation calls for "multiple up-to-date measures of student achievement, including measures that assesses higher-order thinking skills and understanding” (NCLB, 2001, Sec. 1111, b, 2,I, vi). However, student achievement has been continually assessed through more systematic testing that include only multiple choice and standardized measures of achievement. As reviewed in Chapter Two the inadvertent consequences of standardized testing include: narrowed curriculum, adjusted instructional practices, affected teacher quality, low teacher morale, and failing to do what public schools were intended to do prepare students for participation in a democratic society. Research has shown that the use of performance-based assessments that provides multiple ways of viewing student achievement could offer opportunities for students to experience a comprehensive, content-rich curriculum.

Research has demonstrated that other nations that continually outperform the U.S. provide learning opportunities that reach far beyond 'just basics'. Research on performancebased assessments could be utilized to bring understanding to how they are used to increase student learning by focusing on their formative and summative nature. They are formative in how they provide teachers and students with feedback from an authentic task that evaluates whether the student has mastered content. They are summative as they serve as a final assessment as determined by locally determined standards. Continued research in this area would provide evidence of needed changes in assessment that better meets federal educational policy and the needs to students.

\section{Student Perspectives}

There is a need for an investigation of classroom practices from the perspectives of students. Much research studies on classroom practices focuses on the teachers yet democratic habits and student achievement is actually more about students' perspectives and attitudes 
towards. Thus, there is a need to make an investigation about the students' views about democratic habits and student achievement. For example, this study has found that teaching experiences influenced students' passivity during math instruction but were engaged during thematic instructional time. This conclusion is from the perspective of the researcher's observations and interviews with teachers. Do students have the same perceptions? Not much is known about students' liking of various approaches to learning as well as their conceptions of democratic habits. Thus, most of what we know about students is learned from other sources. This is why a study that focuses on students can also provide better insights for the improvement of classroom practices that aim at nurturing and maintaining democratic habits and its affect on student achievement.

This section discussed implications for future research based on evidence provided by this case study and previous research. Further research is needed that investigates the use of performance-based assessments especially in consideration of the increased achievement gaps of students of low socioeconomic status and the ability to prepare students to live in a democratic society. Including multiple forms of assessments is supported, encouraged, and nurtured through inclusion of democratic habits. As such, additional research of students' perceptions of democratic habits would also provide better insight on how to improve classroom practices.

\section{Summary}

This case study attempted to answer the following question what is the best way to prepare the youth of this nation to live in a democratic society? Yet with the current educational arena that has placed such an intense scrutiny on student achievement there has become a seemingly disregard for not only what is right for nurturing democracy but for actual student achievement as well. The need to monitor student performance through instructional objectives, 
competency-based teacher education, and evaluation has significantly impacted pedagogy and curriculum. Teachers are no longer trusted with making decisions regarding curriculum development, pedagogy, and assessment.

As demonstrated in research and within this case study, teachers abandon what they know to be right for student achievement and democracy—problem solving, critical-thinking, expressing opinion, decision-making, art, and real-life connection—for test-taking skills, textbooks, worksheets, and tested content curriculum. The ability of the nation's youth to live in a democratic society is founded in the principles of certain habits that students should and must be equipped with in order to compete and succeed in a global market again--problemsolving, critical thinking, reflection, and the ability to express an opinion. These habits also support and encourage the democratic way of life that include dignity and rights of individuals and minorities, the concern of the 'common good', faith in solving problems, and specifically that democracy is a set of values that guide our lives as people. As such, this case study was circular journey that leaves the researcher questioning how do we prepare our youth to live in a democratic society with a distinct dichotomy in education of what is right and good for students and democracy and imposed federal education policy. 


\section{References}

Anyon, J. (1980). Social class and the hidden curriculum of work. Journal of Education, $162,67-92$.

Apple, M. (1979). Ideology and curriculum. Boston, MA: Routledge.

Apple, M. \& Beane, J. (2007). Democratic school: Lessons in powerful education. Portsmouth: Heineman.

Altermatt, E.R., Javanoivic, J. \& Perry, M. (1998). Bias or responsivity? Sex and achievement-level effects on teachers' classroom questioning. Journal of Educational Psychology, 90, 516-527.

Amrein, A., \& Berliner, D. (2002) High-stakes testing, uncertainty, and student learning. Education Policy Analysis Archives. 10, (18), Retrieved November 12, 2009 from http://epaa.asu.edu/epaa/v10n18/.

Aschbacher, P. (1991). Performance assessments: State activity, interest, and concerns. Applied Measurement in Education, 4 (4), 275-288

Association for Experiential Education, (2010). Retreived from http://www.aee.org/about/whatisEE

Bailey, S. (1992). The AAUW Report: How Schools Shortchange Girls. Washington, DC: National Education Association.

Banks, J. (1988). Approaches to multicultural curriculum reform. Multicultural Leader. 1, 1-2

Banks, J. (1998). Curriculum transformation. In J.A. Banks (Ed.). An introduction to Multicultural education.(2 ${ }^{\text {nd }}$ Ed.). (pp. 21-34). Boston: Allyn \& Bacon.

Barber, B.R. (2001). Public education and democracy. Kettering Review, 19(2), 18-26. 
Benbow, C. P. (1988). Sex differences in mathematical reasoning ability in intellectually talented preadolescents: Their nature, effects, and possible causes. Behavioral and Brain Sciences, 11, 169-232.

Blasé, J. \& Blasé, J. (1994). Empowering teachers: What successful principles do. Thousand Oaks, CA: Corwin Press.

Booher-Jennings, (2005). Below the bubble: "Educational triage" and the Texas accountability system. American Education Researcher. 42, (2), 231-268.

Cartledge, P. (2009). The democratic experiment. London: Pan Macmillan.

Center on Educational Policy. (2006). From the capital to the classroom: Year 4 of the No Child Left Behind Act. Washington, DC: Author.

Center on Education Policy (2009). How state and federal accountability policies have influenced curriculum and instruction in three states. Washington, DC: Author.

Coleman, J.S., Campbell, E.Q., Hobson, C.F., McPartland, J., Mood, A.M. et al. (1966). Equity of educational opportunity. Washington: U.S. Office of Education.

Common Core (2009). Why we're left behind: What top nations teach their students but we don't. Washington, DC Retrieved from http;/www.commoncore.org.

Creswell, J. (2007). Qualitative inquiry and research design: Choosing among five approaches. ( $2^{\text {nd }}$ ed.). Thousand Oaks: Sage Publications.

Cochran, K., DeRuiter, J.A. \& King, R.A. (1993). Pedagogical content knowing: An integrated model for teacher preparation. Journal of Teacher Education. 44, (4), 263-272.

Cochran-Smith, M., \& Lytle, S.L. (1999). Relationships of knowledge and practice: Teacher learning in communities. Review of Research in Education, 24, 249-305. Conant, J. (1967). The comprehensive high school: A second report to interested citizens. 
New York,NY: McGraw-Hill.

Corbett, C., Hill, C., \& Rose, A. (2008). Where the girls are: The facts about gender equity in education. Washington, DC: AAUW Educational Foundation.

Crotty, M. (1998). The foundations of social research: Meaning and perspective in the research process. London: Sage Publications.

Cowley, K. \& Meehan, M. (2003). Student achievement gaps in high performing schools: Differences as a function of the professional staff as a learning community. Paper presented at the Annual Hawaii International Conference on Education, Waikiki, HI.

Crowther, F., Kaagan, S.S., Ferguson, M. \& Hann, L. (2002). Developing teacher leaders: How teacher leadership enhances school success. Thousand Oaks, CA: Corwin Press.

Darling-Hammond, L. \& Wise, A. (1985). Beyond standardization: state standards and school improvement. Elementary School Journal. 85, 315-336.

Darling-Hammond, L. (1997) The right to learn: A blueprint for best practice classrooms. Portland, Maine: Stenhouse.

Darling-Hammond, L. (1999). Teacher quality and supply and demand. The National Commission on Mathematics and Science: Teaching for the 21st Century.

Darling-Hammond, L. (2000). Teacher quality and student achievement: A review of state policy evidence. Education Policy Analysis Archives, 8, 1-48.

Darling-Hammond, L. (2002). Research and rhetoric on teacher certification: A response to "teacher certification reconsidered." Education Policy Analysis Archives, 10, $1-56$.

Darling-Hammond, L., Chung, R., \& Frelow, F. (2002). Variation in teacher preparation: 
How well do different pathways prepare teachers to teach? Journal of Teacher Education. 53, 286-302.

Darling-Hammond, L., \& Youngs, P. (2002). Defining "highly qualified teachers": What does the "scientifically-based research" actually tell us? Educational Researcher, $31,13-25$.

Darling-Hammond, L. (2010). The flat world and education: How America's commitment to equity will determine our future. New York, NY: Teachers College Press.

Darling-Hammond, L. (2011, May 21) The Service of democratic education. The Nation. Retrieved from http://www.thenation.com.

Denzin, N. K. \& Lincoln, Y.S. (2005). The sage handbook of qualitative research $\left(3^{\text {rd }}\right.$ ed.). Thousand Oaks, CA: Sage Publications.

Dewey, J. (1897). My Pedagogic Creed. In: middle works of John Dewey. Op. cit., 5,433-435

-----1899. The School and Society. In: middle works of John Dewey. New York City, NY

-----1902. The Child and the Curriculum. In: middle works of John Dewey. New York City, NY

-----1903. Democracy and Education. In: middle works of John Dewey. New York City, NY, 1915

-----1913. Professional Spirit Among Teachers. In: middle works of John Dewey. New York City, NY

-----1930. The Duties and Responsibilities of the Teaching Profession. In the Later works of John Dewey. Carbondale, IL. Southern Illinois University Press, Op. cite 1986 5,326-330.

-----1938 Experience and Education. In the Later works of John Dewey. Carbondale, IL. Southern Illinois University Press, Op. cite 1986 13,1-62.

Eisner, E. (2002) The educational imagination: On the design and evaluation of school programs $\left(3^{\text {rd }}\right.$ ed.). Upper Saddle River: Pearson Education.

Ellis, J. (2001). Founding Brothers: The Revolutionary Generation. New York: Knopf.

Feagin, J.R., Orum, A.M., \& Sioberg, G. (Eds.) (1991). A case study for case study.

Chapel Hill, NC: University of North Carolina Press. 
Fennema, E. (1996). Mathematics, gender, and research. In G. Hanna (Ed.). Towards gender equity in mathematics education: An ICMI study. (pp. 9-26). Dordrecht, Netherlands: Kluwer.

Fenstermacher, G. D., \& Richardson, V. (2005). On making determinations of quality in teaching. Teachers College Record, 107 (1), 186-213.

Fine J., Pannazzo, G., \& Achilles, C. (2003) The "Why's” of Class Size. Review of Educational Research. 3, (3), 321-368.

Fitzpatrick, J. (Ed.) (1939). The Writings of George Washington From the Original Manuscript Sources. (vol. 30). Washington, DC: Government Printing Office.

Fosnot, C. (2005) Constructivism: Theory, perspectives, and practice. New York, NY: Teachers College Press.

Fraser, J. (2001). The school in the United States: A documentary history. New York: McGraw Hill

Freire, P. (1970). Pedagogy of the Oppressed. New York: The Conum International Publishing.

Gallego, M.A., Cole, M., \& Laboratory of Comparative Human Cognition. (2001). Classroom cultures and cultures in the classroom. In V. Richardson (Ed.), Handbook of research on teaching (4th ed.) (pp.951-997). Washington, DC: American Educational Research Association.

Giroux, H.A. (1994). Toward a pedagogy of critical thinking. In K.Walters (Ed.). Rethinking reason: New perspectives in critical thinking. New York, NY: State University of New York Press.

Giroux, H.A, \& McLaren, P. (1999). Teacher education and the politics of engagement: The 
case for democratic schooling. In P. Leistyna, A. Woodrum, \& S.A. Sherblom (Eds.) Breaking free: The transformative power of critical pedagogy. Cambridge,MA: Harvard Educational Review.

Glickman, C. (1990) Pushing school reform to a new edge: The seven ironies of school empowerment. Phi Delta Kappan, 21, 68-75.

Glickman, C. (1998). Revolutionizing America’s Schools. San Francisco, CA: Jossey-Bass.

Gough, H. G. (1946). The relationship of socio-economic status to personality inventory and achievement test scores. The Journal of Educational Psychology. 37,(9) 527. 540.

Grant, S. G. (2003). History lessons: Teaching, learning, and testing in the U.S. high school classrooms. London: Lawrence Erlbaum Associates.

Greenwald, R., Hedges, L., \& Laine, R. (1996). The effect of school resources on student achievement. Review of Educational Research. 66, (3), 361-396.

Hall, G. \& Hord, S. (2001). Implementing change: Patterns, principles, and potholes. Boston, MA: Allyn \& Bacon.

Heck, R. \& Moriyama, K. (2010). Examining relationships among elementary schools' contexts leadership, instructional practices, and added year outcomes: a regression discontinuity approach. School effectiveness and school improvement. 21, (4), 377-408.

Hogrobo, M. \& Tate, W. (2010). School composition and context factors that moderate and predict $10^{\text {th }}$ grade science proficiency. Teachers College Press. 112, (4), 1096-1136.

Hoffman, J.V., Assaf, L.C., \& Paris, S.G. (2001). High-stakes testing in reading: Today in Texas, tomorrow? The Reading Teacher. 54,(5), 482-494. 
Holsti, O.R. (1969). Content analysis for the social sciences and humanities. Reading: MA: Addison-Wesley.

Hopkins, M. (2008). Training the next teachers for America: A proposal for reconceptualizing Teach for America. Phi Delta Kappan, 6, 721-725.

Hout, M. \& Elliot, S. (Ed.) (2011). Incentives and test based accountability in education. Washington, D.C.: The National Academies Press.

Howley, C. (1994). The academic effectiveness of small-scale schooling. Eric Digest. No. RC-94-1. Charleston, WV: Clearinghouse on Rural Education and Small Schools. (ED 372 897).

Jefferson, T. (1818). "Report of the Commissioners to the University of Virginia" Retreived December 12, 2009 from http://www.libertynet.org/edcivic/jefferva.html Kaplan, L.S. \& Owings, W.A. (2002). Teacher quality, teaching quality, and school improvement. Bloomington, IN: Phi Delta Kappa Educational Foundation.

Katenmeyer, M. \& Moller, G. (1996). Awakening the sleeping giant. Thouasand Oaks, CA: Corwin Press.

Kipfer, B. (Ed.) (2003), Roget Dictonary. (1 ${ }^{\text {st }}$ ed.). Ohio: Writer's Digest.

Klonsky, M. (1995). Small schools: The numbers tell a story. A review of the research and current experiences. Chicago: Univesity of Illinois, College of Education.

Krippendorff, K. (1980). Content analysis: An introduction to its methodology. Newbury Park, CA: Sage.

Koch, J. \& Irby, B. (2002). Defining and redefining gender equity in education. Greenwich, CT: Information Age Publishing.

Koretz, D., Mitchell, K., Barron, S., \& Keith, S. (1996). The perceived effects of the Maryland 
school performance assessment program. (CSE Technical Report No. 409). Los Angeles, Center for the study of Evaluation, University of California.

Laczco-Kerr, J. \& Berliner, D.C. (2002). The effectiveness of "Teach for America" and other under-certified teachers on student academic achievement: A case of harmful public policy. Education Policy Analysis Archives, 10, (37).

Ladson-Billing, G. (1994). The dream keepers: Successful teachers of African-American children. San Francisco: Jossey-Bass.

Lee, V. \& Smith, J.B. (1996). High school size: Which works best and for whom? Paper presented at the Annual Meeting of the American Educational Research Association. New York, NY.

Levine, G. (1995). Closing the gender gap: Focus on mathematics anxiety. Contemporary Education. 67, 42-45.

Lewis, J., \& Ritchie, J. (2003). Generalizing from qualitative research. In J. Lewis \& J. Ritchie (Eds.). Qualitative research practice: A guide for social sciences students and researchers. London: Sage Publications.

Lubienski, S., McGrawm R., \& Struchens. (2004). NAEP findings regarding gender: Mathematics achievement, student affect, and learning practices. In P. Kloosterman \& F. Lester, Jr. (Eds.). Results and interprestions of the 1990 through 2000 mathematics assessments for the National Assessment of Educational Progress (pg. 305-336). Reston, VA: National Council of Teachers of Mathematics.

Marks, H.M. \& Louis, K.S. (1997. Does teacher empowerment affect the classroom? The implications of teacher empowerment for instructional practice and student academic performance? Educational and Policy Analysis, 19. (3), 245-275. 
McLaren, P. (1994). Life in schools: An introduction to critical pedagogy in the foundations of education. New York, NY: Logman.

McLaughlin, M.W. \& Tablert, J.E. (1993). Contexts that matter for teaching and learning. Stanford: Center for Research on the Contest of Secondary School Teaching, Stanford University.

McMillan, J.H., Myran, S., \& Workman, D. (1999). The impact of mandated statewide testing on teachers' classroom assessments and instructional practices. Paper presented at the annual meeting of the American Educational Research Association. Monreal, Quebec: Canada.

Meier, D. (1996). The big benefits of smallness. Educational Leadership. 54, (1), 12-15.

Meier, D. (2002). In schools we trust: Creating communities of learning in an era of testing and standardization. Boston, MA: Beacon Press.

Mehra, B. (2002). Bias in qualitative research: Voices from an online classroom. The Qualitative Report. 7, (1). Retrieved December 12, 2009 from http:// www.nova.edu.sss.QR/QR7-1/mehra.html.

Merriam, S. (1998). Qualitative research and case study application in education. San Francisco, CA: Jossey-Bass Higher Education Series.

Miller, J.W., McKenna, M.C., \& McKenna, B.A. (1998). A comparison of alternately and traditionally prepared teachers. Journal of Teacher Education, 29, 165-176.

Miller, L.S. (1995). An American imperative: Accelerating minority educational achievement. New Haven, CT: Yale University Press.

Minner, S. (2001). Our own worst enemy: Why are we so silent on the issue that matters the most? Education Week, 20, 33. 
The National Commission on Excellence in Education. A Nation at Risk: The full account. Cambridge, MA: U.S.A. Research, 1984.

Newmann, F., Marks, H., \& Gamoran, A. (1996). Authentic pedagogy and student performance. The University Chicago Press. 104, (4), 280-312.

Nichols, S., Glass, G.V., \& Berliner, D.C. (2005). High stakes tesing and student achievement: Problems for the No Child Left Behind Act. (No. EPSL-0509-105-EPRU). Tempe, AZ: Education Policy Studies Laboratory Arizona State University.

No Child Left Behind Act of 2001, 20, U.S.C. § 6319 (2009).

Nye, B., Hedges, L.V., \& Konstantopoulos, S. (2002). Do low-achieving students benefit more f from small classes? Evidence from the Tennessee class size experiment. Educational Evaluation and Policy Analysis. 24, (3), 201-217

Opdenakker, M.C. \& Van Damme, J. (2007). Do school contest, student composition, and school leadership affect school practice and outcomes in secondary education? British Educational Research Journal. 33, 179-206.

Ovando, M.N. (1996). Teacher leadership: Opportunities and challenges. Planning and change: An educational leadership and policy journal. 27, (1), 30-44.

Owens, S.L., Smothers, B.C., \& Love, F.E. (2003). Are girls victims of gender bias in our nation's schools? Journal of Instructional Psychology. 30, 131-136.

Pate, E., Homestead, E. \& McGinnis, K. (1997). Making integrated curriculum work: Teachers, students, and the quest for coherent curriculum. New York, NY: Teachers College Press.

Patton, M. (2002). Qualitative research and evaluation methods. Thousand Oaks, CA: Sage Publications.

Pellegrini, A.D. \& Holmes, R.M. (2006). The role of recess in primary school. In D.G. Singer, 
R.M. Golinkoff, \& K. Hirsh-Paske (Eds.) Play = learning: How play motivates and enhances children's cognitive and social-emotional growth. (pp. 36-53) New York, NY: Oxford University Press.

Pedulla, J., Abrams, J. Madaus, G., Russell, M. Ramos,M., \& Miao, J. (2003). Perceived effects of statewide tesing prorams on teaching and learning: Findings from a national surve of teachers. Center for the study of Testing, Evaluation, and Educational Policy, Boston College. Chestnut Hill, MA.

Piaget, J. (1971). Science of education and psychology of the child. New York, NY: Grossman.

Raymond, M., Fletcher, S. \& Luque, J. (2001). Teach for America: An evaluation of teacher differences and student outcomes in Houston, Texas. CREDO Report.

Ravitch, D. (2010). The death and life of the great American school system. New York, NY: Basic Books.

Raywid, M.A. (1995). Taking stock: The movement to create mini-schools, schools within schools, and separate small schools. Urban Education. ED393 958

Rosenholz, S. (1987). Education reform strategies: Will they increase teacher commitment? American Journal of Education. 95, (4).

Rouse, C.E. \& Barrow, L. (2006). U.S. elementary and secondary schools: Equalizing opportunity or replicating the status quo? The Future of Children. 16, (2), 99-123.

Rush, B. (1786). A plan for the establishment of public schools and diffudion of knowledge in Pennsylvannia; to which are added, thoughts upon the mode of education, proper in a republic. In C. Hyneman (ed) American political writing during the founding era: 1760-1805. Accessed from http://oll.libertyfund.org/title/2066/188739 on November $12,2010$. 
Sadker, M. \& Sadker, D. (1994). Failing at fairness: How our schools cheat girls. New York, NY: Touchstone.

Sadker, D. \& Zittleman, K. (2005). Closing the gender gap-again! Principal Magazine. 84, 1822.

Schulman, L. (1986). Those who understand knowledge growth in teaching. Educational Reseracher. 15, (1), 1-22.

Sheridan, S.M. \& Henning-Stout, M. (1994). Consulting with teachers about girls and boys. Journal of Educational and Psychological Consultation. 5, 93-113.

Silins H. \& Mulford, B. (2002). Leadership and school results. In K. Leithwood \& P. Hallinger (Eds.). Second international handbook of educational leadership and administration. (pp. 561-612) Norwell, MA: Kluwer Academic Publishers.

Sirin, S.R. (2005). Socioeconomic status and academic achievement: A meta-analytical review of research. Review of Educational Research. 75, 417-453.

Sizer, T. (1996). Horace’s Hope. Boston, MA: Houghton Mifflin.

Slattery, P. (2006). Curriculum development in the postmodern era. New York, NY: Routledge.

Stigler, J.W., Gonzales, P., Kawanaka, T., Knoll, S. \& Serrano, A. (1999). The TIMSS videotape classroom study: Methods and findings from and exploratory research project on eighthgrade mathematics instruction in Germany, Japan, and the United States. U.S. Department of Education National Center for Educational Statistics: NCES 99-074. Washington, D.C.: Government Printing Office.

Souza, D. (2001). How the brain learns: A classroom teacher's guide. Thousand Oaks, CA: Corwin Press, Inc.

Thornton, S.J. (2005). Teaching social studies that matters. New York, NY: Teachers College 
Press.

Trent Public School District Profiles (2008, 2009, 2010) Retrieved from http://tpsd.edu

Turner-Bisset, R. (1999). The knowledge bases of the expert teacher. British Educational

Research Journal. 25, (1), 39-45.

U.S. Census Bureau. (2000/2010). QuickFacts: Trent County, NJ (pseudonym) Retrieved November12, 2010 from http://quickfacts.census.gov.

U.S. Department of Education. (2009). Digest of educational statistics 2009. Washington DC: National Center for Education Statistics.

Vygotsky, L. (1962/1986). Language and thought. Cambridge, MA: MIT Press.

Wenglinsky, H. (2002). How schools matter: The link between teacher classroom practices and student academic performance. Education Policy Analysis Archives. 10, (12). Retrieved 10-2009 from http://epaa.asu.edu/epaa/v1012.

Westbrook, R. (1993). John Dewey. Prospects. XXIII, 12, 277-291.

White, K.R. (1982). The relation between socioeconomic status and academic achievement. Psychological Bulletin. 91, (3), 461-481.

White, S.B., Reynolds, P.D., Thomas, M.M., \& Gizlaff, N.J. (1993). Socioeconomic status and achievement revisited. Urban Education. 28, (3), 328-343.

Wheelock, A., Haney, W., \& Bebell, D. (2000). What can student drawings tell us about highstakes testing in Massachusetts? TCRecord.org. Available: http://tcreocrd.org/Content.asp? ContentID=10634.

Williams, D.T. (1990). The dimensions of education: Recent research on school size. Working Paper Series. Clemson, SC: Clemson University, Strom Thurmond Institute of Government and Public Affairs. 
Wolcott, H.F. (1994). Transforming qualitative data: Description, analysis, and Interpretation. Thousand Oaks, CA: Sage Publications.

Wolk, S. (1998). A democratic classroom. Portsmouth, NH: Heinemann.

Wood, G. \& Meier, D. (2002). Many children left behind. Boston, MA: Beacon Press.

Wood, G., Darling-Hammond, L., Neill, M., \& Roschewski, P. (2007). Refocusing accountability: Using local performance assessments to enhance teaching and learning for higher order skills. Briefing paper prepared for members of the Congress of the United States, Washington, DC.

Yin, R.K. (1994). Case study research: Design and methods. (2 ${ }^{\text {nd }}$ ed.). Thousand Oaks, CA: Sage Publications. 


\section{Footnotes}

${ }^{1}$ When compared to Baltimore, Maryland, which is approximate in size and location to the study, respondents reported 31.6 percent White, 64.3 percent Black, 1.7 percent Hispanic, 1.5 percent American Indian or Alaska Native and 1.5 percent two or more races.

${ }^{2}$ Observations on $3 / 16 / 10,3 / 25 / 10$ and $3 / 31 / 10$ researcher observed this statement to be an accurate account.

${ }^{3}$ However, for failing to meet adequate yearly process (AYP) in 2006, 2007, 2009, and 2010 in aggregate and failing to meet AYP in the sub groupings of low income and Black in 2008, 2009, and 2010 Demey School was required to purchase the Trent Public School District's mathematics curriculum Investigations.

${ }^{4}$ Currently, no changes have been made or required in the area of English Language Arts despite Improvement Year 1 status.

${ }^{5}$ There were no reported rankings for the United States in 2006 due to an error in printing of test booklets. 


\section{Appendix A \\ WestVirginiaUniversity \\ College of Human Resources and Education}

Good morning, good afternoon, or good evening, and thank you for agreeing to meet with me. My name is Lucretia Hubler-Larimore and I am a doctoral student at West Virginia University conducting this research study under the supervision of Joy Faini Saab, Ed.D., Interim Chair of Curriculum and Instruction in the College of Human Resources and Education at West Virginia University. The purpose of this research study is to examine the pedagogies utilized within a democratic learner-centered school. I may like to audiotape this interview in order to accurately represent what you say, if so may I have your permission to tape this interview? Our interview should last about 30 minutes. Before we begin I want to make sure you understand the following:

- You must be 18 years of age or older to participate.

- Your participation is entirely voluntary, you can choose to stop the interview at any time and you do not have to answer any question you do not want to answer.

- Your responses will be kept as confidential as legally possible. Your name will not be attached to notes from this interview or to transcribed data, and the audio will be erased once transcription is complete. At no time will your name be revealed during reporting.

- Your class standing, grades, or job status will not be affected if you decide either not to participate or to withdraw.

- West Virginia's University's Institutional Review Board has acknowledgement of this project is on file.

Thank you again for your willingness to participate in this study.

Sincerely,

Lucretia Hubler-Larimore

540-455-5950

Ihubler@mix.wvu.edu

Joy Faini Saab, Ed.D.

304-293-3221

joy.saab@mail.wvu.edu 


\section{Appendix B}

Good morning, good afternoon, good evening, thank you for participating in this research study. The purpose of the study is to look at pedagogical practices of teachers in a school who seeks to nurture and maintain democratic habits. This study is being conducted in partial fulfillment of doctoral degree requirements at West Virginia University. I would like to digitally audiotape this interview in order to accurately represent your responses to interview questions. May I have your permission to tape this interview? Before we begin I want to make sure you understand the following:

- Your responses will be kept anonymous confidential; at no time will your name be revealed during reporting.

- Your name will not be attached to either the tape or notes from this interview or to transcribed data.

- Your participation is entirely voluntary.

- You can choose to stop the interview at any time and you do not have to answer every question although information will be strengthened if you do.

- Your job status will not be affected by your refusal to participate or to withdraw from the study.

I appreciate your willingness to participate in this study. Thank-you.

For the interviewer only. Democratic Habits: citizenship, democracy, reflection, critical thinking, problem solving, respect, ability to express opinion (voice), analysis, real life application, and cooperative learning.

1. Please describe your background in education. Including any degrees and certifications you hold, how many years you have been teaching, and whether you are considered highly qualified as determined by federal educational policy?

2. How did you come to teach at Demey Elementary (pseudonym)?

3. Your school's mission seeks to nurture and maintain democratic habits, based on your experiences what is your understanding of democratic habits?

a. Are there any other habits you consider? (Used as follow-up question).

4. How do you think your understanding influences your teaching and student learning?

a. Is there an activity that you use that you believe best represents your understanding?

5. What do you find challenging about incorporating democratic habits in your classroom? 
6. Can you describe, the background of your students? (Please do not provide specific names or any other means of identifying students)

7. Since you are responsible for the curriculum in your classroom, how do you begin to plan your curriculum?

8. When you are planning your curriculum, what strategies and materials do you use to make sure all races, ethnicities, and both genders are represented within your curriculum? How do you involve students in this process?

9. Do you make considerations for your students who may be considered low socioeconomic status specifically regarding resources and materials incorporated?

10. Do you think your understanding of democratic habits helps your curriculum planning in regards to the prior two questions?

11. How do you encourage civic understanding, community participation and/or bring real life to the classroom in your curriculum?

12. How do you incorporate things such as art, music, or perhaps other disciplines into your curriculum?

13. Please describe your teaching and curriculum planning/ assessment prior to your current restructuring status as determined by AYP and state/federal education policy?

14. Please describe your teaching and curriculum development/assessment now in consideration to the prior question?

a. Do you use different resources, materials, or teaching strategies? (Used for clarification).

15. Is there anything else you would like to add? 


\section{Appendix C}

\section{Demey School's Statement of Purpose}

The task of public education is to help parents raise youngsters who will maintain and nurture the best habits of a democratic society - be smart, caring, strong, resilient, imaginative and thoughtful. It aims at producing youngsters who can live productive, socially useful and personally satisfying lives, while also respecting the rights of all others. The school, as we see it, will help strengthen our commitment to diversity, equity and mutual respect.

Democracy requires citizens with the capacity to step into the shoes of others, even those we most dislike, to sift and weigh alternatives, to listen respectfully to other viewpoints with the possibility in mind that we each have something to learn from others. It requires us to be prepared to defend intelligently that which we believe to be true, and that which we believe best meets our individual needs and those of our family, community and broader public - to not be easily conned. It requires also the skills and competencies to be well informed and persuasive to read well, to write and speak effectively and persuasively, and to handle numbers and calculations with competence and confidence.

Democracy requires citizens who are themselves artists and inventors - knowledgeable about the accomplishments, performances, products and inventions of others but also capable of producing, performing and inventing their own art. Without art we are all deprived.

Such habits of mind and such competence are sustained by our enthusiasms, as well as our love for others and our respect for ourselves, and our willingness to persevere, deal with frustration and develop reliable habits of work. Our mission is to create a community in which our children and their families can best maintain and nurture such democratic habits.

Toward these ends, our community must be prepared to spend time - even when it might seem wasteful - hearing each other out. We must deal with each other in ways that lead us to feel stronger and more loved, not weaker and less loveable. We must expect the most from everyone, hold all to the highest standards, but also respect our different ways of exhibiting excellence. We must together build a reasonable set of standards for our graduates so that they can demonstrate to us their capacity to meet this mission. 


\section{Appendix D}

Katy's Classroom

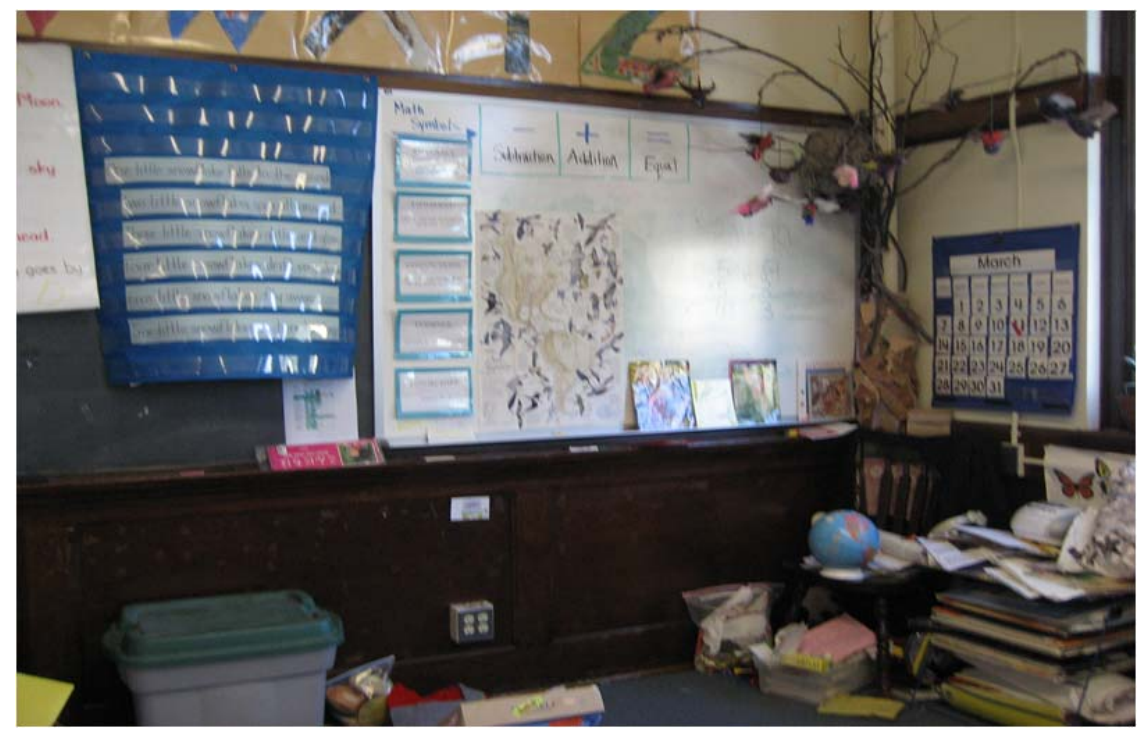

Photograph Katy 1. This photo highlights the meeting area. Here one sees the Habits of Mind posters, artwork from a previous thematic unit, math instructional posters, and various resources.

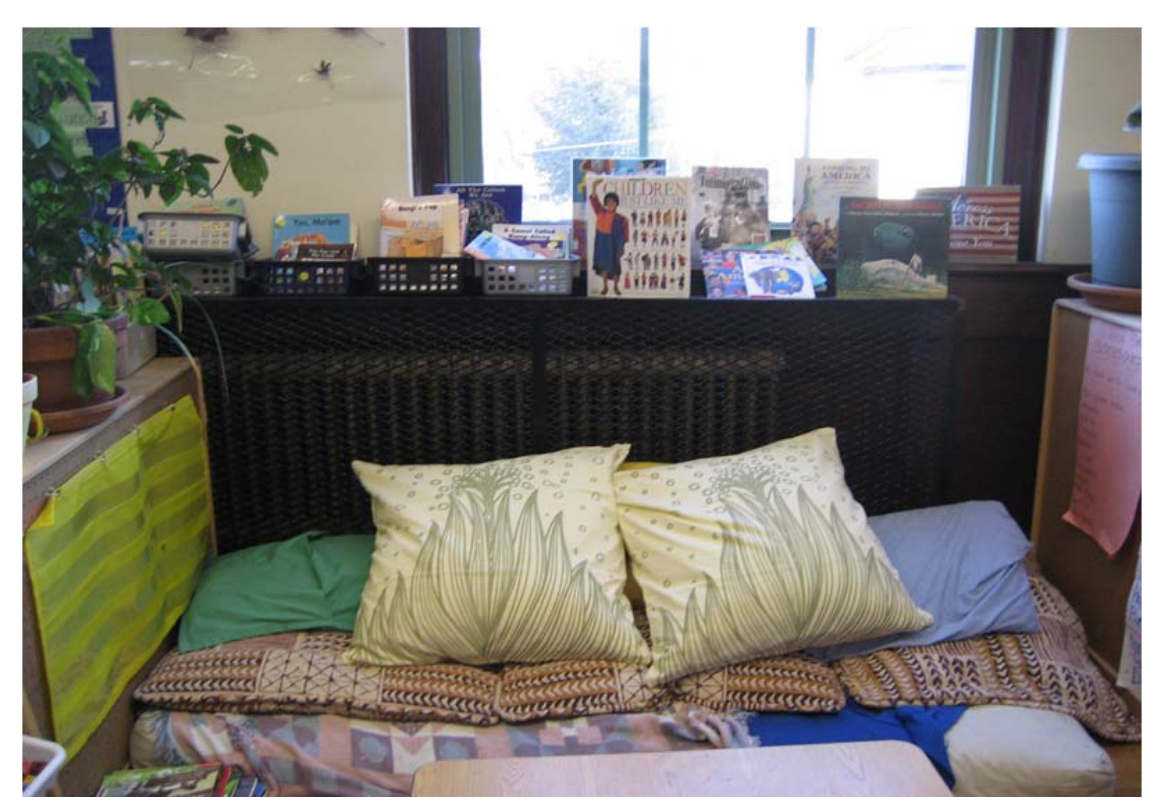

Photograph Katy 2. There are no desks in the classroom so the students often sit on pillows while reading, reflecting, and problem solving. 


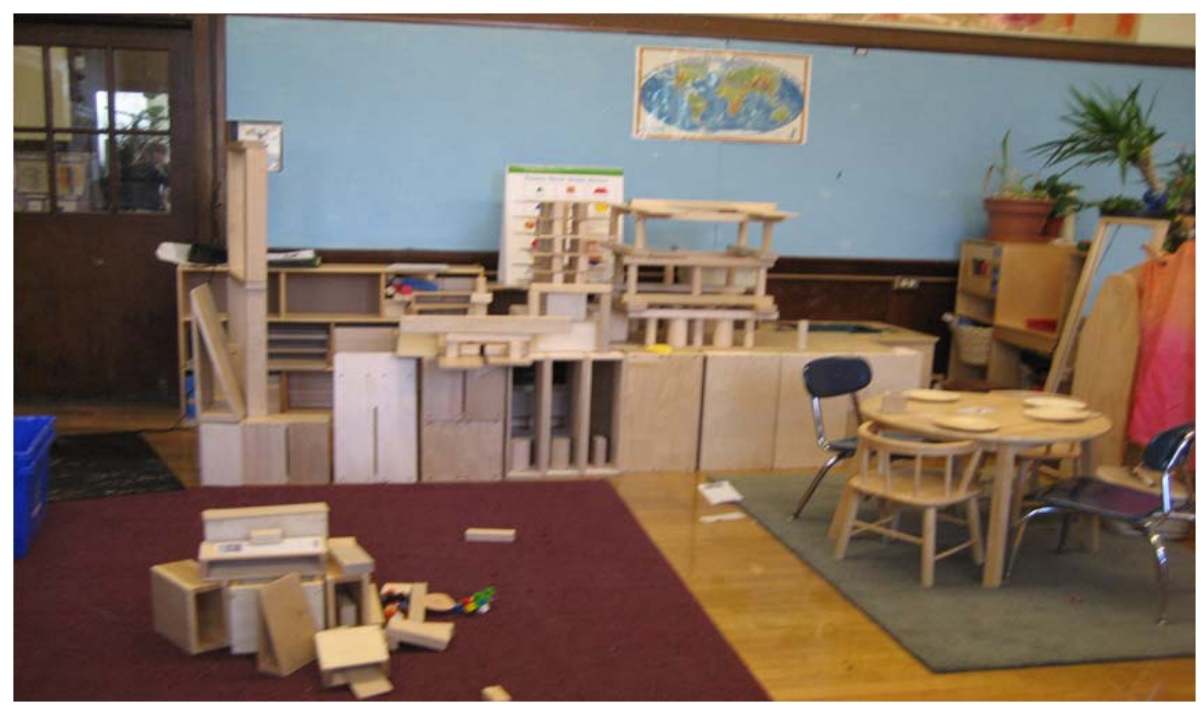

Photograph Katy 3. Much of the morning instruction is guided by the concept of 'play'. This photograph and the following two demonstrate the various items in the play area to include blocks, dress-up, kitchenette, and reflection journals.

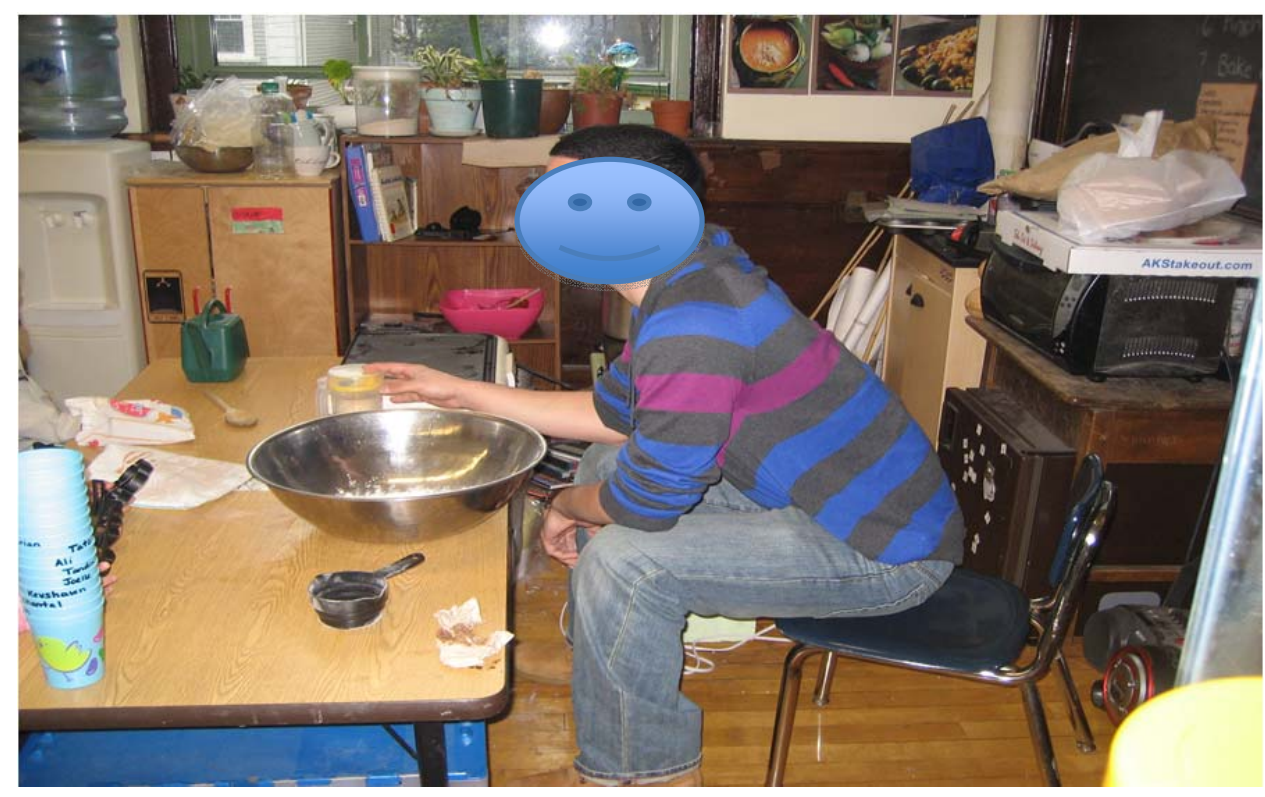

Photograph Katy 4. Kitchenette. 


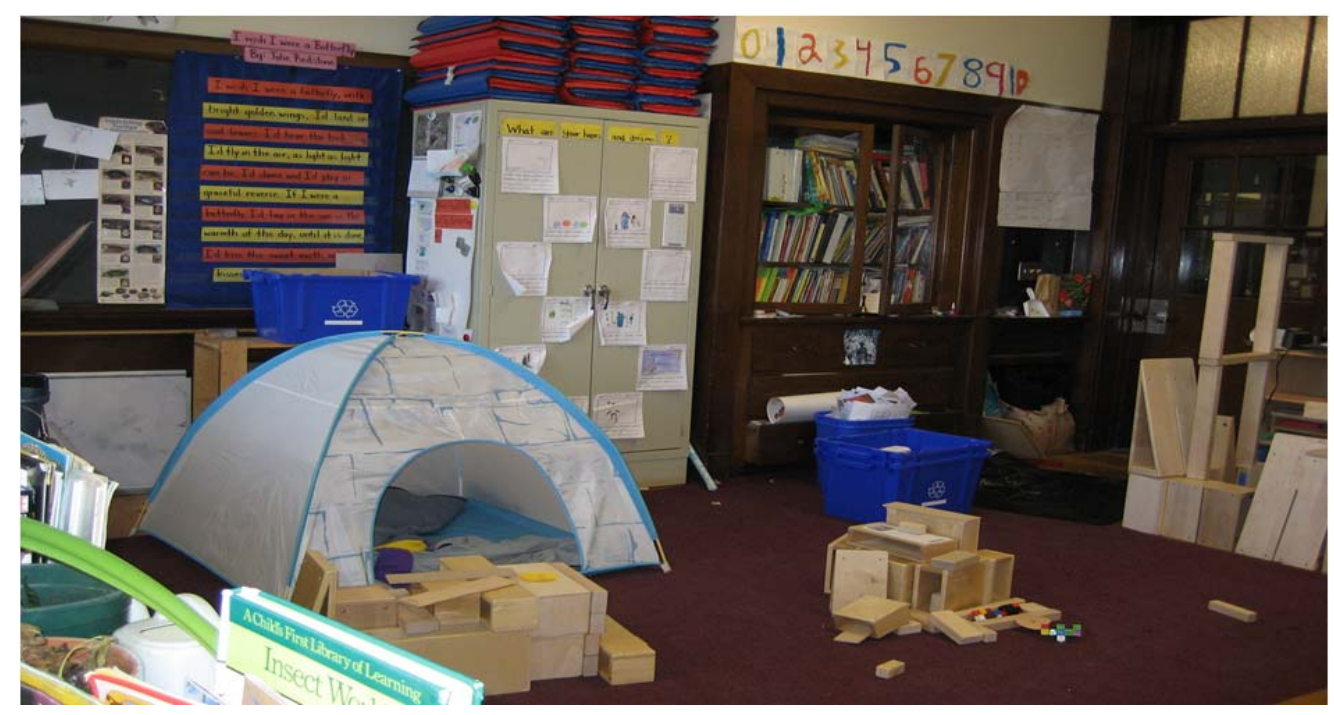

Photograph Katy 5. Blocks, Tent.

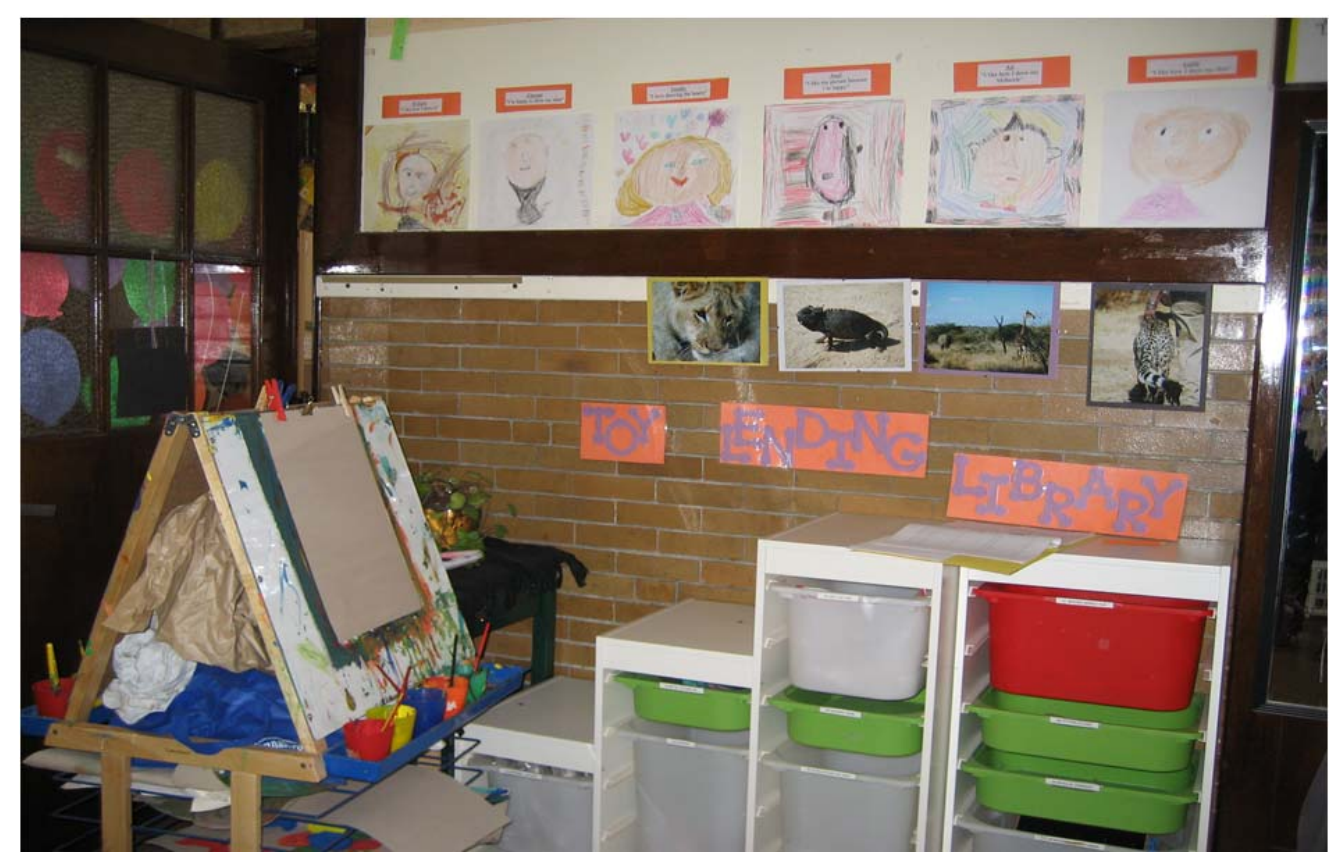

Photograph Katy 6. Katy utilizes the hallway outside of her classroom to house many items such as the painting easel, sandbox, and the classroom greenhouse. This area is also used to display student work. This photograph and the following show some of these items. 


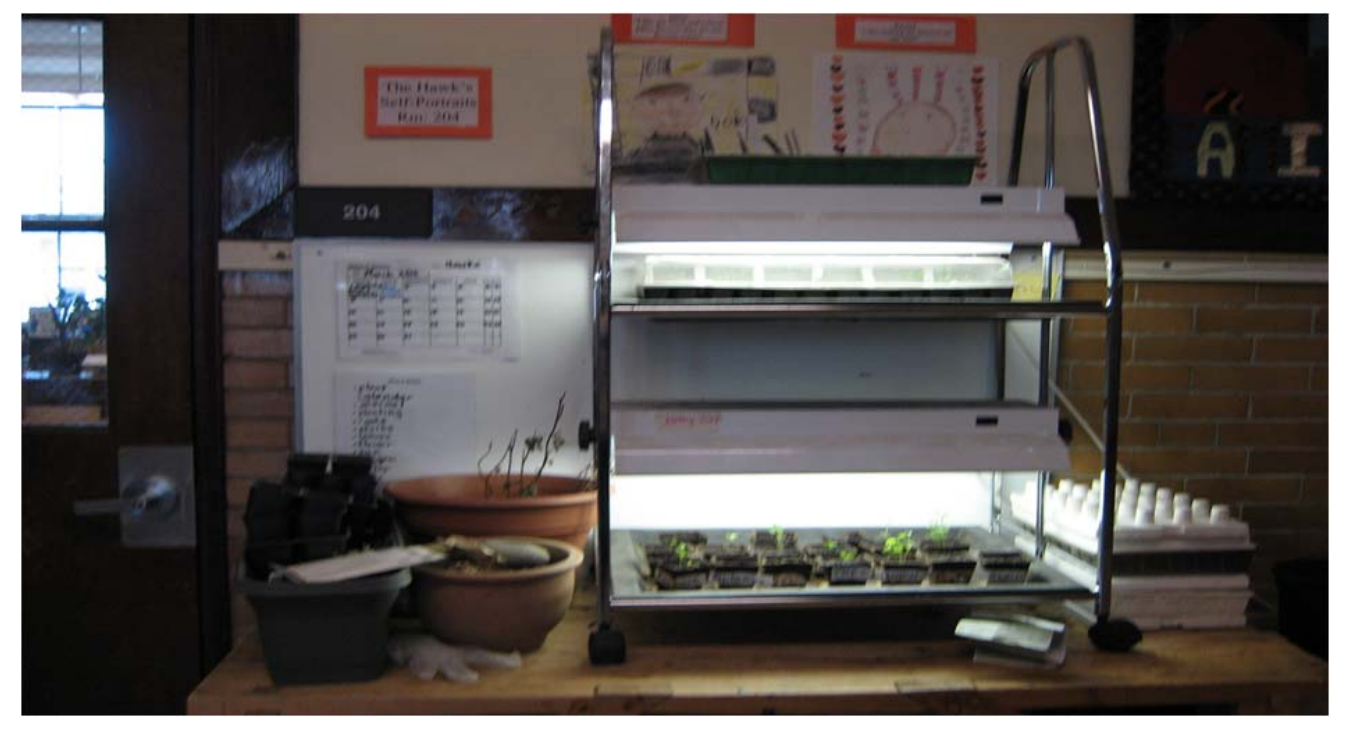

Photograph Katy 7. Greenhouse.

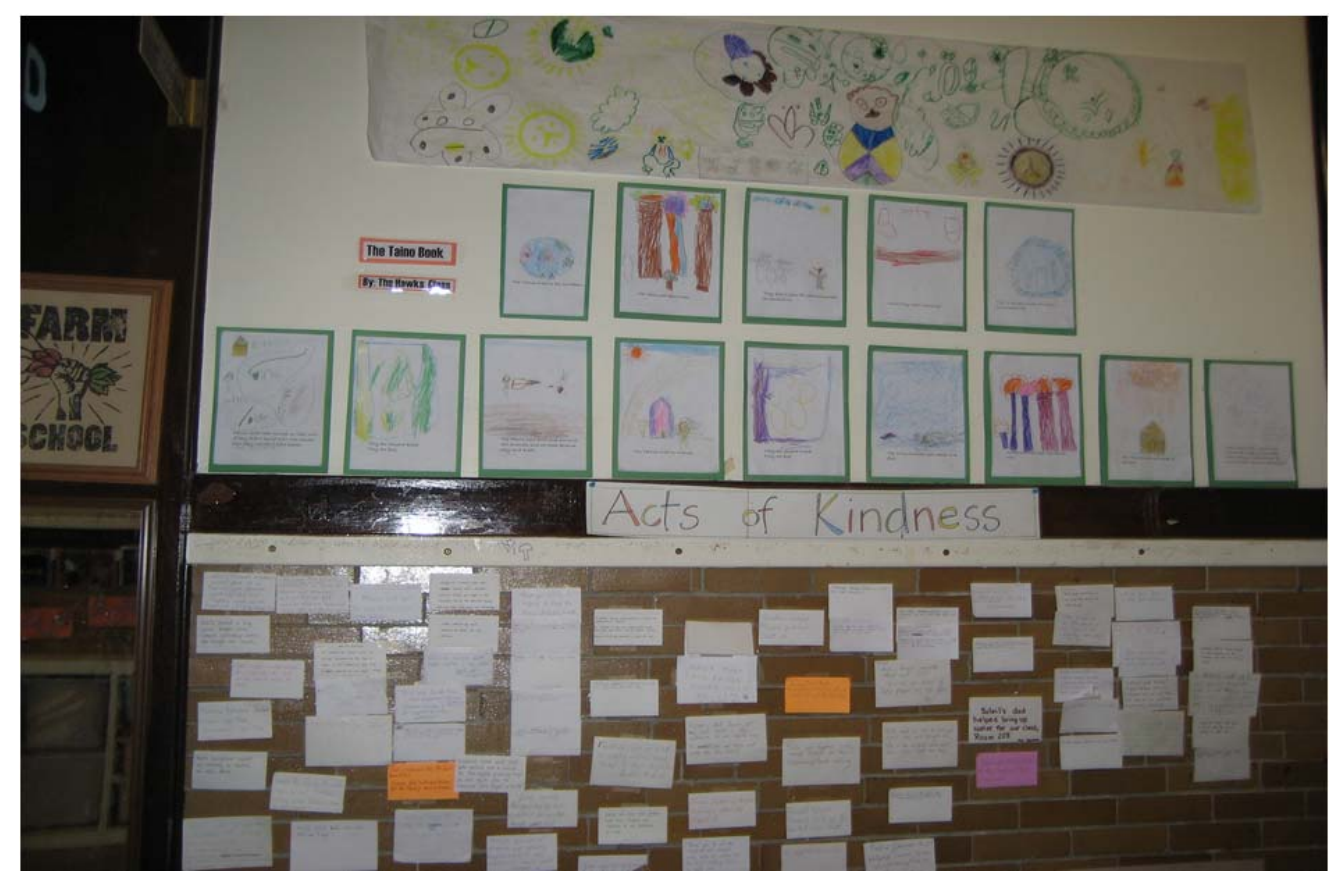

Photograph Katy 8. Student work. 


\section{Appendix E}

Janessa'a Classroom

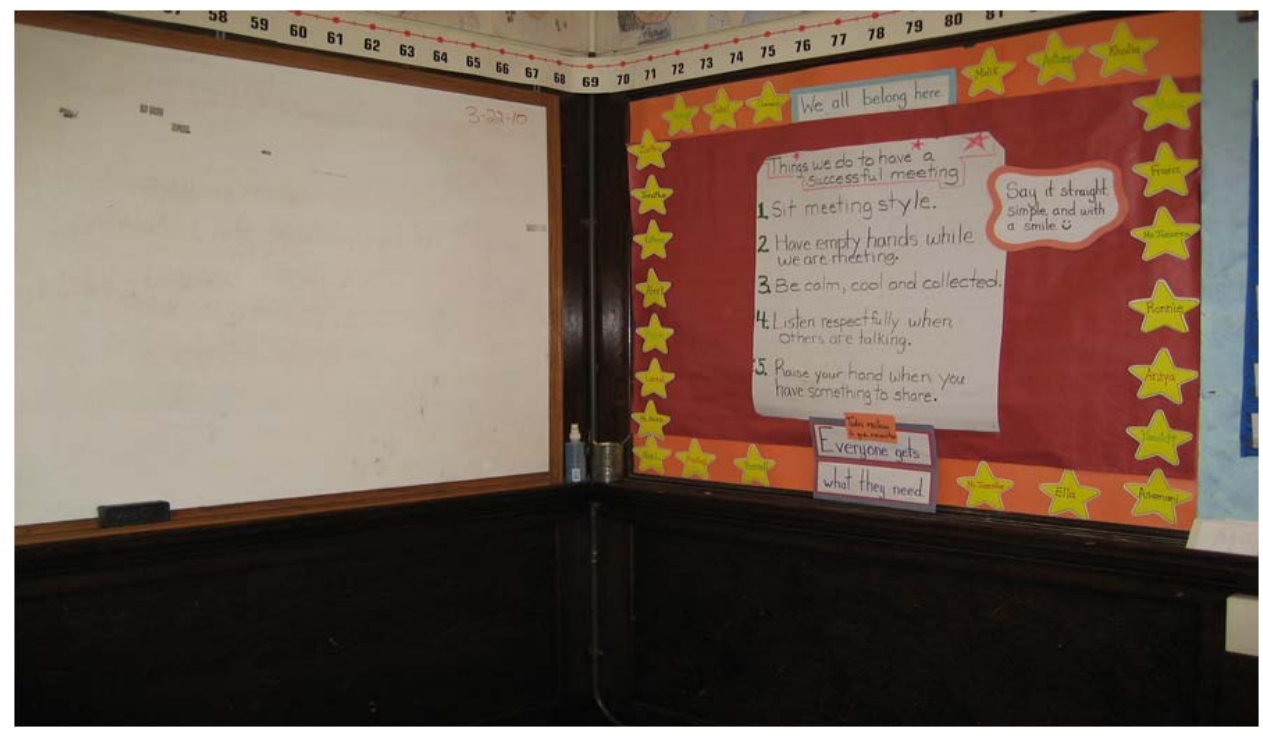

Photograph Janessa 1. This photo and the next two photos highlight the meeting area. Here one sees the meeting guidelines as well as a white board for instructional purposes.

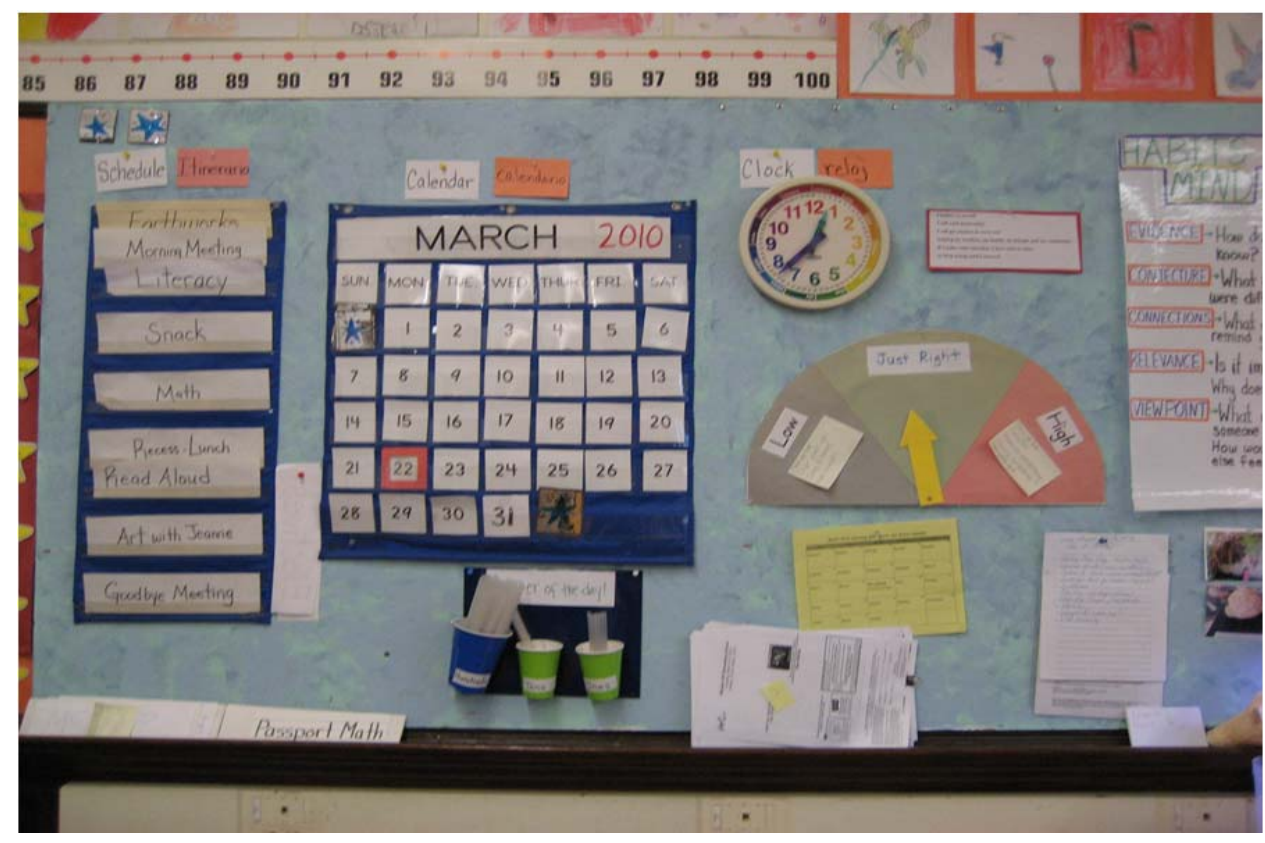

Photograph Janessa 2. In this photo are items Janessa uses during math instruction, daily schedule, and the Habits of Mind poster. 


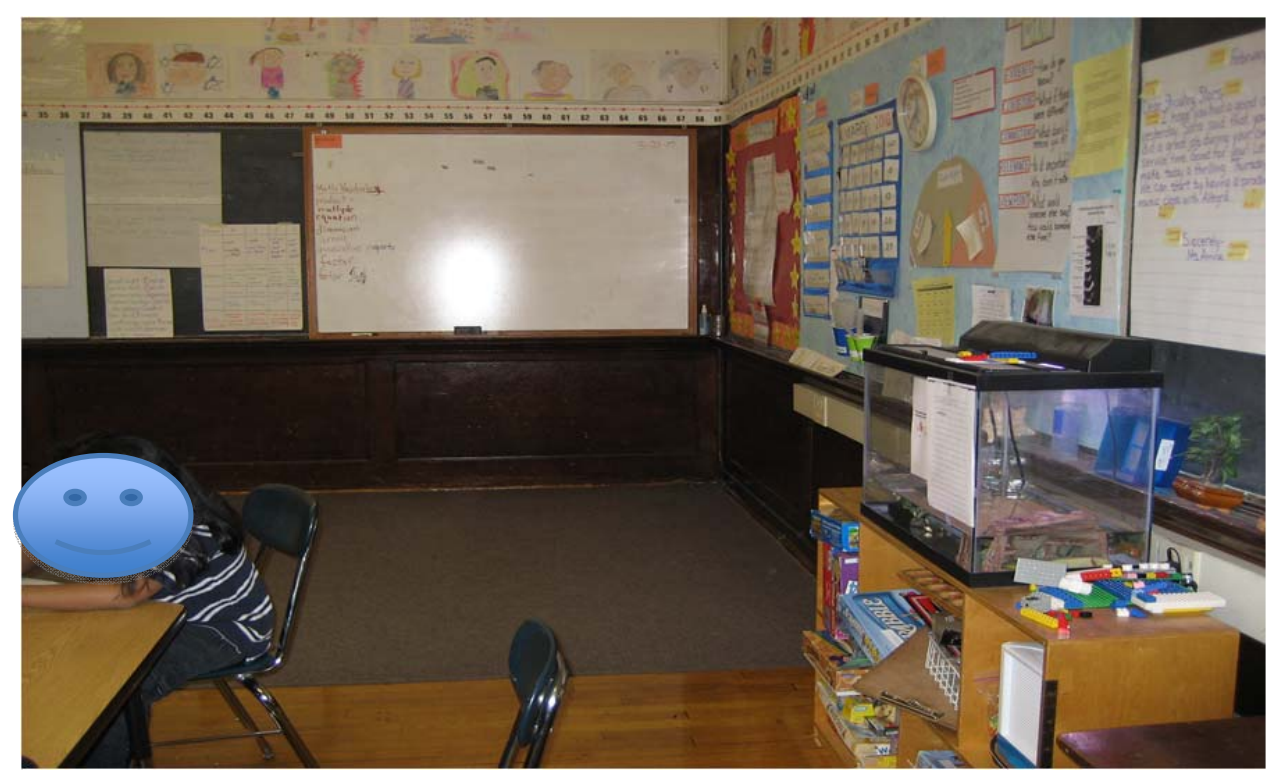

Photograph Janessa 3. This is a full representation of the meeting area.

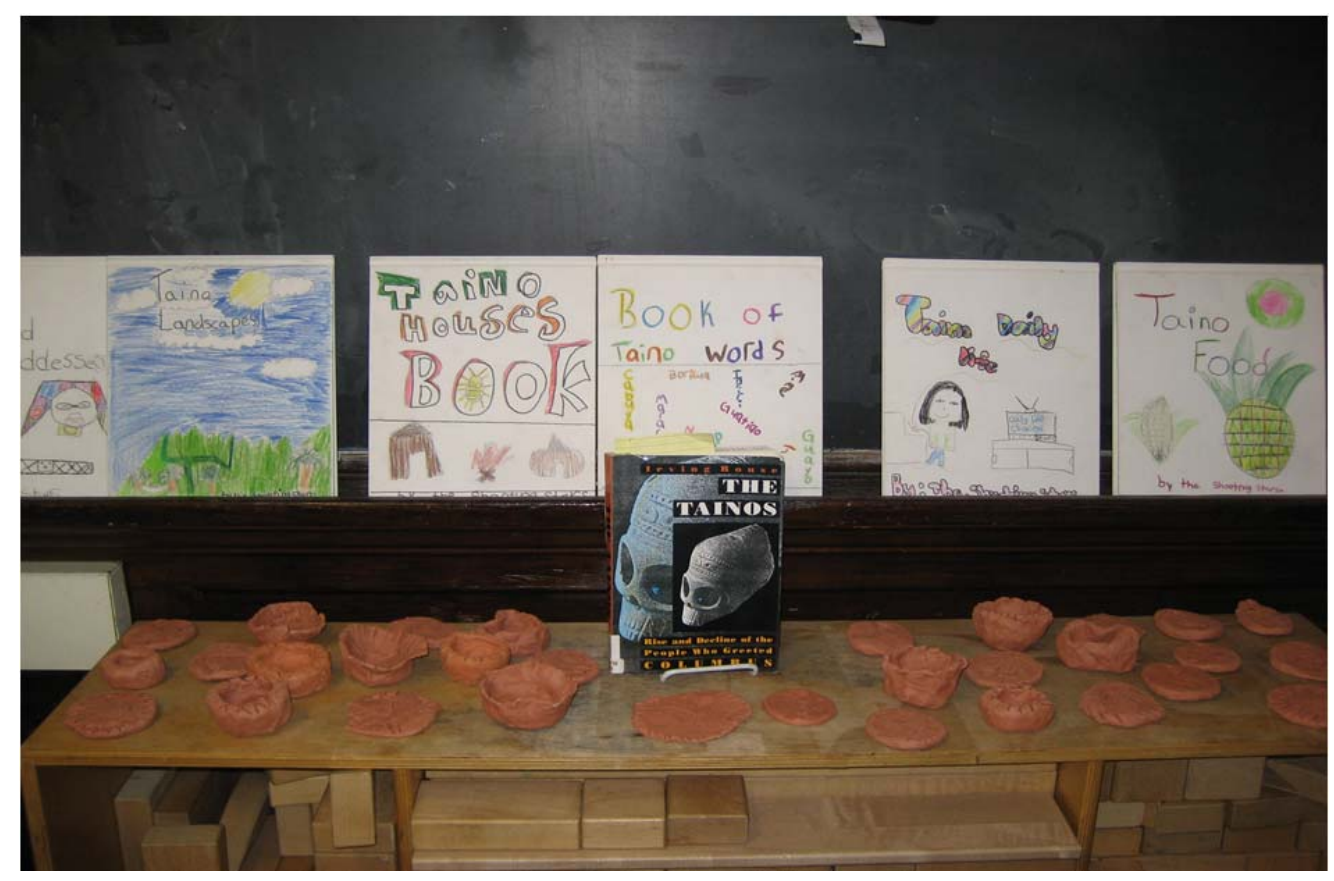

Photograph Janessa 4. This photo and the next photo show the art projects that Janessa incorporated into her Ancient Civilizations Thematic Unit. 


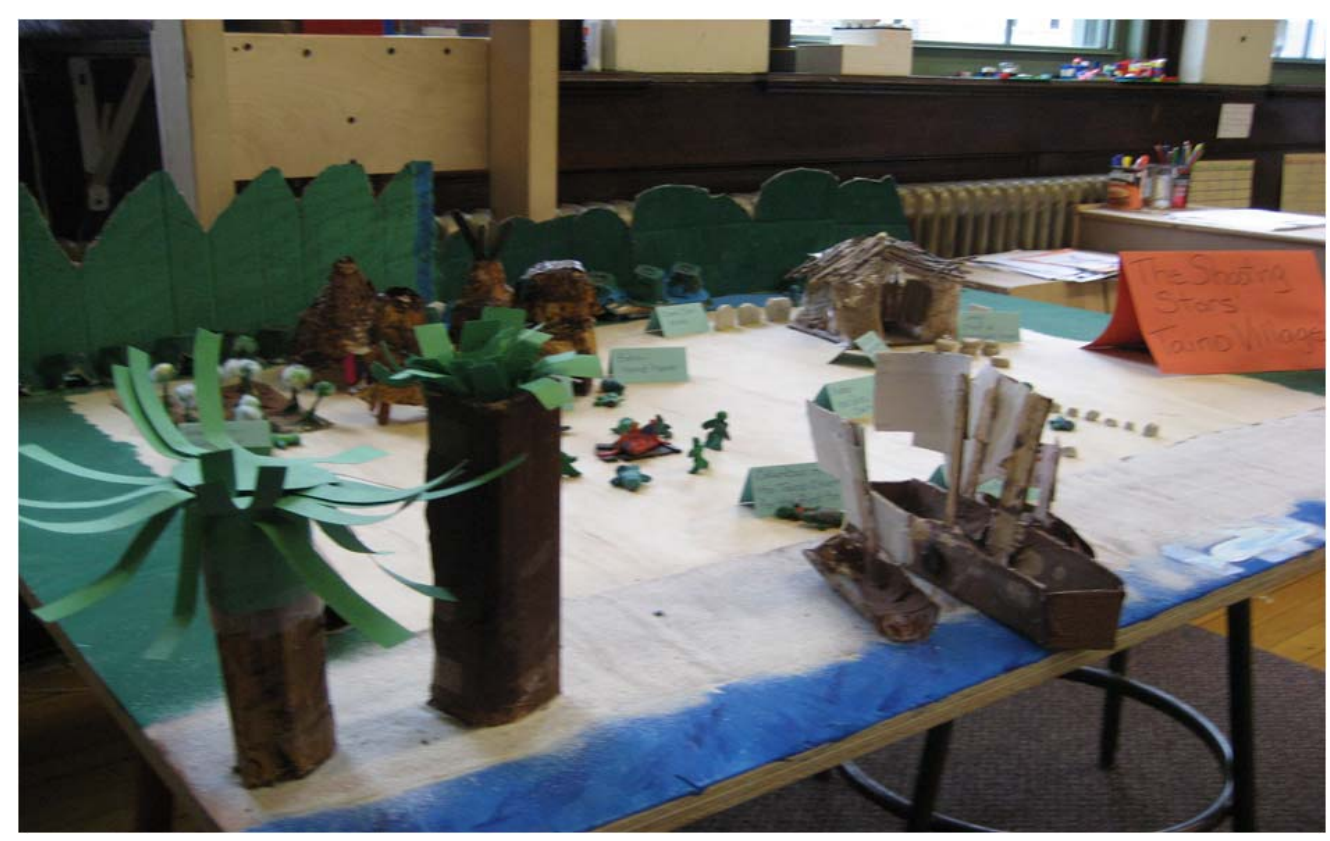

Photograph Janessa 5. In this picture is the Taino Village that Janessa's students created as part of their study. Students were asked to research the various components of the Taino Village and then reproduce a representation of the village.

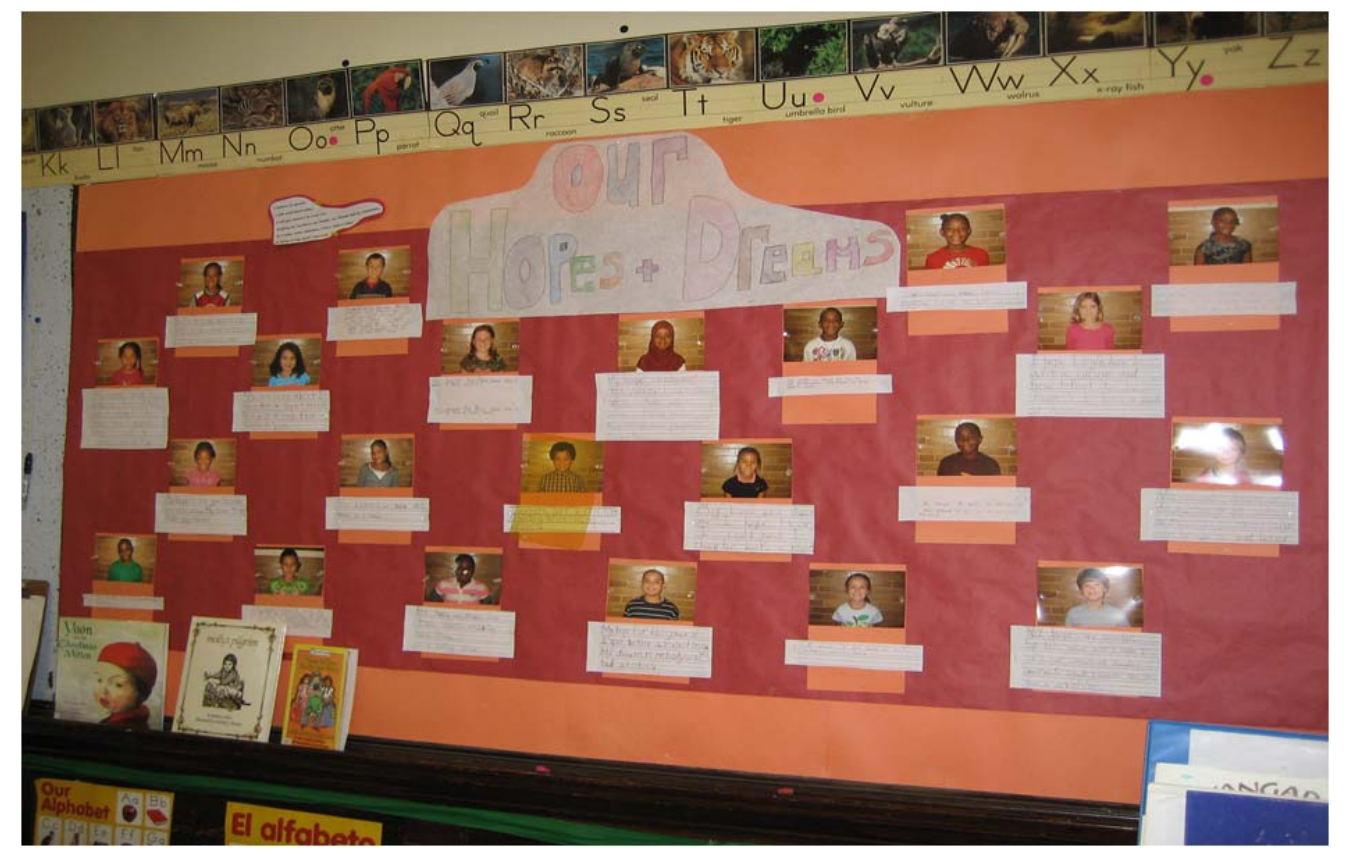

Photograph Janessa 6. Each year Janessa asks her students what their hopes and dreams are for the school year and for their lives. Here is the display that has been created by Janessa and her students. 


\section{Appendix F}

Jack's Classroom

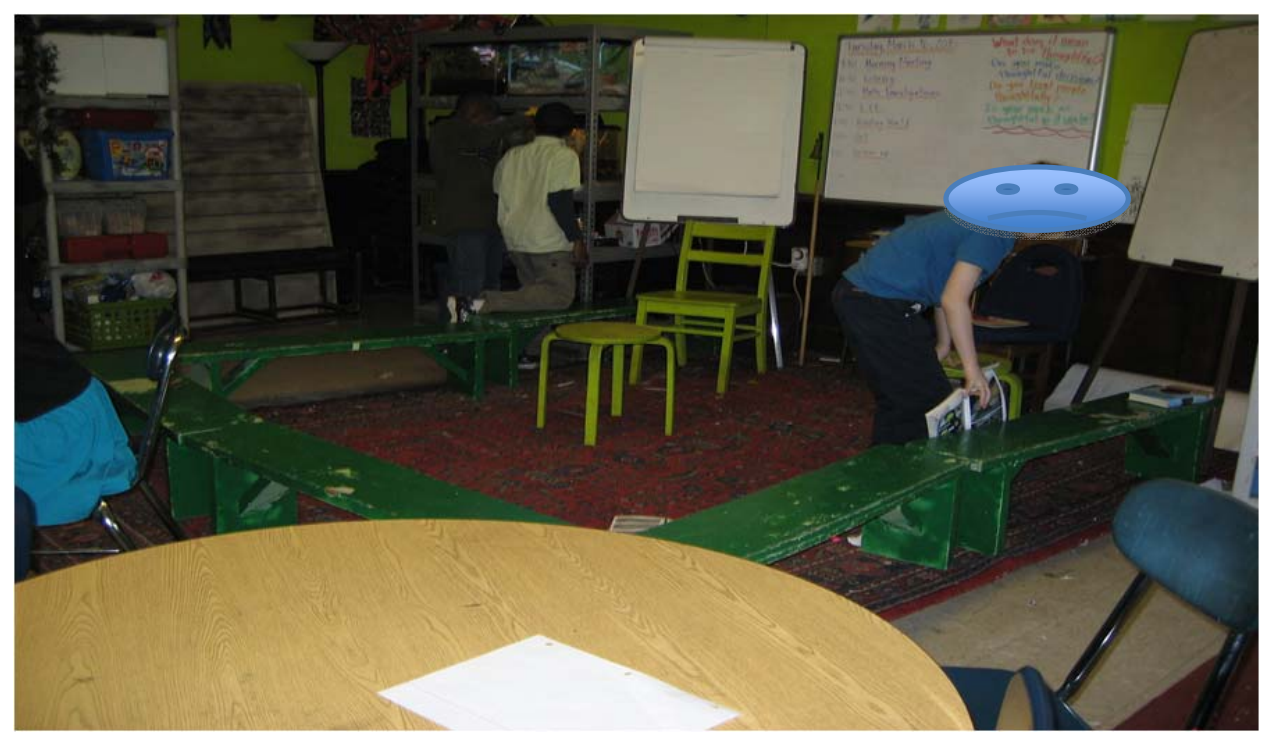

Photograph Jack 1. This photo highlights the meeting area of the 9-10-11 multiage classroom ( $4 / 5$ the grade). In the back of the photo are the living habitats created during the Life Sciences thematic unit. Students are responsible for feeding and maintaining the animals and habitats.

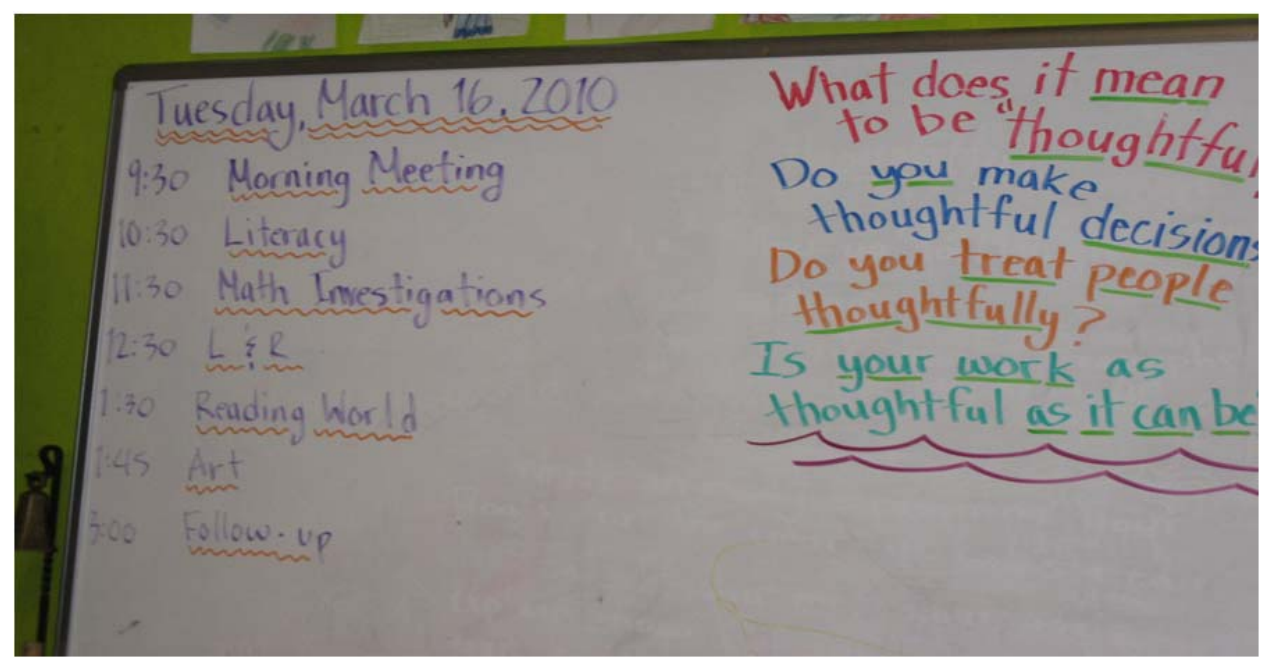

Photograph Jack 2. This is the board used during meeting time. It displays the day's schedule as well as questions that Jack has his students consider through out the day. He references these questions often during instruction and as part of classroom leadership. 


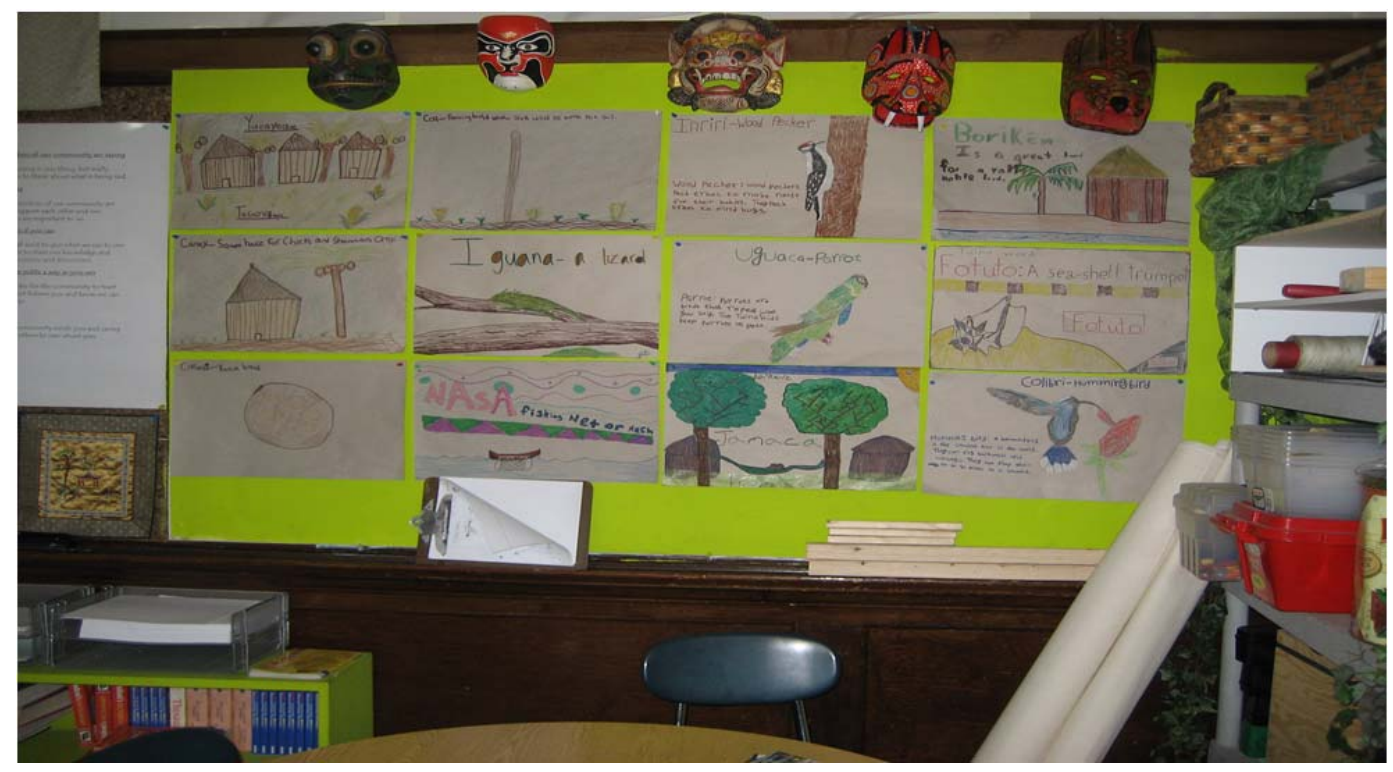

Photographs Jack 3. This photo shows the artwork that Jack incorporated into two thematic units. The posters were created during the life sciences unit to guide students as they created their habitats. The masks were created during the ancient civilizations unit where the students studied the Taino people.

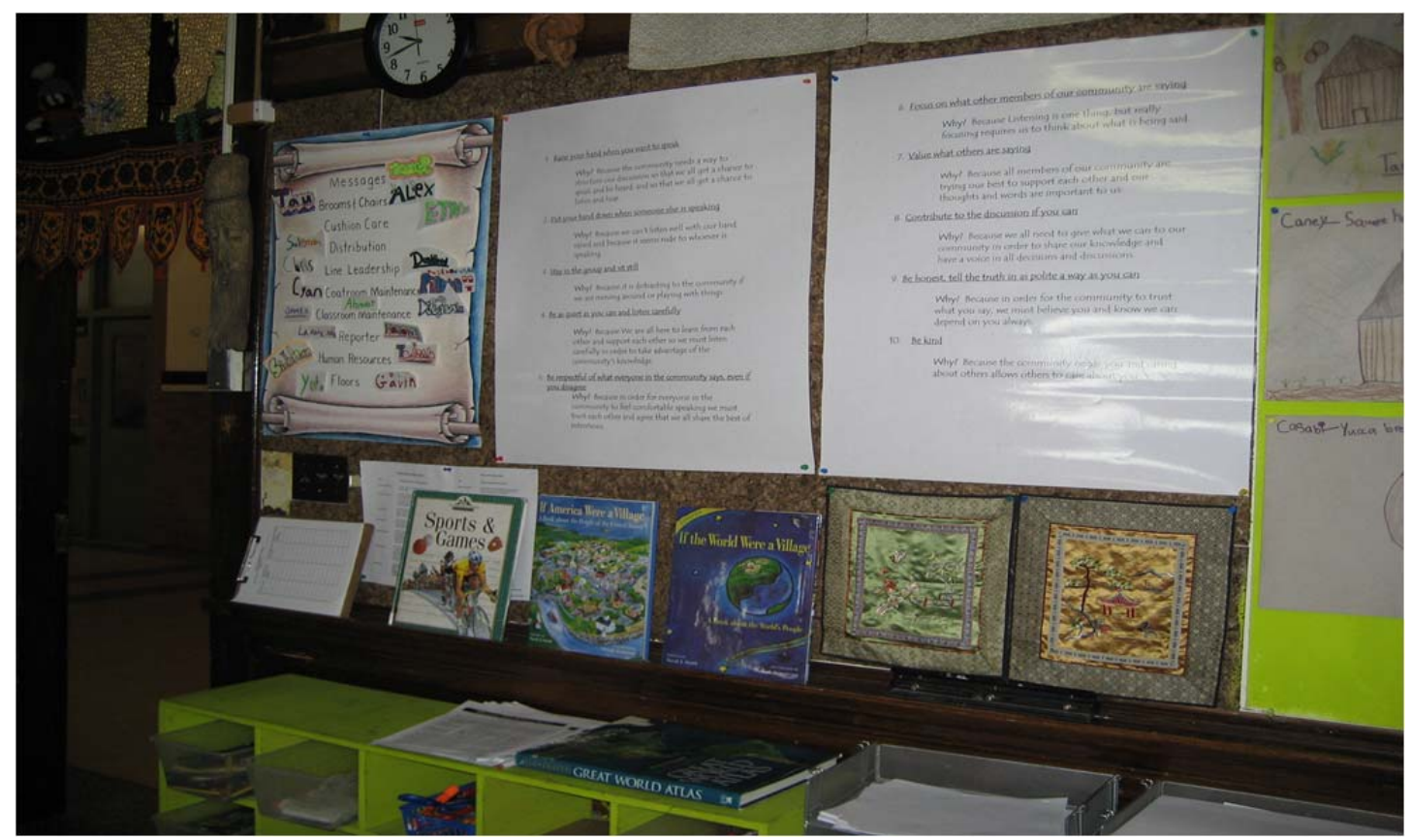

Photograph Jack 4. These posters are actually the rules/guidelines created by Jack's class at the beginning of the school year. This photo also shows the classroom job's chart; quilt work patches made by a previous class, and the entrance into the classroom. 


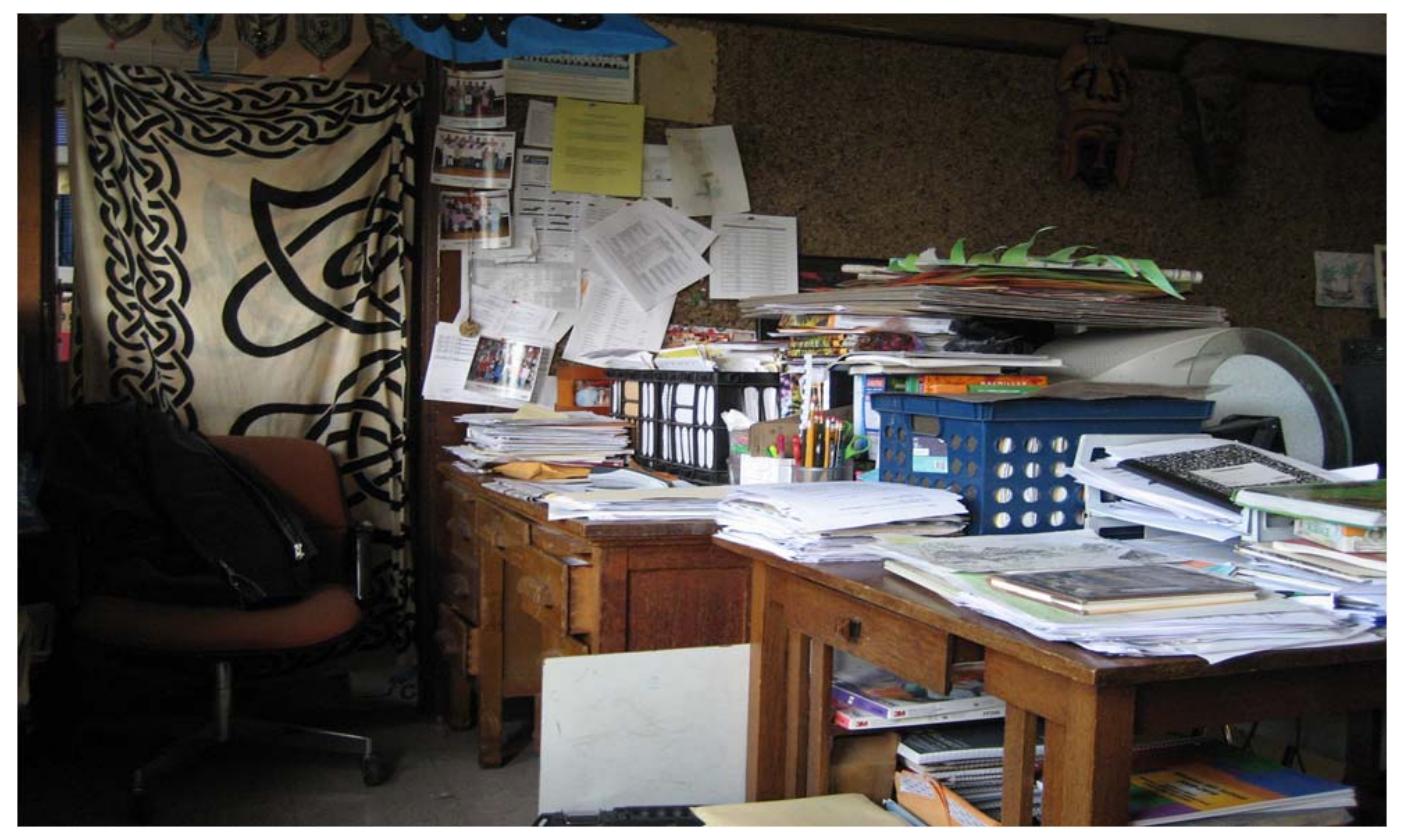

Photograph Jack 5. This is Jack's desk. It is piled with thematic unit ideas, math curriculum folders, and various piles of graded and ungraded papers. It basically serves as a storage unit and is never used by Jack other than that. 


\section{Appendix G}

\section{**Names changed to protect participant identity}

Topic: Immigration, Peopling of the United States, "Who We Are and Where We Come From"

-When people populated the United States

Guiding Questions:

-When people started coming to the United States

What

is an American?

Why do people move from place to place?

How does your environment change you? Who you are?

Experiences/Projects:

I. What is an American-Use picture prompts (power point) identifying if an American, yes or no. Write why and discuss.

II. Who are you? Are you an American? Who is your family? Have your family members always been 'Americans'? (Tell your true story)

a. Bio Poems

b. Family Scrapbooks-title, dedication page, table of contents, me page (picture, questions), personal flag and writing, bio poem, footprint/handprint and name (meaning), family tree, family interview, family portrait, holidays and traditions (information), family recipe, relative biography poster

III. Where do you come from? (Why do people move from place to place?) Family presentations

a. How did we get here? US, Trent, WHY?

b. Was it a choice?

c. How did your family change after coming? (Culturally, spiritually, etc)

d. How much did your family give up to fit in? Losing pieces of culture/giving up pieces of culture to assimilate

IV. What if...story-pick one piece of your family history to change and rewrite the outcome. Read the 'true story and the 'what if' story

\section{Culminating Event:}

-Family lunch with all of the classroom families brining culturally relevant food and for students to share work.

-Families sharing an information table about their family history/country culture.

\section{Assessment:}

What is an American? Re-prompt

Venn Diagram Packet-comparing families of the classroom

What if...story presentations

Discussions 


\section{Appendix $\mathbf{H}$}

**Names changed to protect participant identity.

\section{Animal Habitats and Where We Live}

\section{Essential Question:}

How can I get students to understand human beings as one of several species whose actions shape the ecosystem system that they live in and evolved from, but on a global scale?

\section{Curriculum Goals:}

1. Students will develop their ability to identify and define the function of natural habitats and ecosystems and the human equivalent, including their place and role living in a system and maintaining the health of their personal environment and the greater environment at large.

2. Students will develop their understanding of the basic needs and behaviors of animals including identifying basic needs such as food and water, shelter and warmth, and social interaction and reproduction; identifying the role of adaptation to environmental factors; and recognizing the difference between learned behavior and instinct.

3. Students will develop their understanding of the living world including life cycles and biodiversity, and the basics of the processes of evolution, natural selection, adaptation and heredity.

4. Students will develop their understanding of the scientific method of inquiry and investigation, and of organization and classification (Taxonomy).

MA Standards: Life Science GR. 3-5: 5, 6, 8, 9, 10 \& GR. 6-8: 1

pgs. $42,43,46$

\section{Additional Academic Goals:}

1. Students will be reading fiction and non-fiction texts with the goal of developing their ability to acquire and evaluate useful data, form relevant and thoughtful views based on text and deconstruct key elements of storytelling. 
2. Students will write expository and narrative essays.

3. Students will write fictional stories including animal fables and folk tales.

4. Students will develop their understanding of basic geographical concepts related to ecosystems and habitats (hemispheres, continents, regions, oceans and seas, equator, arctic, tropics, mountains, jungles, woodlands, grasslands, etc.).

5. Students will encounter some of the following mathematical concepts such as money, estimation, calculation, graphing, organizing, finding patterns, measuring, data analysis, probability, and identifying coordinate points.

6. Students will use Internet technology to investigate and research various topics and may use computers to present data by creating graphs and PowerPoint presentations.

\section{Essential Questions for Students to Investigate:}

1. What are the basic needs and traits of living organisms?

2. In what ways do animals relate to the Earth's environment?

3. In what ways do humans relate to the Earth's environment that differs from other animals?

\section{Overview of Timeline for Study:}

The unit will begin with students writing a series of narrative essays focused on topics related to our theme. First, students will observe and write about their own "habitats" and how those habitats affect the way that they live. Next, students will write about experiences that they have had with animals in their lives. And finally, students will write a fictional narrative told from the perspective of an animal of their choice. In addition, students will be introduced to concepts and vocabulary through reading assignments from handouts and reference books. Students will also be reading fiction related to animals and regular Read Alouds will take place including both animal fables and expository text.

During the second phase of this unit students will design and build a model habitat in groups of 3 or 4 using 10 to 20 gallon aquariums (one per research team). Each habitat 
must display all essential needs of the living organisms contained therein. Each habitat must be as self-sufficient and self-contained as possible. Students will be required to provide a plan for the support of the living organisms within their habitat prior to production. A budget will be provided for production and maintenance and a cost projection will be required prior to production. During this phase, students will begin writing original folk tales and fables. Ongoing reading assignments will continue to provide relevant information.

\section{Additional Events and Expectations:}

1. Students will be expected to help maintain the health of any/all classroom pets and/or habitat projects.

2. Possible field trips include Franklin Park Zoo and the Harvard Museum of Natural History.

3. Students are expected to participate in class discussions, respectfully offering opinions, analysis, and critique of data, concepts, and methods.

\section{Assessments:}

Assessments will include one group project - a model habitat - illustrating knowledge of the related science and a portfolio of pieces representing a full term's work that displays knowledge of the unit's subject matter, including written work relevant to theme goals. Among the pieces in the portfolio will be at least three narrative essays, one fable, and one piece related to their habitat project - either an observation journal or an expository summary of the project. Some use of theme related vocabulary is expected and will be assessed by the expectation that key terms will be used appropriately in writing assignments (or verbally in the case of a required accommodation). 


\section{Appendix I}

\section{Humanities}

\section{Global Consumer Project}

\section{Assignment:}

In your project you will act as the CEO of a company. Your task is to develop a new shoe. In this assignment, you wilnot only be responsible for designing the shoe but also for every other dcecision in thes shoe making process.

\section{Your project will include...}

- A detailed description of your project

- A desing of your product

- A completed "From Factory to Consumer" sheet

- An explanation of your decision making of each step of the process

- A response paper that details your experience working on the project and what you learned.

- A code of conduct for your company.

\section{Shoe Description: Some questions to consider in your mock-up:}

- Is your shoe something new or will you be improving on something that already exists?

- What are the features of your shoe? Are you going for comfort or style?

- Who is your targeted audience-teens, adults, or professionals?

- For what occasions will people wear your shoe, to work, sports, walking, or hanging out with friends? 
- With each of these questions think about how each aspect should affect the design of the shoe.

\section{The Design:}

- Draw a profile of your shoe. A brief explanation of each feature shoe be included.

- The final design should be representative of the actual shoe to be produced. You should consider color, fabric, and other items your shoe will support.

- The design should not be larger than 8 x 11 inches.

\section{From Factory to the Consumer:}

- Review information regarding company investments, trade unions, labor unions, and foreign labor.

- Write an essay/explanation for how your shoes will be produced. Consider the following questions:

o Will you have your shoes made in a sweatshop?

o Will you invest in inventing new designs or go with existing designs?

o Will you make your shoes affordable to the working class people? 


\section{Appendix J}

\section{Classroom Observation Protocol}

Democratic Habits: citizenship, democracy, reflection, critical thinking, problem solving, respect, ability to express opinion (voice), analysis, real life application, and cooperative learning.

\section{A. Classroom Contexts}

a. How is the classroom organized? Does it encourage democratic habits? If so, which ones? How is the classroom decorated? Is student work displayed? Evidence of thematic units using art, music? Are classroom rules displayed? What is the primary focus of the classroom? What type of seating is used? Where do students mainly work? Are there students who are placed in relation to the teacher? How does the teacher interact with the students? Are students placed in relation to race, ethnicity, gender, and discipline? Is there a teacher desk? Does the teacher use it? Where are resources stored? Learning centers present? Safe? Inviting?

\section{B. Pedagogical Strategies}

a. What type of instruction did the teacher use? How does the teacher include student voice? Do students feel free to engage other students and the teacher? How do students react to the teacher? How do students express their like or dislike for a teaching strategy? How does the teacher address students? How do students address the teacher? What type of questioning 
strategies does the teacher use? How does the teacher introduce or transition the class? Does he/she call on particular students consistently? Speak to particular students consistently?

\section{Curriculum Implementation}

a. What activities are used in the class? Does the teacher lecture? Are there classroom discussions? Do the students use textbooks? What resources are used? Books, charts, diagrams, manipulatives, or models? Do students touch or use resources? Are students on task? How are thematic units introduced, taught, and incorporated? What type of feedback is given? Are students grouped for lessons? Use of technology? Assessment practices? Use of rubrics? Self-evaluation? Reflection? 